University of Wollongong

Research Online

Australian Institute for Innovative Materials -

Papers

Australian Institute for Innovative Materials

$1-1-2019$

Superparamagnetic nanoarchitectures for disease-specific biomarker detection

Mostafa Masud

Jongbeom $\mathrm{Na}$

Muhammad Younus

Md Hossain

Yoshio Bando

University of Wollongong, yoshio@uow.edu.au

See next page for additional authors

Follow this and additional works at: https://ro.uow.edu.au/aiimpapers

Part of the Engineering Commons, and the Physical Sciences and Mathematics Commons

Research Online is the open access institutional repository for the University of Wollongong. For further information contact the UOW Library: research-pubs@uow.edu.au 


\title{
Superparamagnetic nanoarchitectures for disease-specific biomarker detection
}

\author{
Abstract \\ (c) 2019 The Royal Society of Chemistry. The detection of clinically relevant disease-specific biomolecules, \\ including nucleic acids, circulating tumor cells, proteins, antibodies, and extracellular vesicles, has been \\ indispensable to understand their functions in disease diagnosis and prognosis. Therefore, a biosensor \\ for the robust, ultrasensitive, and selective detection of these low-Abundant biomolecules in body fluids \\ (blood, urine, and saliva) is emerging in current clinical research. In recent years, nanomaterials, especially \\ superparamagnetic nanomaterials, have played essential roles in biosensing due to their intrinsic \\ magnetic, electrochemical, and optical properties. However, engineered multicomponent magnetic \\ nanoparticle-based current biosensors that offer the advantages of excellent stability in a complex \\ biomatrix; easy and alterable biorecognition of ligands, antibodies, and receptor molecules; and unified \\ point-of-care integration have yet to be achieved. This review introduces the recent advances in \\ superparamagnetic nanostructures for electrochemical and optical biosensing for disease-specific \\ biomarkers. This review emphasizes the synthesis, biofunctionalization, and intrinsic properties of \\ nanomaterials essential for robust, ultrasensitive biosensing. With a particular emphasis on \\ nanostructure-based electrochemical and optical detection of disease-specific biomarkers such as \\ nucleic acids (DNA and RNA), proteins, autoantibodies, and cells, this review also chronicles the needs \\ and challenges of nanoarchitecture-based detection. These summaries provide further insights for \\ researchers to inspire their future work on the development of nanostructures for integrating into \\ biosensing and devices for a broad field of applications in analytical sensing and in clinic.

\section{Disciplines} \\ Engineering | Physical Sciences and Mathematics

\section{Publication Details} \\ Masud, M., Na, J., Younus, M., Hossain, M., Bando, Y., Shiddiky, M. \& Yamauchi, Y. (2019). \\ Superparamagnetic nanoarchitectures for disease-specific biomarker detection. Chemical Society \\ Reviews, 48 (24), 5717-5751.

\section{Authors} \\ Mostafa Masud, Jongbeom Na, Muhammad Younus, Md Hossain, Yoshio Bando, Muhammad Shiddiky, \\ and Yusuke Yamauchi
}




\section{Superparamagnetic nanoarchitectures for disease-specific biomarker}

detection

Mostafa Kamal Masud, ${ }^{\mathrm{a}, \mathrm{b}}$ Jongbeom Na, ${ }^{\mathrm{a}, \mathrm{e}}$ Muhammad Younus, ${ }^{\mathrm{c}}$ Md. Shahriar A. Hossain,,d Yoshio Bando, ${ }^{\mathrm{e}}$ Muhammad J. A. Shiddiky, ${ }^{\mathrm{f}, *}$ and Yusuke Yamauchi, ${ }^{\mathrm{a}, \mathrm{e}, \mathrm{g}, *}$

a Australian Institute for Bioengineering and Nanotechnology (AIBN), The University of Queensland, Brisbane, QLD 4072, Australia

${ }^{\mathrm{b}}$ Department of Biochemistry \& Molecular Biology, School of Life Sciences, Shahjalal University of Science \& Technology, Sylhet 3114, Bangladesh

${ }^{c}$ Department of Chemistry, School of Physical Sciences, Shahjalal University of Science \& Technology, Sylhet 3114, Bangladesh

${ }^{\mathrm{d}}$ School of Mechanical and Mining Engineering, Faculty of Engineering, Architecture and Information Technology (EAIT), The University of Queensland, Brisbane, QLD 4072, Australia

e International Center for Materials Nanoarchitechtonics (MANA), National Institute for Materials Science (NIMS), 1-1 Namiki, Tsukuba, Ibaraki 305-0044, Japan

${ }^{\mathrm{f}}$ School of Environment and Natural Sciences and Queensland Micro- and Nanotechnology Centre, Griffith University, Queensland 4111, Australia

g School of Chemical Engineering, Faculty of Engineering, Architecture and Information Technology (EAIT), The University of Queensland, Brisbane, QLD 4072, Australia 


\section{Abstract}

The detection of clinically relevant disease-specific biomolecules, including nucleic acids, circulating tumor cells, proteins, antibodies, and extracellular vesicles, has been indispensable to understand their functions in disease diagnosis and prognosis. Therefore, a biosensor for the robust, ultrasensitive, and selective detection of these low-abundant biomolecules in body fluids (blood, urine, and saliva) is emerging in current clinical research. In recent years, nanomaterials, especially superparamagnetic nanomaterials, have played essential roles in biosensing due to their intrinsic magnetic, electrochemical, and optical properties. However, engineered multicomponent magnetic nanoparticle-based current biosensors that have excellent stability in a complex biomatrix; easy and alterable biorecognition of ligands, antibodies, and receptor molecules; and unified point-of-care integration have yet to be achieved. This review introduces the recent advances in superparamagnetic nanostructures for electrochemical and optical biosensing for disease-specific biomarkers. This review emphasizes the synthesis, biofunctionalization, and intrinsic properties of nanomaterials essential for robust, ultrasensitive biosensing. With particular emphasis on nanostructure-based electrochemical and optical detection of disease-specific biomarkers such as nucleic acids (DNA and RNA), proteins, autoantibodies, and cells, this review also chronicles the needs and challenges of nanoarchitecture-based detection. These summaries provide further insights for researchers to inspire their future work in the development of nanostructures for integrating into biosensing and devices for a broad field of applications of analytical sensing and clinics.

Keywords: Disease-specific biomolecules, biomarker, superparamagnetic, nanostructure, biofunctionalization, signal amplification, nanozymes, electrochemical and optical detection, biosensors 
1. Introduction Error! Bookmark not defined.

2. Synthesis of superparamagnetic nanoparticles Error! Bookmark not defined.

2.1. General synthesis Error! Bookmark not defined.

2.2. Template-based synthesis Error! Bookmark not defined.

2.3. Multicomponent (hybrid) magnetic nanoparticle synthesis Error! Bookmark not defined.

3. Surface functionalization of superparamagnetic nanoparticles Error! Bookmark not defined.

3.1. Small organic molecules, functional groups, and surfactants ......Error! Bookmark not defined.

3.2. Polymers Error! Bookmark not defined.

3.3. Bioactive molecules Error! Bookmark not defined.

3.4. Inorganic materials Error! Bookmark not defined.

4. The function of superparamagnetic nanoparticles in biosensor development Error! Bookmark not defined.

4.1. Magnetic capture and separations Error! Bookmark not defined.

4.2. Development of a detection platform (sensor and biosensor)......Error! Bookmark not defined.

4.2.1. Immobilization of biomolecules Error! Bookmark not defined.

4.2.2. Electrocatalytic signal amplification Error! Bookmark not defined.

4.2.3. Signal-generating probes Error! Bookmark not defined.

4.3. Nanocarriers Error! Bookmark not defined.

4.4. Natural enzyme mimetics: Nanozymes Error! Bookmark not defined.

5. Application of superparamagnetic nanoparticles in biomolecular detection .47

5.1. Electrochemical biosensors .47

5.1.1. Nucleic acid assay .48

5.1.2. Immuno assay .52

5.1.3. Cytosensors .53

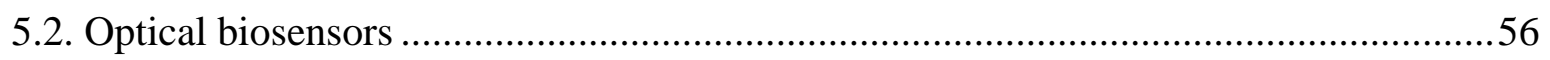

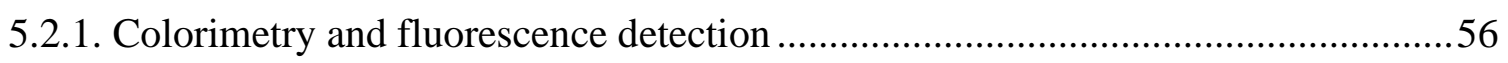

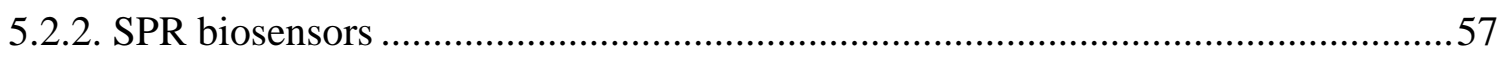

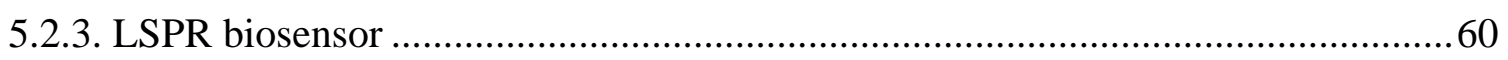

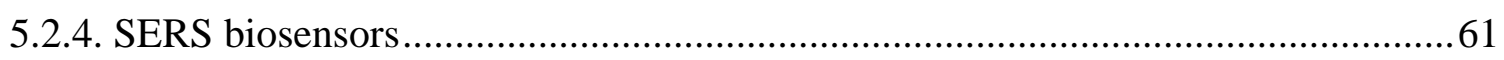

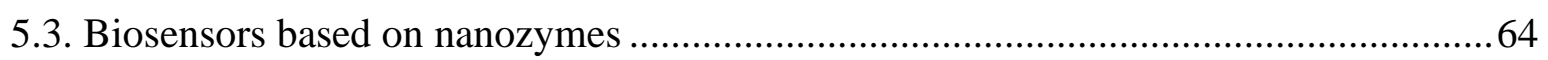

6. Point-of-care testing: The impact of superparamagnetic particles ..................................... 


\section{Introduction}

Detection of a disease-specific biomolecular target, including DNA- and RNA-based biomarkers, circulating tumor cells, and small molecules (exosomes), is essential to understand its physiological and biological functions, disease diagnosis, and prognosis. ${ }^{1-5}$ These biomolecules carry out several anatomical and physiological functions: for instance, DNA encodes genetic information for the development and regulation of genetic expression; RNA transmits that genetic information and translates it into proteins for structural and regulatory roles and therefore is involved in protein expression and different cellular functions. ${ }^{6-8}$ Exosomes, membrane-bound cargo that is enriched with proteins, lipid rafts, micro RNAs (miRNAs), messenger RNAs (mRNAs), and other noncoding RNAs (ncRNAs), exchange genetic information between neighboring cells during their circulation. ${ }^{9}$ Moreover, they are now routinely used for the diagnosis and management of many diseases as the disease progresses, resulting in alternation of the physiological state or genetic expression of these biomolecules. Consequently, there has been a rising demand for detection of those biomolecules, especially for early diagnosis and treatment. Early-stage detection enables effective therapies to reduce suffering and disease-related burdens. Over the last century, numerous detection platforms have been developed to detect these biomolecules. These methodologies range from classical molecular biology to advanced procedures, such as bisulfite sequencing, ${ }^{10}$ microarrays, ${ }^{11}$ quantitative real-time PCR (qRT-PCR), ${ }^{12}$ RNA sequencing, ${ }^{13}$ colorimetry, ${ }^{14}$ surface plasmon resonance (SPR), ${ }^{15}$ and surface-enhanced Raman spectroscopy (SERS), ${ }^{16}$ to more recent analytical approaches such as high-performance liquid chromatography (HPLC), ${ }^{17}$ mass spectrophotometry (MS), ${ }^{18}$ and electrochemical biosensors. ${ }^{6,}$ 
${ }^{19}$ The classical molecular biology techniques, despite of their robustness and high efficiency, nevertheless suffer from sensitivity and specificity (amplification biases) and require cumbersome sample pretreatment and expensive instrumentation. ${ }^{20-22}$ HPLC and MS can provide rapid, accurate, and selective detection, but they are limited in practical application due to their high cost, bulky equipment size, immobility, specialized operation, and throughput. Notably, they are not suitable when an ultrasensitive, miniaturized, portable detection system is looked for in field and wearable applications. ${ }^{23,24}$ Optical and electrochemical methodologies are relatively inexpensive and rapid, and they provide sensitive detection in a portable arrangement with a small volume input of clinical samples. ${ }^{6,19,25}$ Furthermore, tremendous advances in microfabrication and allied technologies have been have been improving the design and development of electrical readout-based chemical sensors and biosensors. ${ }^{26}$ However, target-specific electrode surface modification is vital to achieve the selectivity of a functional biosensor. The most straightforward and widely used approach is to immobilize enzymes or proteins (antibodies) on the electrode with a polymer layer. ${ }^{27}$ Additionally, the sensor needs to bind with signaling or redox molecules to produce the target-specific responses. Even though a plethora of cutting-edge electrochemical biosensors have been developed, most of the approaches still suffer from low sensitivity, complex instrumentation, and multifaceted, tedious, and time-consuming chemistry. Furthermore, the clinical application of most of these has yet to be realized.

With the advancement of nanotechnology, nanostructured magnetic materials have aroused immense interest in the field of analytical sensing and biomedicine due to their flexible and modular structure, easy synthesis, small size, low toxicity, intrinsic enzyme-mimicking activity, superparamagnetic behavior, and biocompatibility. ${ }^{28-30}$ With their small volume, magnetic NPs (MNPs) smaller than the single domain limit ( 20 $\mathrm{nm}$ for iron oxide) reveal superparamagnetism at room temperature; i.e., MNPs (ferromagnetic) lose their magnetism 
below their Curie temperature. ${ }^{30-32}$ In brief, the magnetic moment of an individual NP able to rotate randomly (in reference to the orientation of the MNP) by the influence of temperature. Due to the fact that, in the absence of an electromagnetic field, the net magnetic moment of NPs became zero at high enough temperatures. However, in the presence of a magnetic field, a net statistical alignment of magnetic moments occurs, similar to that of paramagnetic materials. This characteristic, obvious by the lack of remnant magnetization (i.e., the value of the magnetization at zero field) after elimination of external magnetic fields. This enables MNPs to maintain their colloidal stability and avoid agglomeration, which is essential for magnetic manipulation of the sample in order to achieve nonspecific response free, highly specific and sensitive detection of target molecules. ${ }^{33}$ MNPs uniquely combine with more modestly sized or same-size molecular analytes and hence are often involved in isolation, purification, target-molecule-carrying, signal-generating, and signal-enhancing steps in biosensing, resulting in specific and highly sensitive diagnosis in clinics (Fig. 1). ${ }^{34-36}$ Nanostructured materials also exhibit impressive advantages in molecular diagnostics, particularly in disease diagnosis applications. For instance, they break down the barrier to structural miniaturization of diagnostic platforms, enable direct contact with sensing environments (e.g., electrolyte, labeler), and provide reagentless biosensing, biomimetic, in vivo detection, allowing them to be used as carrier or capture vehicles for loading a large number of specific biological probes. ${ }^{37-39}$ In addition, the plasmonic and electrochemical properties of nanostructured materials can be exploited to adopt many novel transduction schemes, and the nanozyme activity could potentially replace natural enzymes in a wide range of uses in ELISA-like biosensing. ${ }^{36,40}$ Over the past few decades, numerous superparamagnetic NPs have been synthesized, including iron oxides $\left(\mathrm{Fe}_{3} \mathrm{O}_{4}\right.$ and $\left.\mathrm{Fe}_{2} \mathrm{O}_{3}\right)$; different ferrites of cobalt, nickel, and manganese; gold-containing ferric oxide; graphene; and other functional nanostructured wrapped iron oxides. ${ }^{41-43}$ In recent years, porous nanomaterials have also 
attracted increasing interest, as they possess a large surface area and large pore volumes, narrow pore-size distribution, high loading capacity, and modifiable surface characteristics. ${ }^{42}$, 44, 45 These intrinsic properties enabled them highly potential for the uptake and release of guest molecules. The porous structure has also improved catalytic volume as they increase the mass transfer as compared to that of bulk materials of the same mass. $\left.{ }^{46,47}\right]$ Notably, for detecting biomarkers, each nanostructure is designed in such a way that it is biocompatible with the target (cells, proteins, exosomes, DNA, RNA, etc.) and can be integrated into target-isolation and purification, immobilization, signal-transduction, signal-generating, or signal-amplification steps. Thus, nanostructures need to be highly specific and selective of the biomolecule structure (shape, size, length, charge, interaction affinity, etc.).

Based on the synthesis, intrinsic characteristics, and application of nanostructure materials, several reviews have also been authored in which their different synthetic strategies, functionalization, and biosensing were discussed. ${ }^{34,43,48-52}$ There is extensive literature based on the promise, facts, and challenges of the various nanostructures, e.g., graphene, ${ }^{53}$ carbon nanotubes,${ }^{54}$ and quantum dots ${ }^{55}$ in biomedical applications, and the human healthcare field has already been expressly focusing on individual materials and their uses in biosensing. Recently, we authored "Nanoarchitecture Frameworks for Electrochemical miRNA Detection," 56 in which the pros and cons of previously reported nanostructures were discussed with regard to microRNA detection. Another review also explored the structure-based relationship for sensing performance; however, no specific biomolecules were considered. ${ }^{57}$ No reviews have yet focused on the nanostructures that are specifically engineered for the detection of disease-specific biomarkers. Reports are needed in which the target-specific and unique engineering of nanostructures is comprehensively discussed to guide future science in detecting biomarkers, and hence disease diagnosis and prognosis. In summary, a review that focuses on biomolecule-specific magnetic nanostructure synthesis, further 
biofunctionalization, and intrinsic properties is required to achieve robust biosensing and magnetic nanostructure-based electrochemical and optical biosensors (nucleic acid sensor, immunosensor, cytosensor, etc.).

In this review, we have focused extensively on the biomolecule-specific magnetic nanostructure synthesis, further biofunctionalization, and intrinsic properties required to achieve robust biosensing and magnetic nanostructure-based, clinically relevant disease biomarker detection. Following the particular emphasis on nanostructure-based electrochemical and optical detection, the nanostructure-based point-of-care diagnostics are also discussed. With a comprehensive discussion in each section, this review also chronicles the needs and challenges involved in nanoarchitecture-based biomarker detection.

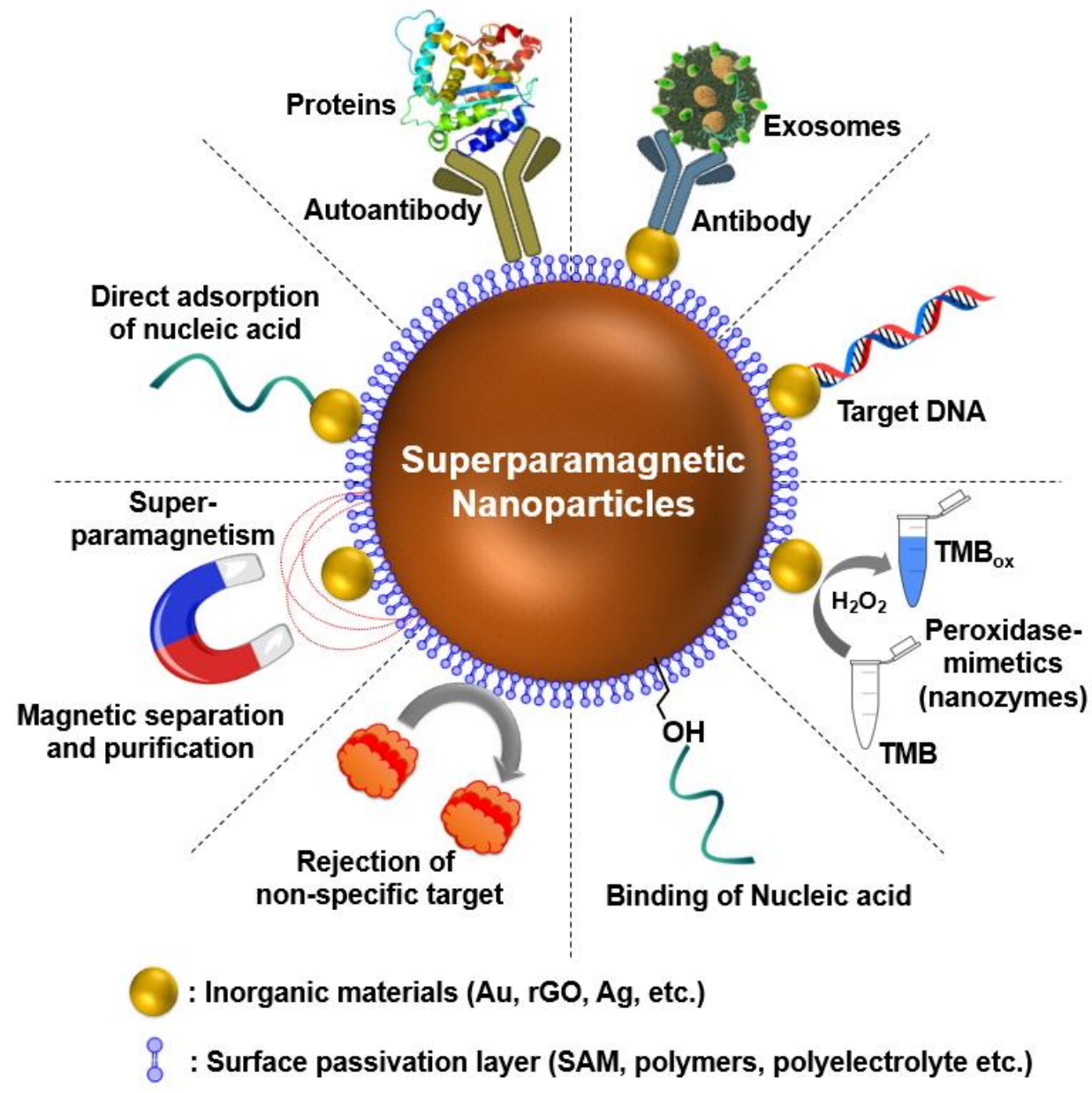


Fig. 1 Schematic representation of the building blocks of nanoengineered superparamagnetic nanoparticles, their surface functionalization, and their functions for integration into biomolecular biosensors.

\section{Synthesis of superparamagnetic nanoparticles}

To date, various approaches have been developed for the synthesis of superparamagnetic NPs and porous nanomaterials with controlled narrow size distribution for desired chemical and physical properties. Among the types of superparamagnetic NPs, ferrite colloids, magnetite, and maghemite are widely studied due to their biodegradability and biocompatibility. Broadly, the synthetic methodology can be categorized into three classes: general synthesis of MNPs, such as coprecipitation, thermal decomposition, microemulsion, hydrothermal reaction, and sol-gel synthesis; templating methods for the synthesis of porous nanomaterials; and doped metal synthesis for biofavorable hybrid metal NPs.

\subsection{General synthesis}

The conventional and most commonly used wet chemical methods for the synthesis of superparamagnetic iron oxide nanoparticles (IONPs) are the coprecipitation method, wherein $\mathrm{Fe}_{3} \mathrm{O}_{4}$ and $\gamma-\mathrm{Fe}_{2} \mathrm{O}_{3}$ are precipitated from a basic solution of ferric and ferrous salts or by oxidation of a ferrous hydroxide suspension using oxidizing agents. ${ }^{58,59}$ A mixture of ferric and ferrous ions in a 1:2 molar ratio is used to obtain iron oxide precipitation at room temperature or elevated temperature according to the following reaction;

$$
\mathrm{Fe}^{2+}+2 \mathrm{Fe}^{3+}+8 \mathrm{OH}^{-} \rightleftharpoons \mathrm{Fe}(\mathrm{OH})_{2}+2 \mathrm{Fe}(\mathrm{OH})_{3} \longrightarrow \mathrm{Fe}_{3} \mathrm{O}_{4}+4 \mathrm{H}_{2} \mathrm{O}
$$

The size and shape of the IONPs depend on the type of iron salt (e.g., chloride, sulfide, or nitrite), ferric and ferrous ion ratio, $\mathrm{pH}$ of the solution, reaction temperature, and reaction conditions. One of the most pioneering examples of this method was reported by Sugimoto (1980): iron oxides were obtained by the interaction of $\mathrm{FeSO}_{4}$ with $\mathrm{KOH}$ in the presence of a 
nitrate ion followed by aging of the resultant gelatinous suspension at $90{ }^{\circ} \mathrm{C}$ for several hours. ${ }^{60}$ Since then, several coprecipitation-based methods have been developed to synthesize IONPs. For example, $\mathrm{Fe}_{3} \mathrm{O}_{4}$ magnetic powder with an average gain diameter of $15 \mathrm{~nm}$ was prepared from high-purity iron using ultrasonic-assisted chemical coprecipitation. ${ }^{61}$ Recently, Pereira et al. reported a one-step aqueous coprecipitation-based method for the synthesis of $\mathrm{MFe}_{2} \mathrm{O}_{4}$ using the alkanolamines isopropanolamine and di-iso-propanolamine as an alkaline agent. ${ }^{62}$ The synthesized $\mathrm{MFe}_{2} \mathrm{O}_{4}$ nanomaterials exhibited high colloidal stability, particle sizes in the range of 4-12 nm, and superparamagnetic properties. Moreover, this method generated smaller particle sizes (up to 6 times) and superior saturation magnetization (up to 1.3 times) than those prepared with $\mathrm{NaOH}$ or $\mathrm{KOH}$. This method can be used to prepare IONPs on a large scale in a short time. NPs of different sizes and morphologies were also obtained by adjusting the $\mathrm{pH}$, oxidizing agents, ionic strength, and concentration of the growth solution. Moreover, the stirring rate and reaction time have a considerable effect on the structural properties, specifically the particle sizes and corresponding magnetic properties. ${ }^{63}$ However, the coprecipitation method is limited by the fact that the produced NPs tend to agglomerate in aqueous and physiological conditions. To overcome this limitation, different polymers, polyethylene or surfactants such as dextran and polyvinylalcohol (PVA), are used to immobilize the IONPs. ${ }^{64,65}$

The thermal decomposition approach can be used to obtain highly crystalline, monodisperse, and narrowly size-distributed IONPs from the high-temperature thermal decomposition of coordinated iron precursors or organometallics such as Fe (cup) $)_{3}(\operatorname{cup}=\mathrm{N}$ nitrosophenylhydroxylamine), $\mathrm{Fe}(\mathrm{acac})_{3}$ (acetylacetonate), or $\mathrm{Fe}(\mathrm{CO})_{5}$ in organic solvents. ${ }^{66}$ In this method, precursors are injected into either a hot reaction mixture (high temperature) or a room temperature reaction mixture, followed by heating in a closed or open reaction vessel. A size-controlled monodispersed IONPs synthesis was reported by Sun and Zeng, wherein 
$\mathrm{Fe}(\mathrm{acac})_{3}$ in phenyl ether was heated to $265{ }^{\circ} \mathrm{C}$ in the presence of alcohol, oleic acid, and oleylamine. Larger monodispersed NPs with a size of up to $20 \mathrm{~nm}$ were obtained by using smaller MNP seeds. ${ }^{67}$ This procedure does not need a size selection process. The size of the IONPs is controlled by varying the aging temperature and other reaction parameters. This method is suitable for preparing NPs with a different shape (nanospheres or nanocubes). The size and shape can also be tailored by using varieties of precursors, solvents, or additives during the thermal decomposition process. One of the shortcomings of this approach is that the exact shape of the IONPs is not reproducible, as the nucleation of NPs involves boiling the solvents. The nanomaterial produced via this method is usually dissolved in nonpolar solvents.

An alternative wet chemical method for obtaining crystalline NPs is the hydrothermal one, wherein a mixture of iron salts was dissolved in an aqueous medium and heated in a sealed Teflon container at a temperature $\left(130\right.$ to $\left.250{ }^{\circ} \mathrm{C}\right)$ higher than the boiling point of water and high vapor pressure (0.3 to $4 \mathrm{MPa}) .{ }^{68,69}$ This method generates higher crystalline MNPs with a superior magnetic feature due to the synergistic effect of high temperature and pressure. The microemulsion method is also employed for the synthesis of shape- and size-controlled MNPs. The binary system (water/surfactants or oil/surfactants) of microemulsion, which can be formed by different types of self-assembled structures such as spherical and cylindrical micelles, enables the desired growth, nucleation, and agglomeration of NPs. ${ }^{70}$ In this method, an iron-containing nanoemulsion is mixed with sodium hydroxide, followed by lysis with acetone to remove the surfactants. The dynamics of MNPs and controlled size can be achieved by varying the droplet size, reactant concentrations, and surfactant nature. Although these colloidal NPs show higher superparamagnetic properties, they need several washing procedures to remove surfactants and further stabilization before use in biomedical applications. Another two-phase method for the synthesis of NPs is the sol-gel method, wherein the hydroxylation and condensation of precursor molecules in solution generate the 
sol of nanometric particles. A three-dimensional metal oxide wet gel is obtained by further condensation and inorganic polymerization. Heat treatments are also required to obtain a crystalline state, as gel preparation is carried out at room temperature. The predetermined nanostructure with a pure amorphous phase and monodisperse, size-controlled NPs can be synthesized using the sol-gel method. ${ }^{71}$ For instance, $\gamma-\mathrm{Fe}_{2} \mathrm{O}_{3}$ in silica with a size of 15 to 30 $\mathrm{nm}$ was synthesized by heating the gel to $400{ }^{\circ} \mathrm{C}$. The gel was prepared by the hydrolysis of $\mathrm{Fe}\left(\mathrm{NO}_{3}\right)_{3} \cdot 9 \mathrm{H}_{2} \mathrm{O}$ and tetraethyl orthosilicate (TEOS) in ethanol. ${ }^{72}$ Some physical methods have also been developed to synthesize MNPs, such as electron beam lithography and gas-phase deposition. ${ }^{73}$ These methods required tedious and time-consuming procedures and were unable to generate size-controlled NPs. In comparison to physical processes, the wet chemical methods are more straightforward, more tractable, and more efficient for the synthesis of monodisperse, highly crystalline, superparamagnetic NPs with controlled size, shape, and composition. $^{74}$

\subsection{Template-based synthesis}

The term "template synthesis" represents the direct preparation of nanomaterials with a uniform morphology, such as size and shape, using a central structure as a template. ${ }^{69,75}$ Within the template, a network structure is formed in such a manner that removal of the template may create a cavity with the designed morphological and stereochemical nanostructure. The template enables higher reproducibility of the structure and provides a skeleton for obtaining the desired function of a nanostructure. ${ }^{76}$ Template synthesis generally involves three main steps: first, selection or creation of the template; second, assembly or synthesis of the desired nanomaterials using common synthetic strategies; and third, removal of the template to generate a porous nanostructure. Broadly, there are three template-based syntheses: $(i)$ softtemplating methods, (ii) hard-templating methods, and (iii) sacrificial-templating methods. The soft-templating methods use structurally flexible materials such as surfactants, polymers, 
micelles, and viruses, whereas in hard templating, the porous materials were prepared using a rigid structure such as colloidal silica, latex, or a carbon sphere. ${ }^{77}$ Elimination of the template is relatively simple and easy in soft templating. Hard templating is advantageous for the synthesis of stable, controlled morphological NPs, but it requires tedious template removal procedures. Thus, proper template selection is a prerequisite for obtaining the desired porous nanostructure.

Soft-templating approaches have been used for the synthesis of a variety of hollow nano- and microstructures, including superparamagnetic metal oxides ${ }^{78}$ and metals (e.g., $\mathrm{Ni}$, Pd, and Ag). ${ }^{79-81}$ An emulsion, micelle, vesicle, or hydrophilic polymer is generally employed as a template. These soft templates are usually aggregated via inter- and intramolecular interactions such as hydrogen bonding, Van der Waals forces, and chemical bonding. ${ }^{82}$ The inorganic precursor is then deposited onto the surface of the interior of the template following conventional precipitation, electrochemical, or other synthetic approaches. Finally, removal of the soft template is usually carried out via a more straightforward process, such as washing or evaporation. This method offers excellent repeatability and a simpler operation and avoids chemical or structural changes during template removal. As the biological system requires mild template removal, this technique has the potential for the synthesis of a hollow structure with biosensitive functionalities such as molecular catalysis, biocatalysis, and biosensing. Moreover, using an emulsion template, hollow shells with an additional functional component such as bioactive or catalytically active species can be synthesized by incorporating them into the hollow materials. ${ }^{83}$ For example, Lu et al. reported achieving a magnetic $\mathrm{Fe}_{3} \mathrm{O}_{4} @ \mathrm{~h}$ C/noble-metal rattle-type NP by incorporating surface-functionalized, preexisting $\mathrm{Fe}_{3} \mathrm{O}_{4}$ nanocrystals into the droplets of oil/water emulsion, followed by interfacial polymerization to generate a hollow polymer shell $\mathrm{Fe}_{3} \mathrm{O}_{4} @$ h-P. ${ }^{84}$ The shell contains a carboxylate group and binds the noble metal via an ion exchange process. The metal cation was then converted to 
nanocrystals via pyrolysis under an inert atmosphere. Soft templates are sensitive to reaction parameters such as $\mathrm{pH}$, temperature, and solvent polarity, which presents challenges to using this method to obtain a hollow structure with a particular structural feature.

In hard-template synthesis, a rigid material provides the size, morphology, and surface properties of nanostructured materials. Colloidal $\mathrm{SiO}_{2}$, latex, and carbon spheres are the most frequently used materials as a hard template. In addition to the three steps of the soft-templating method, hard templating adopts one more step. The hard template inhibits the aggregation or crystallization of the precursor molecules and allows the generation of NPs with a structure opposite to that of the template. The surface of the as-synthesized template materials needs to be either modified or functionalized to fit its chemical compatibility with the precursor molecules. Different synthetic approaches to forming the shell on the template have been applied to prepare the desired hollow nanostructure. The shells are formed by adsorption, layerby-layer methods, chemical deposition, or nanocasting. ${ }^{69}$ In the adsorption methods, precursor molecules are adsorbed on the surface of the template materials via electrostatic attraction followed by thermal treatment to induce cross-linking and development of the continuous shell. For example, Wang et al. demonstrated the synthesis of three nanoporous metal oxides $\left(\mathrm{Fe}_{2} \mathrm{O}_{3}\right.$ nanorods, $\mathrm{NiO}$ nanosheets, and $\mathrm{Co}_{3} \mathrm{O}_{4} \mathrm{NPs}$ ) using sulfonated polystyrene (SP) microspheres as a hard template. ${ }^{85}$ The SP microsphere was achieved by gradual sulfonation of the outer sphere of polystyrene. When the sulfonated SP microsphere was placed in the solution of precursor metal salt, the ions from the precursor adsorbed within the outer surface of the sphere. A further heat treatment simultaneously cross-linked the metal precursors into the shell and removed the template polymer particles, thereby generating the hollow (hierarchical) metal oxide. Layerby-layer methods also involve the electrostatic adsorption of metal precursor ions around the template materials to form alternating layers of oppositely charged building blocks. ${ }^{86}$ Unlike the adsorption or layer-by-layer shell formation, the chemical deposition method utilizes the 
chemical attachment of the shell precursors to the template surface. Here, cross-linking of the precursor occurs via condensation or polymerization reactions and does not require further heat treatment to develop a continuous shell around the template materials. ${ }^{87}$ Nanocasting synthesis offers superior structural features of hollow materials, such as shell thickness, porosity, and higher mass-transport properties. ${ }^{88}$ In the above discussed methods, a porous scaffold around the shell is initially formed, followed by the infiltration of precursors into the porous rim of the template materials. Thermal or chemical treatment is required for appropriate cross-linking. The synthesis of nonspherical hollow materials using a hard template remains challenging due to the lack of templates and difficulties in achieving uniform surface (sharp edge and corners) coverage on template. ${ }^{89}$

Another template-based method, called a sacrificial template, is used to synthesize various magnetic metal oxide NPs. The use of metal-organic frameworks (MOFs) or porous coordination polymers (PCPs) as a sacrificial template has drawn significant attention due to their structural diversity, large surface area, and different surface morphologies. ${ }^{90}$ Though thermal decomposition or calcination of iron oxide or iron hydroxide at a certain temperature generated porous NPs, the pore volumes and pore size obtained by this method are not very large. However, thermal treatment of MOFs or PCPs produces microporous metal/metal oxide NPs with a large surface area. Prussian blue (PB) coordination polymers and PB analogues are considered the most promising cyano-bridged MOFs for preparing porous metal oxide NPs. In such MOFs, iron ions are bridged by cyano groups [(-Fe-CN-Fe)-]. Cyano groups are labile and easily removed ( $\mathrm{C}$ and $\mathrm{N}$ are oxidized into gases and escape) by calcination, resulting in porosity in the metal nanostructure with super/quasisuperparamagnetism. ${ }^{91}$ Recently, some attempts to synthesize porous iron oxide through the thermal decomposition of $\mathrm{PB}$ have been reported. For instance, $\mathrm{Hu}$ et al. synthesized elongated PB nanocubes via selective etching followed by the conversion of PB crystals into a mixture of iron (III) oxide. ${ }^{91,92}$ However, the 
obtained NPs had a low surface area, poor crystallinity, and several crystalline phases $(\alpha, \beta$, and $\gamma$ phases). To overcome such limitations, Yamauchi et al. synthesized nanoporous IOs (crystalline $\alpha-\mathrm{Fe}_{2} \mathrm{O}_{3}$ and $\gamma-\mathrm{Fe}_{2} \mathrm{O}_{3}$ ) with hollow interiors by calcinating previously prepared hollow PB nanocubes. ${ }^{91}$ The crystalline phases and their crystalline grain sizes were controlled by the volume of internal hollow cavities in PB nanocubes and by the calcination temperature (Fig. 2). The cubic structure was preserved even at a higher calcination temperature $\left(400{ }^{\circ} \mathrm{C}\right)$. Moreover, the crystalline phase of porous nanocubes became higher at an elevated temperature, but the particle size slightly decreased with increasing temperature. The reduction in particle size arises from the higher degree of decomposition of cyano groups. In addition to this method, later on, Yamauchi et al. controlled the particle size (from $20 \mathrm{~nm}$ to $500 \mathrm{~nm}$ ) of nanoporous metal oxides by adjusting the amount of sodium citrate chelating agent for the synthesis of hollow PB nanocubes. ${ }^{93}$

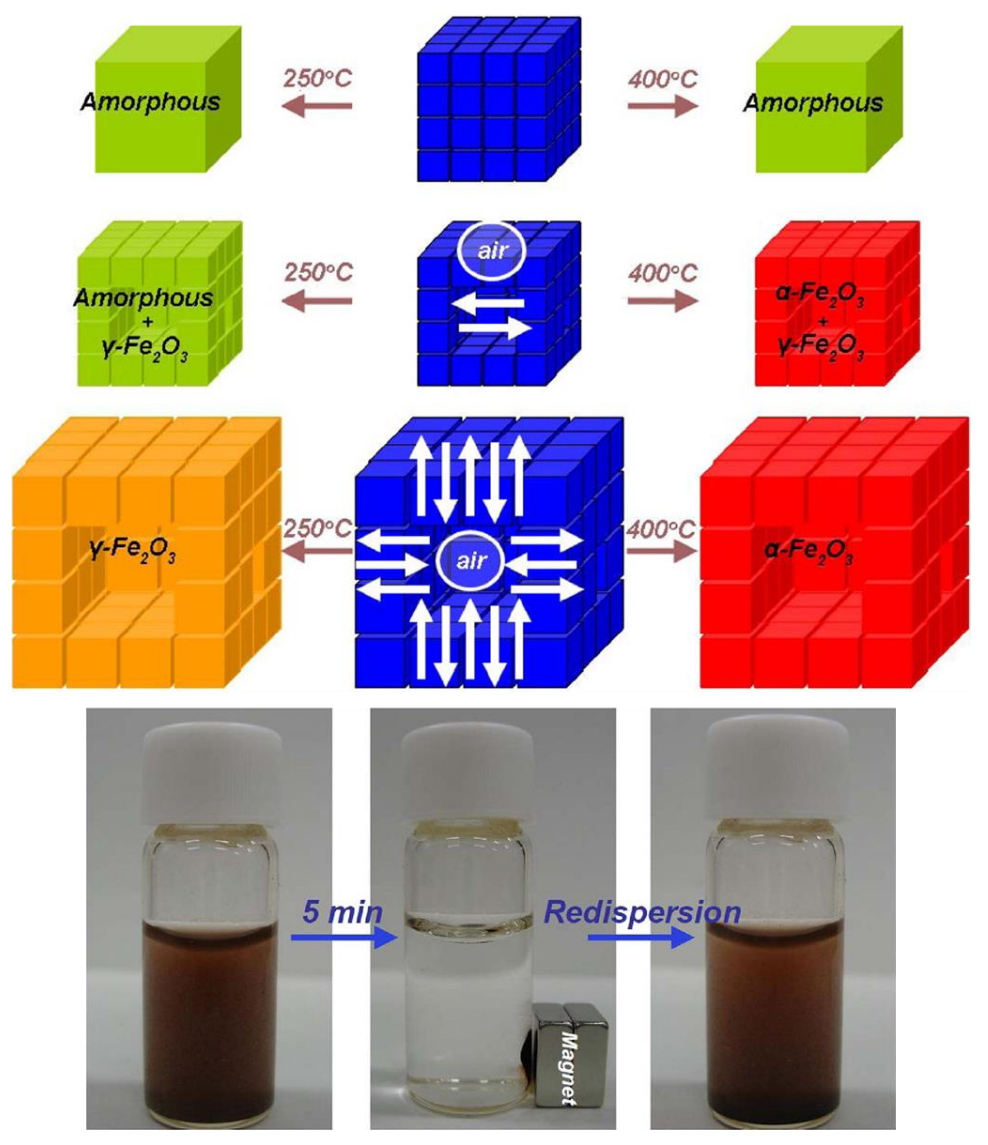


Fig. 2 Schematic illustration of the fate of PB nanoparticles at different applied calcination temperatures. Reproduced with permission..$^{91}$

\subsection{Multicomponent (hybrid) magnetic nanoparticle synthesis}

Hybrid nanomaterials combining two or more functional constituents and nanoscale functionalities have attracted increasing interest due to their numerous applications in electronics, catalysis, bioimaging, biotechnology, and nanotechnology. ${ }^{94}$ In hybrid (bimetallic) materials, one metal may confer the electrochemical or optical or both properties, whereas others may provide long-term stability, biocompatibility, and specific affinity to target biomolecules. During synthesis, the individual component may be combined and optimized independently for target analysis. Hybrid materials achieve the cooperative performance of individuals via interaction between or among constituents. To date, most biomolecular analyses involving hybrid materials have been reported with the combination of MNPs (mainly iron oxide) with gold ( $\mathrm{Au}$ ). However, other metals such as $\mathrm{Pt}, \mathrm{Zn}$, and $\mathrm{Cu}$ have also been explored. In addition to these, the synthesis of carbon and graphene, silica-containing hybrid materials, has been reported as a promising platform for biomedical applications. The general strategy for obtaining composite NPs is to prepare one NP, followed by coating or loading another constituent (metal or nonmetal) or using the first NP as a nucleation seed to deposit other materials..$^{94,95}$

Au-containing MNPs (mostly iron oxide based) (Au@MNPs) have attracted particular interest in the electroanalytical chemistry for bioseparation, the fabrication of immunoassays, and the development of optical and electrochemical sensors due to the superparamagnetic properties of magnetic materials and the biofavorable (i.e., optical and electrical) behavior of Au. ${ }^{96,97}$ Different synthetic approaches have been reported for monodispersed $\mathrm{Au}-\mathrm{Fe}_{\mathrm{x}} \mathrm{O}_{\mathrm{y}}$ nanohybrids with diverse morphologies such as core/satellite, core/shell, multilayer, Au-coated 
iron oxide, and flower-like structures (Fig. 3).${ }^{98}$ In recent last decades, a significant number of $\mathrm{Au}-\mathrm{Fe}_{\mathrm{x}} \mathrm{O}_{\mathrm{y}}$ nanocomposites have been reported for the development of different biosensing tools such as glucose sensors and aptasensors. ${ }^{99}$ For instance, Chin et al. (2009) synthesized monodispersed $\mathrm{Au}$ and silver $(\mathrm{Ag})$-coated superparamagnetic $\mathrm{Fe}_{3} \mathrm{O}_{4}$ core-shell NPs via seedmediated growth. A thin layer of 2-3 nm Au NPs and Ag were attached to $-\mathrm{NH}_{2}$ functionalized superparamagnetic $\mathrm{Fe}_{3} \mathrm{O}_{4}$ through the reduction of $\mathrm{Au}^{3+}$ and $\mathrm{Ag}^{+} \cdot{ }^{100}$ Very recently, we developed an electrocatalytically active gold-loaded nanoporous superparamagnetic nanocube $\left(\mathrm{Au} @ \mathrm{NPFe}_{2} \mathrm{O}_{3} \mathrm{NC}\right.$ ) in which 2\% Au NPs were loaded onto the porous cubic $\mathrm{Fe}_{2} \mathrm{O}_{3}$ nanocubes via the reduction of $\mathrm{HAuCl}_{4}$. A porous $\mathrm{Fe}_{2} \mathrm{O}_{3}$ nanocube was prepared by the calcination of Prussian blue (PB) nanocubes followed by the thermal decomposition of that porous $\mathrm{PB}$ powder. ${ }^{45}$

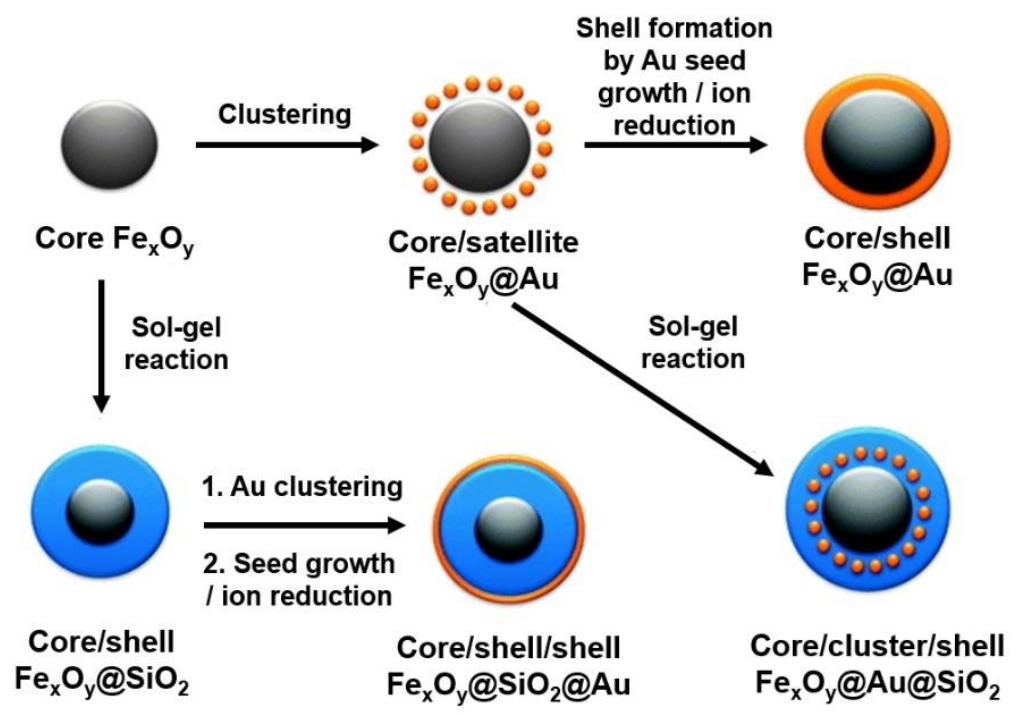

Fig. 3 Schematic representation of the conversions of selected multilayer FexOy@Au composites. Reproduced with permission. ${ }^{98}$

Carbon nanomaterials such as graphene, graphene oxide (GO), and carbon nanotubes (CNTs) have also played a significant role in biomolecular analysis. For example, two-dimensional graphene (or GO) possesses excellent surface-bound properties such as a large surface area (up 
to $2630 \mathrm{~m} 2 / \mathrm{g}$ ), unique $\mathrm{sp}^{2} / \mathrm{sp}^{3}$ bonded structure, thermal conductivity, and high carrier mobility. They (carbon NMs) demonstrate a different binding affinity toward the double-stranded and single-stranded DNA and thereby are used in designing a sensor to detect DNA or a DNAbased marker by discriminating between different DNA sequences. Inspiring form their intrinsic properties, several graphene-containing superparamagnetic iron oxide nanocomposites have been synthesized. A one-step synthesis of $\mathrm{Fe}_{3} \mathrm{O}_{4}$ NPs decorated with reduced graphene oxide was reported by Teymourian et al. for the sensing of various analytes (e.g., $\mathrm{NADH}, \mathrm{H}_{2} \mathrm{O}_{2}$, uric acid, nitrite, ascorbic acid, and dopamine). ${ }^{101}$ A bifunctional $\mathrm{Fe}_{3} \mathrm{O}_{4}$ $\mathrm{Pt} / \mathrm{rGO}$ has also been reported, wherein $\mathrm{Fe}_{3} \mathrm{O}_{4}$ and Pt NPs were coated onto the rGO surface. ${ }^{102}$ This nanocomposite had been used for the catalytic reduction of methylene blue and the aerobic oxidation of benzyl alcohol. Very recently, a new composite of GO sheets and PB consisting of a different ratio of GO and PB has been reported by Tanaka et al. ${ }^{103}$ They synthesized nanoporous GO/iron oxide (IO) hybrid composites via thermal decomposition of GOsheets/PB composites in the air at $400{ }^{\circ} \mathrm{C}$. Among all ratios (GO:PB ratio $=25: 75,50: 50$, and $75: 25)$, the $25: 75$ ratio resulted in a higher surface area $\left(120 \mathrm{~m}^{2} \mathrm{~g} 1\right)$ than those of the pure GO (34.9 m2 g1) and IO (93.1 m2 g1) samples. In addition to GO, a number of multiwalled CNTcontaining IO nanohybrids also possessed promising applications for catalysis and biosensing due to their combined functionalities, such as the high chemical stability and electrical conductivity of cylindrical graphene sheets and the superparamagnetic properties of IO. ${ }^{54,104}$

\section{Surface functionalization of superparamagnetic nanoparticles}

The ability to tune the surface in a controllable manner and at a particular molecular level makes possible the use of MNPs in biomedical and biotechnological applications. Generally, MNPs have a large surface-to-volume ratio $\left(10-50 \mathrm{~m}^{2} \mathrm{~g}^{-1}\right)$ and thus possess surface energy. In order to minimize the surface energy, naked IONPs tend to aggregate via magnetic interactions, 
limiting their dispersion in solution and complex matrices. ${ }^{105,} 106$ Moreover, naked IONPs have high chemical activity and are easily oxidized in the air; they are unstable in strong acidic solutions and undergo leaching, which actively reduces their magnetism, reusability, and lifetime. Therefore, surface functionalization or covering of the surface with biocompatible compounds is crucial to $(i)$ prevent degradation in an aqueous, acidic, or aggressive (blood) environment; (ii) suppress the magnetic interactions to avoid aggregation; and (iii) provide a functional group to bind or attach a wide range of biomolecules (e.g., protein and nucleic acids). These strategies include coating with biofavorable inorganic materials; immobilization with small organic molecules, surfactants, polymers, or biomolecules; and functionalization with metal and inorganic substances such as silica, graphene, gold, or platinum.

\subsection{Small organic molecules, functional groups, and surfactants}

Organic molecule-functionalized superparamagnetic NPs have been used in various applications, especially in the field of biomedicine for targeted drug delivery, magnetic cell separation and isolation, designing immunoassays, etc. ${ }^{66}$ To prevent particle aggregation and preserve good biocompatibility, IONPs are generally functionalized using different organic materials (e.g., polyethylene glycol (PEG), dextran, and starch) and various functional groups such as $-\mathrm{OH},-\mathrm{COOH},-\mathrm{NH}_{2}$, and $-\mathrm{SH}{ }^{106}$ These functionalized groups are also suitable for the further addition of different bioactive molecules for targeted bioapplication. For example, small-sized silane is used to modify the end groups of the IONP surfaces for conjugating NPs with polymer or other metal ions, biomolecules, or biological entities. ${ }^{107} p$ Aminophenyltrimethoxysilane (APTS), mercaptopropyltriethoxysilane (MPTES) and 3aminopropyltriethoxysilane (APTES) agents are the most commonly used silanes for fastening the $-\mathrm{NH}_{2}$ and $-\mathrm{SH}$ groups. For instance, Shen et al. reported a synthetic approach of APTScoated magnetic IONPs ( $\mathrm{Fe}_{3} \mathrm{O}_{4} @$ APTS), where $\mathrm{Fe}_{3} \mathrm{O}_{4} \mathrm{NPs}$ (mean diameter $6.5 \mathrm{~nm}$ ) were synthesized in the presence of APTS via the hydrothermal synthetic route to obtain an amine 
functional group on the IO surfaces. ${ }^{108}$ The organic compounds oleic acid and oleylamine, which consist of a C18 tail with a cis-double bond, play essential roles in the adequate stabilization of IONPs via high-temperature thermal decomposition, as they can form a stable, protective monolayer around the synthesized IO ${ }^{59}$ For instance, oleic acid (OA) has been used to coat $\mathrm{Fe}_{3} \mathrm{O}_{4}$ during the synthesis via thermal decomposition of $\mathrm{Fe}(\mathrm{acac})_{3}$. The resulting OAcoated NPs had an OA coating $3 \mathrm{~nm}$ thick and possessed good superparamagnetic properties (magnetic saturation value $78.68 \mathrm{emu} / \mathrm{g}) .{ }^{109}$

Moreover, the IONPs obtained from the organic iron precursor are capped with nonpolar groups, and they become stable in organic solvents such as hexane. These hydrophobic NPs generally are not suitable for biological applications. In order to make them biocompatible, the hydrophobic organic phase needs to be replaced or transferred by the aqueous phase. To prepare water-soluble MNPs directly, small molecules such as amino acids, cyclodextrin, or citric acid need to be used in the reaction process. ${ }^{110,111}$ For example, Gao et al. synthesized hydrophilic superparamagnetic colloidal nanocrystals using an anionic polyelectrolyte PSSMA (4-styrenesulfonic acid-co-maleic acid) sodium salt containing both sulfonate and carboxylate groups as the stabilizer. The synthesis was achieved by a one-step solvothermal method. The nanocrystals were well dispersed in an aqueous solvent such as water, PBS buffer, or ethanol. ${ }^{112}$ In addition to these approaches, ligand-exchange transformation is used to convert oil-soluble functionalized iron oxide NPs to a water-soluble ones. This method involves the addition of an excess amount of hydrophilic ligands into the nanoparticle solution, resulting in displacement of the original ligands on the NP surface. A ligand-exchange method was reported for the synthesis of monodispersed water-soluble MNPs where oleic groups present (initially) on the NP surfaces were replaced by various capping agents bearing reactive hydroxyl moieties via ligand-exchange reactions. ${ }^{113}$ These hydroxyl groups could be exploited to initiate ring-opening polymerization of polylactic acid from the 
nanoparticle surfaces and esterified by acylation to permit the addition of alkyl halide moieties (Fig. 4). Various surfactants, such as dodecyl amine, sodium oleate, and sodiumcarboxymethyl cellulose, were also used to enhance the dispersibility of MNPs in aqueous media. ${ }^{114}$
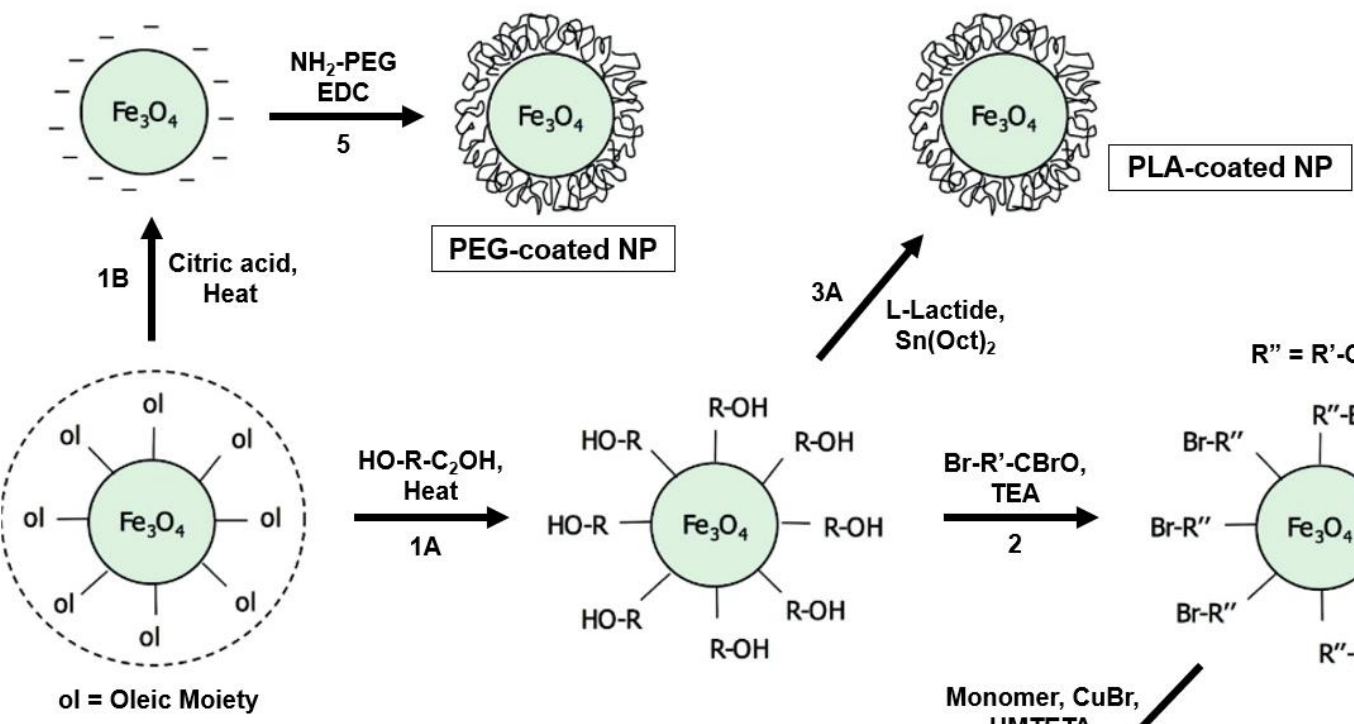

Sn(Oct)
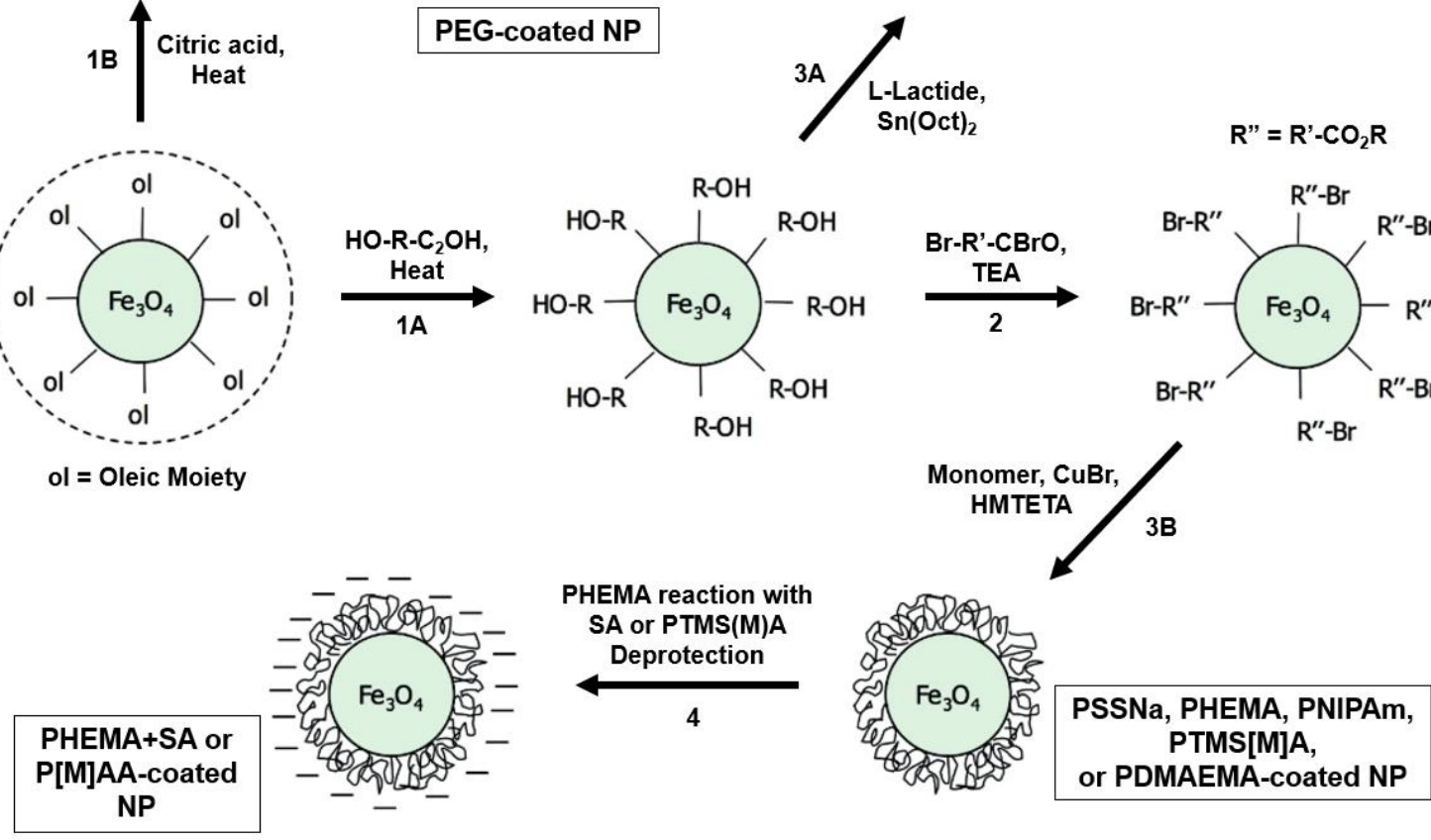

Fig. 4 Schematic representation of the functionalization of magnetic nanoparticles. Steps 1A and 1B: ligand-exchange reactions. Step 2: acylation of hydroxyl groups to prepare ATRP surface initiators. Step 3A: surface-initiated ring-opening polymerization of L-lactide. Step 3B: surface-initiated ATRP. Step 4: deprotection or additional reaction after polymerization. Step 5: grafting of end-functionalized PEG chains onto the nanoparticle surface using amidation chemistry. Reproduced with permission. ${ }^{113}$ 


\subsection{Polymers}

Polymer-functionalized MNPs have drawn much attention due to several advantages of polymer coating, such as that polymer coating increases the pharmacokinetics and biodistribution of NPs and increases the Van der Waals attractive and repulsive forces to balance the magnetic forces on the NPs. ${ }^{59,106}$ Several natural and biodegradable synthetic polymers, such as polysaccharides, polyaspartate, polyethylene glycol (PEG), poly(vinyl alcohol), and poly(vinyl-pyrrolidone), are currently used to produce MNPs with tailored and desired properties. ${ }^{59,66,68}$ There are two main purposes for the polymer coating of NPs: one is to broaden the application of NPs by introducing different functional groups, and the other is to manufacture monodisperse NPs with a controlled composition and well-defined shape. However, after polymerization, the superparamagnetic properties of NPs have been decreased.

The conventional approaches to the polymer functionalization of MNPs are in-situ and postsynthesis coating. In the in-situ strategy, the NPs can be functionalized with polymers through mini- or microemulsion polymerization or the sol-gel process during the synthesis of NPs. ${ }^{115}$ Here, the organic precursor molecules capped the IONPs and formed an overlying layer through emulsion polymerization. The conventional structure obtained by this approach is mainly a matrix-dispersed structure or a core-shell structure. ${ }^{116}$ Unfortunately, this method failed to maintain the colloidal stability and thickness of the shell. The predominant method of polymer coating is postsynthesis functionalization, where the polymer functionalization has been carried out on the prepared IONPs via the one-pot method, self-assembly, or heterogeneous polymerizations. The resulting polymer@NPs is prone to form core-shell structure. In addition, a number of heterogeneous polymerizations with different water-soluble monomers have been used to prepare a well-defined monodisperse core-shell structure. ${ }^{117}$ An example of such polymerization was reported by Pimpha et al., where an all-in-one NP platform was developed using an oil-in-water emulsion system. The emulsion consisted of an 
iron oxide nanocrystal containing a hydrophobic oil core. The oil droplets were successively stabilized by a lipid mixture containing a near-infrared (NIR) fluorophore (Cy5.5), followed by further modification with PEGylated lipids to increase the stability of the particles. The lipid mixture favors the creation of small particles of 30-100 nm. ${ }^{118}$ Currently, MNPs are modified with smart polymers, which provide stimulus-responsive characteristics such as $\mathrm{pH}$, temperature, and light for a wide variety of biomedical applications such as drug delivery, MRI, biomimetics, and biosensors. ${ }^{119-121}$

\subsection{Bioactive molecules}

In recent years, biomolecule-functionalized MNPs have drawn attention in nanomedicine due to their biocompatibility and diverse application in the separation of biomolecules from complex biomatrix, detection, sensor-development, and other bioapplications. Numerous small biomolecules such as proteins, antibodies, enzymes, human/bovine serum albumin, avidin, and peptides have bound onto the surface of NPs. ${ }^{122-125}$ The bioactive molecules can be attached to the surface of NPs, mostly by activating the functional groups. In this strategy, small particles or polymer-functionalized NPs are synthesized, followed by the addition of biomolecules through physical adsorption or chemical bond. For example, Lee et al. reported an approach to conjugating the IONPs with single-strand oligonucleotides. In this report, water-soluble carboxyl group-containing magnetic $\gamma-\mathrm{Fe}_{2} \mathrm{O}_{3}$ was prepared, followed by modification of the NP surface with streptavidin. Streptavidin-functionalized $\gamma-\mathrm{Fe}_{2} \mathrm{O}_{3} \mathrm{NPs}$ were then used to bind biotin-labeled oligonucleotides via the strong affinity interactions between avidin (streptavidin) and biotin. ${ }^{126}$ The reactivity of the NP surface-linked carboxyl group can be modified by the reaction with thionyl chloride $\left(\mathrm{SOCl}_{2}\right)$ followed by coupling with the hydroxyl group-containing small molecules. ${ }^{127}$ As this approach has been carried out under anhydrous conditions (e.g., in DMSO or in the presence of $\mathrm{AlCl}_{3}$ ), it is not suitable for immobilizing antibodies or enzymes. EDC (1-ethyl-3-(3-dimethylaminopropyl)carbodiimide) and NHS (N- 
hydroxysuccinimide) can be used instead of anhydrous reagents to make the carboxylated NPs suitable for amine group or enzyme immobilizations. ${ }^{128}$ In this modification, the aggregation of NPs via cross-linking of the particles also happened; therefore, it is not ideal for immobilizing proteins. Proteins can be immobilized on the surface of NPs with thiol functional groups. The protein-thiol bonds are highly selective, and thiol groups reduce the probability of NP aggregation. ${ }^{129}$ Another way to achieve chemical modification of NPs with proteins, antibodies, or enzymes is via the attachment of bifunctional aldehyde groups (e.g., glutaraldehyde) to their premodified amine groups through the Schiff-base condensation reactions. ${ }^{130}$

\subsection{Inorganic materials}

Inorganic materials can possess numerous outstanding properties, such as high electron density and strong optical properties (e.g., Au and Ag), photoluminescence (e.g., CdSe, CdTe, and Y2O3), magnetic moment (e.g., cobalt and manganese oxides), and affinity interaction with biomolecules (e.g., Au, GO, and Pt). ${ }^{30,131-135}$ Inorganic metal functionalization greatly enhances the antioxidation properties of unmodified NPs (e.g., iron oxides). Moreover, this coating extends the optoelectronic, storage, biocompatibility, catalytic, and sensing properties, and thereby, inorganic material-functionalized magnetic materials become very promising for application in catalysis, bioseparation, biolabeling, biosensing (optical and electrochemical), and so on. Different inorganic materials such as silica, Au, carbon, GO, and metal oxides have been used to functionalize NPs, especially IONPs in nanomedicine.

Silica-coated MNPs such as IONPs (IONP@ $\left.\mathrm{SiO}_{2}\right)$ are promising and widely used nanocomposite materials for biological applications. They possess several advantages: $(i)$ silica coating enhances the dispersion of NPs in solution and complex biological samples, as silica coating can screen the interparticle interactions; (ii) they have good biocompatibility, stability,

and hydrophilicity; (iii) the variation of silica shell thickness is relatively easy and 
straightforward; and (iv) silica coating enables the binding of biomolecules of other biofavorable ligands for biological applications. ${ }^{136}$ In general, three strategies have been used to prepare IONP@ $\mathrm{SiO}_{2}$ nanocomposites: the Stöber process, microemulsion synthesis, and aerosol pyrolysis. The Stöber process is the commonly used method for silica coating. In this method, IONPs are dispersed in alcohols, followed by the addition of silane. Water or ammonia solution is then added to form $\mathrm{IONP} @ \mathrm{SiO}_{2}$. The thickness of silica can easily be tuned from 5 to $200 \mathrm{~nm}$ by varying the concentration of ammonia and the ratio of silica precursors (tetraethoxysilane, TEOS). ${ }^{137}$ For example, Xuan et al. synthesized a monodisperse $\mathrm{Fe}_{2} \mathrm{O}_{3} @$ mesoSiO $\mathrm{O}_{2}$ as a bifunctional agent for application in drug carriers and MRI. ${ }^{138}$ Micelles or inverse micelles have been used in the microemulsion process to obtain a confined and controlled coating of silica on core IONPs. ${ }^{139}$ This process requires the additional separation of core-shell NPs from a large number of surfactants. In aerosol pyrolysis, IONP@ $\mathrm{SiO}_{2}$ is obtained by phase segregation of the iron precursors (bulk iron) and silica oxide or alkoxides in flame environments. ${ }^{140}$

Carbon-coated NPs (e.g., IONP@C) have also attracted enormous interest in bioapplications due to their elevated intrinsic electrical conductivity and excellent chemical and thermal stability. Carbon protects the NPs from oxidation and corrosion of the core materials. In general, a carbon coating can be applied using a simple three-step process. MNPs are first prepared using conventional synthetic approaches. MNPs generally act as seeds. Then the selective polymer is coated via a polymerization process. Finally, the IONP@C composite is generated by the annealing treatments. ${ }^{66}$ Recently, much attention has been drawn to the functionalization of magnetic materials by using highly conductive GOs. IONP/GO hybrid materials have been used in biological fields; for example, Chen et al. synthesized an aminodextran coated-Fe ${ }_{3} \mathrm{O}_{4} / \mathrm{GO}$ composite for cellular MRI. ${ }^{141}$ 
Different metallic NPs (e.g., Au, Ag, Pt, Cu, and Co) possess different properties, such as optical (surface plasmon resonance, light scattering, surface-enhanced Raman scattering), electrical (conductivity), and catalytic ones, and are widely used in contrast imaging, catalysis, sensing, and medicine. ${ }^{142,} 143$ The combination of such metals with MNPs significantly enhances the functional properties of metal/NP composite via cooperative interaction of the intrinsic properties of metal and metal oxide NPs. Among all metal-coated NPs, Au-coated IONPs have been intensively studied and showed enormous potential in biotechnology and biomedicine. ${ }^{143}$ More specifically, the planar gold surfaces or gold nanoparticles (AuNPs) hold significant advantages for the electrochemical and optical detection of biomolecules, as they have a selective and specific affinity toward DNA, RNA, antibodies, and proteins. ${ }^{133}$ However, the Au coating on MNPs is not thick enough and may cause aggregation. Hence, ionic capping ligands must be attached to the system during NP synthesis. Moreover, Au-coated MNPs (Au@MNPs) can be modified with a variety of molecular linkers to bind the target analyte for designing optical and electrochemical biosensors. For example, MNP@Au can be adjusted with 1,9-nonanedithiol and mercaptoundecanoic acid (MUA) through the ligand-exchange reactivity at the gold shells to form a thin film assembled core (iron oxide)-shell (gold) nanocomposite. The assembly of $\mathrm{Fe}_{3} \mathrm{O}_{4} @ \mathrm{Au}$ nanoparticles involved an initial thiolateoleylamine exchange reaction followed by cross-linking. The cross-linking was carried out by using the alkyl chain (dithiol as linker A) or hydrogen bonding (carboxylic acid-functionalized thiol as linker B) as shown in Fig. $5 .^{144}$ 


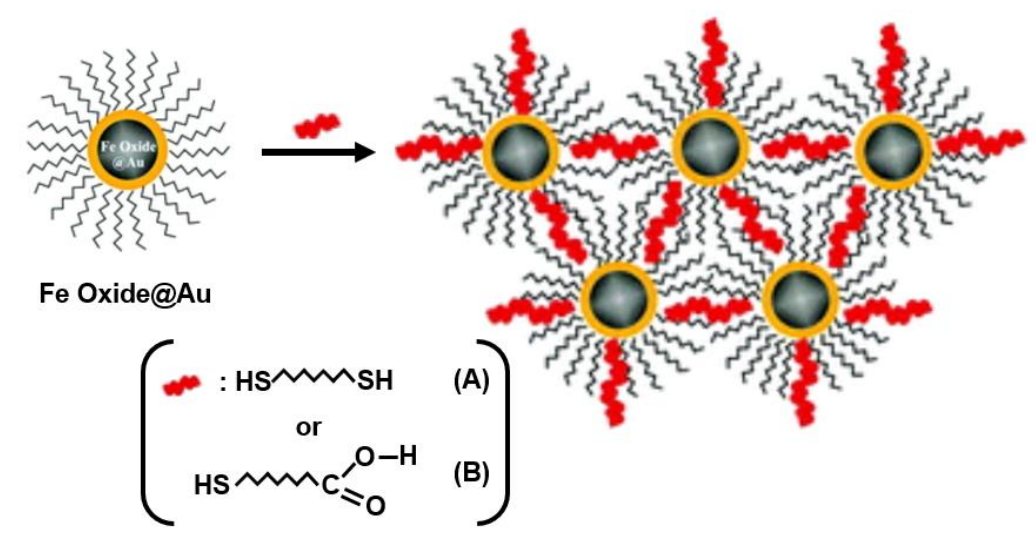

Fig. 5 Schematic representation of the thiolate-oleylamine exchange reaction followed by cross-linking via different linkers ( $\mathrm{A}$ and $\mathrm{B}$ ) for the assembly of $\mathrm{Fe}_{3} \mathrm{O}_{4} @ \mathrm{Au} \mathrm{NPs} . \mathrm{Fe}_{3} \mathrm{O}_{4}$ core: dark circle; Au shell: gray circle; oleylamine monolayer: thin gray zigzag lines. Reproduced with permission. ${ }^{144}$

Various metal oxides and metal sulfides, such as $\mathrm{ZnO}, \mathrm{TiO}_{2}, \mathrm{Al}_{2} \mathrm{O}_{3}, \mathrm{CuO}, \mathrm{CdS}, \mathrm{ZnS}$, and $\mathrm{PbS}$, have also been used to modify the surface of MNPs for a wide variety of biological technologies, as they add unique and selective properties to nanocomposites. ${ }^{145-148}$ For example, Li et al. prepared air-stable $\mathrm{Fe}_{3} \mathrm{O}_{4} @ \mathrm{Al}_{2} \mathrm{O}_{3}$ core-shell NPs through displacement reactions. The NPs possessed high magnetic responses and were used to capture a MALDI target. ${ }^{149}$ In another example, thiol-modified superparamagnetic $\gamma-\mathrm{Fe}_{2} \mathrm{O}_{3}$ beads were modified by CdSe@ZnS quantum dot NPs to form luminescent/magnetic nanocomposite particles via thiol-metal conjugations. The composites showed a threefold higher emission quantum yield, and their emission peaks showed a slight blue shift as compared with individual luminescent QDs. This luminescent/magnetic nanocomposite was used for cell separation, magnetic separation, and luminescent detection. ${ }^{150}$

\section{The function of superparamagnetic nanoparticles in biosensor development}


Superparamagnetic materials are traditionally used for the concentration, magnetic separation, isolation and purification, and identification of molecules and cells. Recently, the magnetic properties of superparamagnetic particles have also been used as detection and signalamplifying tools in various biosensing platforms. The electrocatalytic activity is largely utilized to enhance detection sensitivity and specificity. Superparamagnetic materials are also used as nanocarriers to transfer different biomolecules or bring target biomolecules to a biosensing system. Additionally, it has been discovered that several superparamagnetic NPs, especially magnetic ferric oxide-containing NPs, exhibited intrinsic natural enzyme-like activity.

\subsection{Magnetic capture and separations}

Superparamagnetic nanomaterials are becoming a promising tool for the capture, concentration, isolation, and separation of biomolecules such as in vitro cells, antibodies, proteins, DNA, enzymes, bacteria, and different pathogens from their complex biological matrixes. $^{29,66,151}$ MNPs offer several significant advantages over conventional separation techniques such as chromatography: they possess a large surface-to-volume ratio, are readily dispersible in solution, can be quickly localized or retrieved using a typical external magnet, and provide high versatility and reusability of NPs after the magnetic separation. ${ }^{152}$ Generally, MNPs are functionalized with different surfactants, polymers, and ligands to introduce functional end groups such as $-\mathrm{OH},-\mathrm{NH}_{2},-\mathrm{COOH}$, and $-\mathrm{SH}$ for the selective capturing of target biomolecules. The porous structure of polymer beads containing a magnetic core is also employed to capture size-induced biomolecules. The separation of target biomolecules can be achieved via hydrophobic interactions, antibody-antigen interactions, or direct affinity adsorptions. Two factors greatly influence the separation efficiency of NPs: $(i)$ the amount of active functional group per mass of magnetic materials and (ii) the saturation magnetization value. ${ }^{153}$ A large amount of functional group and high saturation magnetisation value favours the efficient separation of biomolecules. Magnetic microsphere or composite materials fulfill 
these two requirements, as they contain a higher amount of magnetic materials, a porous polymer structure, and selective metal structure for affinity interaction with target biomolecules. NPs with a porous structure can also be good candidates, as they have an enormous surface area and the ability to incorporate a larger number of functional groups or adsorbed manifold biomolecules. A schematic representation of the magnetic separation of biomolecules is shown in Fig. 6.

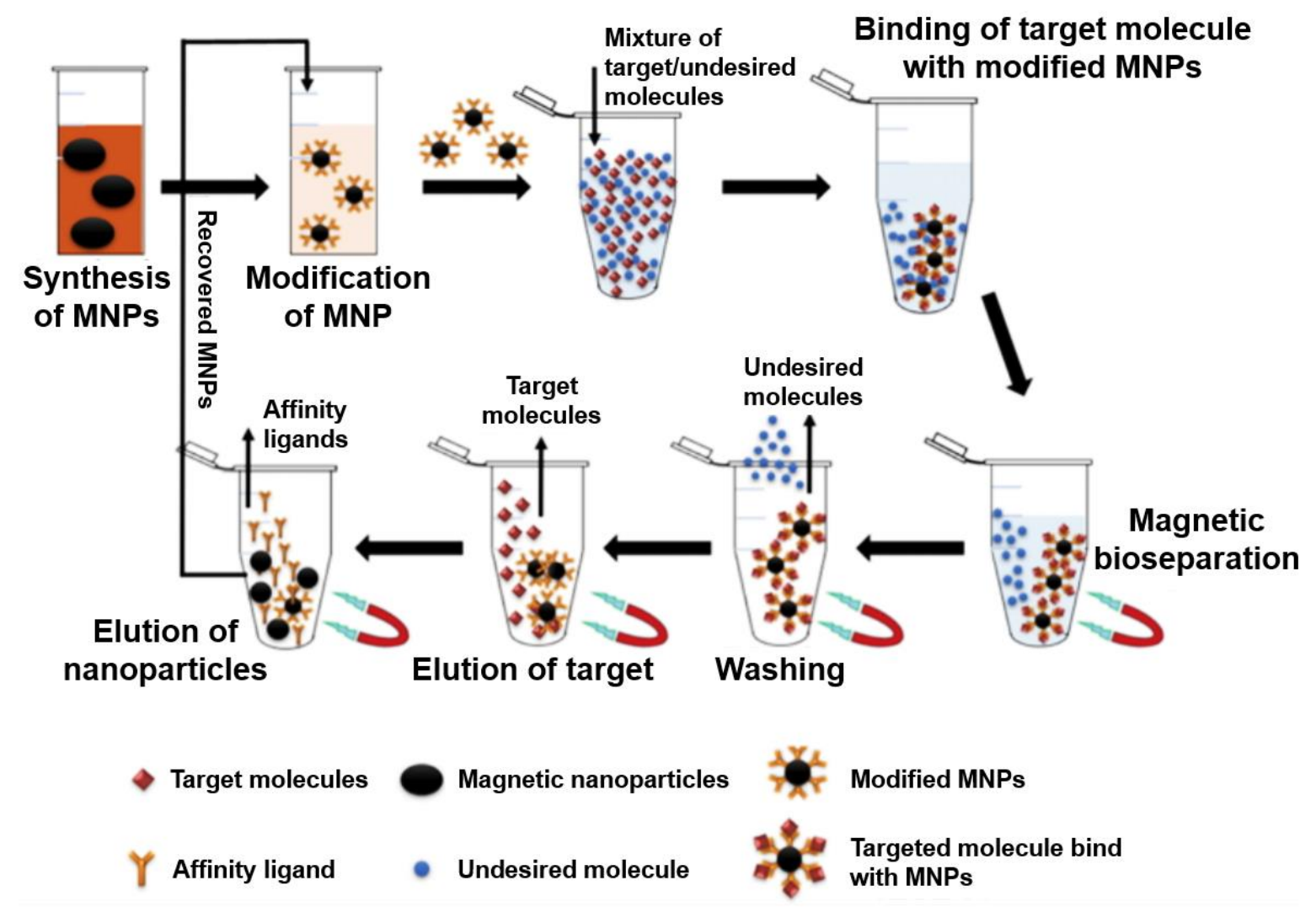

Fig. 6 Schematic representation of superparamagnetic NP-based bioseparation of biomolecules. Reproduced with permission. ${ }^{154}$

Recently, Min et al. isolated and purified genomic DNA from human blood using monodisperse biofunctionalized superparamagnetic nanoparticles. ${ }^{155}$ The NPs were functionalized with meso-2,3-dimercaptosuccinic acid (DMSA), which contains both 
carboxylate and thiol groups for DNA absorption. Small quantities of resulting DMSA-MNPs can isolate DNA from blood samples with a maximum yield of $86.16 \%$, which was shown to be much better than that with a commercial microbead (NucliSENS-easyMAG, BioMérieux). Several colloidal IO-based magnetic nonporous NPs were also reported to be used in the isolation of DNA from chicken erythrocyte bacterial cells of Bifidobacterium longum. The isolated DNA was tested and quantified by PCR amplification and used for the identification of Bifidobacterium bacterial strains. ${ }^{156}$ In the case of proteins and peptides, the magnetic particles can couple with an appropriate affinity ligand or biopolymers to exhibit the affinity interaction toward the target. The particles can then be added to the sample matrix to bind with the target. In another approach, the respective antibody has been used as a free affinity ligand and added to the samples to unite with the antibody-specific target proteins or peptides. Magnetic particles are then functionalized with a secondary antibody (e.g., protein A or protein G) to facilitate interaction with the target-antibody complex. ${ }^{157}$ For instance, Wittrup et al. performed an antibody-conjugated MNP-based isolation of heparan sulphate proteoglycan (HSPG)-induced endocytic vesicles to understand the role of the GRP75 protein in the HSPGmediated endocytosis of macromolecules. ${ }^{158}$ The extracellular vesicles and exosome can also be isolated using an antibody-MNP complex following a method similar to that for proteins.

Superparamagnetic nanoparticles are also widely used in the isolation of mammalian and bacterial cells from complex biomatrixes. Specific cell-recognition moiety-functionalized NPs are incubated with the cells, followed by separation using an external magnet. ${ }^{29}$ For example, anti-CD4 antibody-functionalized IONPs were used to isolate and separate the CD4+ T cells from human blood samples. The anti-CD4 antibody has a specific affinity to CD4+ T cells. Thus, anti-CD4 IONPs precisely capture the T cells. The cells were then captured with a magnet, and cell-purification efficiency was tested by using mass spectrometry through assessment of the $\mathrm{T}$ cell peptide mass fingerprints. ${ }^{159}$ Cell-specific ligands (e.g., 
oligonucleotides or peptides) such as aptamers are also used in the recognition and isolation of cancer cells using MNPs. Aptamer (specific sequence for acute leukemia cells)-modified MNPs were reported to develop a rapid collection and detection platform for acute leukemia cells from whole blood samples. In this strategy, the aptamer was modified with iron oxidedoped NPs and used to extract the target cells, while aptamer-tagged fluorescent NPs were used to detect the target cells. ${ }^{160}$ The separation of apoptotic cells can also be achieved by using streptavidin-modified MNPs. The apoptotic cells express the phosphatidylserine receptors (not revealed by a healthy cell), which can specifically bind to annexin V. ${ }^{161}$ Thus biotinylatedannexin V-labeled apoptotic cells can bind to streptavidin-modified MNPs via the accessible avidin-biotin interaction. This MNP-cell complex can be easily separated and collected using a magnet before visualization of the cells. ${ }^{162}$ Though MNP-based isolation and preparation has many advantages (e.g., being inexpensive, sensitive, and reusable), the method is relatively time consuming due to the multiple steps involved in the isolation and separation process. However, the processing time can be reduced by integrating the isolation and separation method into a microfluidic device using free-flow magnetophoresis. ${ }^{163}$ Chen et al. have developed a POC viral assay to purify and concentrate whole-particle HIV-1 (human immunodeficiency virus) from plasma samples by using a microfluidic magnetic separator chip. In this method, the anti-CD44 antibody was conjugated with a superparamagnetic NPs. Virus-containing plasma was then mixed with antibody MNPs to obtain an HIV-MNP conjugate. The conjugate was then passed through a packed bed of IO particles, and an external magnet was applied to magnetize the bed, which trapped the HIV-MNP conjugates, thereby separating the viral protein with a $62 \%$ extraction efficiency and 80 -fold concentration. ${ }^{164}$ In addition to biomolecules, MNPs can be used to adsorb heavy metals such as arsenic from the aqueous environment, and even bare MNPs (without surface coverage) can be used to separate pollutants from wastewater via nonspecific interactions. ${ }^{165}$ 


\subsection{Development of a detection platform (sensor and biosensor)}

The application of superparamagnetic NPs to the development of a sensing and detection platform is highly advantageous, as most of the biological species are nonmagnetic (they possess inherited low background noise), and their size is analogous to that of the biomolecular targets (e.g., DNA, protein, cells, and exosomes). ${ }^{28}$ Therefore, MNPs can be easily integrated with biomolecules that have a lower steric hindrance, and such an interaction can be easily controlled by controlling the NP morphology and sensor fabrication steps. Several magnetic metal NPs, metal oxide NPs, nanowires, and composite materials have been reported to have potential for use in a wide variety of biosensors for a broad range of bioanalytical applications. ${ }^{41,166}$ MNPs with a different size, nature, morphology, and composition can play significant roles in diverse sensing platforms. Figure 7 schematically represents the critical function of MNPs that can be achieved when they are integrated into a sensor platform, and the details of each feature will be discussed in the following sections.

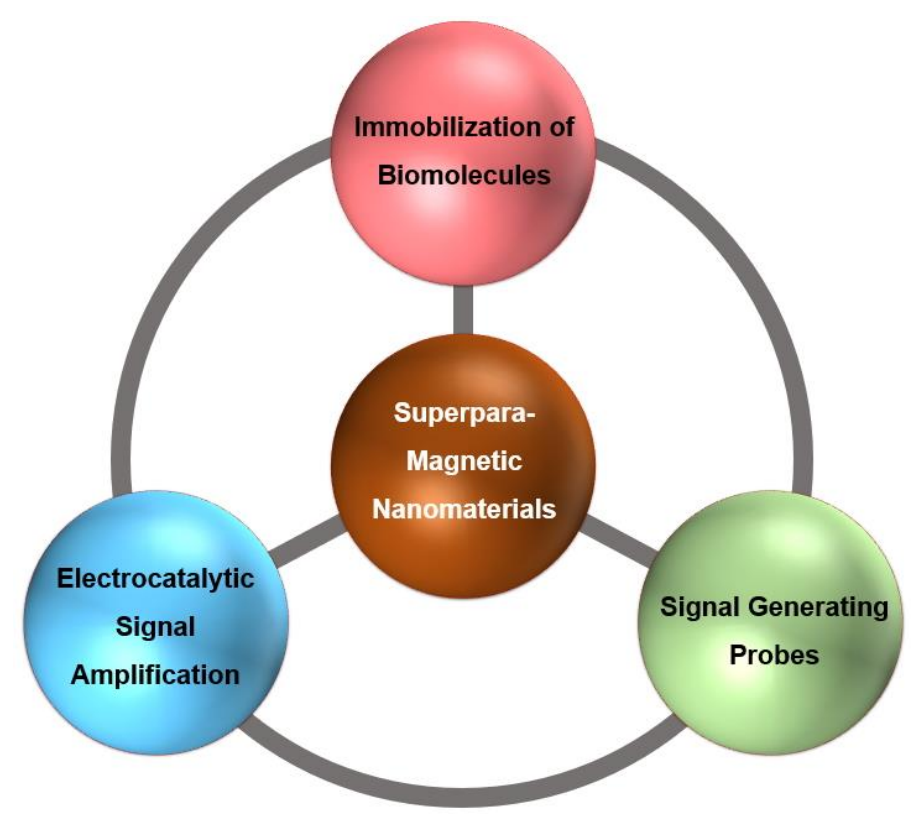

Fig. 7 The function of superparamagnetic nanomaterials in a biomolecule detection platform 


\subsubsection{Immobilization of biomolecules}

Immobilization of biomolecules has been considered a critical step in biosensor design, as the direct adsorption or attachment of biomolecules onto bulk materials results in the denaturation or decrease of their activity. ${ }^{167}$ Therefore, traditional approaches to the immobilization of biomolecules in sensing platforms have been dramatically improved in recent years by the inclusion of magnetic and superparamagnetic NPs. Nanomaterials offer a larger surface area for enhanced biomolecule loading, have a greater ability to adsorb biomolecules and reduce the diffusion limit of biomolecules on the transducer surface. ${ }^{168}$ The prerequisite requirement for biomolecule (e.g., protein or enzyme) immobilization is that the particles should provide an inert and biocompatible environment so that NPs cannot interfere with the native structure and function of target species. ${ }^{169}$ Therefore, in recent decades, we have witnessed a significant number of studies on designing bioactive nanomaterials and their application as an immobilization platform in biosensing. ${ }^{170-172}$ Among all materials, superparamagnetic NPs have been used extensively to immobilize and capture biomolecules or analytes (direct attachment) on a transducer surface. ${ }^{173-175}$ In addition to the high surface area, high binding capacity, and high catalytic specificity of superparamagnetic materials, MNPs provide for the easy capture of biomolecule-modified NPs on the transducer surface. There are four principal methodologies to link biomolecules (proteins or enzymes) with NPs. As shown in Fig. 8, these are electrostatic adsorption, covalent attachment, affinity-based immobilization, and direct conjugation to the NP surface. ${ }^{176}$ 


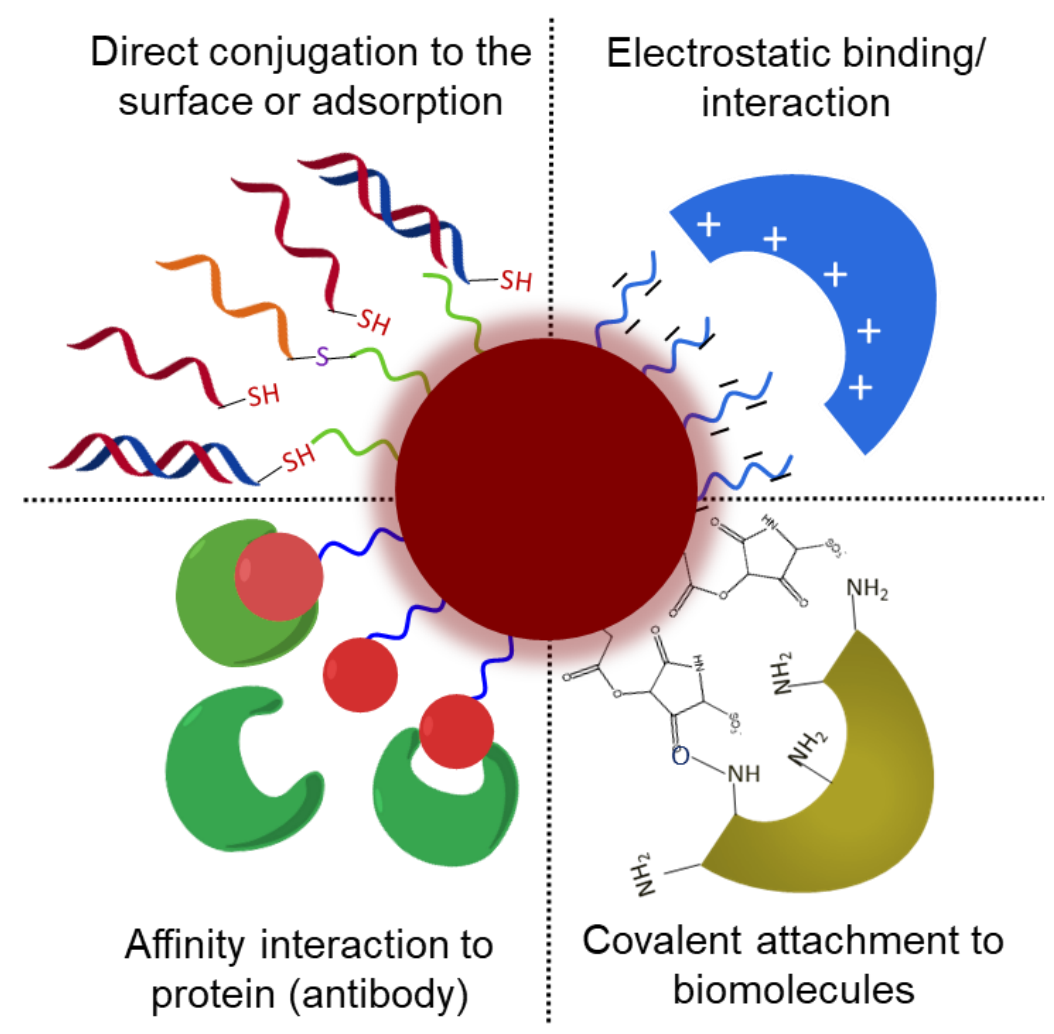

Fig. 8 General strategies for the immobilization of MNPs with biomolecules. Reproduced with permission.

The electrostatic interaction (through the intrinsic charge of NPs and biomolecules) approach is widely used, and such an interaction between NPs and proteins can be easily modulated by the ionic strength and $\mathrm{pH}$ of the medium. Covalent attachment (NPs modified by primary amine or carboxylic groups) is another frequently used method of NP-protein/enzyme conjugation, and the conjugation is greatly improved by controlling the surface chemistry of the NPs and reaction media. For instance, a ferric oxide nanomaterial can be coated with a polymer (e.g., PEKY), which facilitates the covalent attachment to a monoclonal antibody. ${ }^{177}$ It can also be coated with dextran to bind peptide sequences. ${ }^{178}$ In addition to NP surface coating, the NP surface can be modified with thiol chemistry followed by the covalent addition of proteins, enzymes, or antibodies. ${ }^{179}$ Wang and Lee proposed a method for the direct binding of proteins onto superparamagnetic $\mathrm{Fe}_{3} \mathrm{O}_{4}$ through carbodiimide chemistry. They activated the $\mathrm{Fe}_{3} \mathrm{O}_{4}$ surface with two kinds of carbodiimide, cyanamide and $\mathrm{N}$-ethyl-N'-(3-dimethylamino- 
propyl)carbodiimide (EDC), followed by immobilization by two model proteins, trypsin and avidin. The immobilization was increased by increasing the molar ratio of the EDC/NPs, and NP activation with EDC gave a higher yield of immobilization than cyanamide did. The avidinbound NPs were bound to a biotinylated ssDNA and hybridized with a DNA probe to form a DNA sensor. ${ }^{180}$ The avidin (streptavidin)-biotin interactions are the most robust noncovalent affinity interactions and using this specific affinity; avidin coated NPs can selectively bind with biotinylated proteins or disease-specific antibody modified NPs can bind with the selective target proteins. ${ }^{181}$ Protein can also be directly conjugated with the NPs using a linker, and such conjugation is desirable when NPs are used in the preparation of sensors involving electron transfer. Composite nanomaterials containing $\mathrm{Au}$ or $\mathrm{Ag}$ are usually used to bind biomolecules in this approach. For instance, $\mathrm{Au}$ or $\mathrm{Ag}$ can be bound to a protein using a cysteine residue of proteins through $\mathrm{Au}$-thiol/Ag-thiol chemistry. Lately, biomolecule (e.g., proteins, DNA, RNA)-gold direct adsorption (the affinity interaction of DNA/RNA/proteins with gold) has also been considered a more promising method to adsorb biomolecules over unmodified gold NPs or gold surfaces. ${ }^{20,133}$ Though a number of significant studies have been carried out and streptavidin-modified MNPs (e.g., magnetic beads or protein-G magnetic beads) are commercially available, the application of magnetic beads in a sensor platform suffers from a lack of reproducibility and renewal of transducer surfaces. In this regard, nanoporous superparamagnetic materials containing different bioactive materials could be a possible solution, as they will not require complex chemistry and would have a large surface-to-volume ratio, strong magnetic affinity, and reusable surface morphology.

\subsubsection{Electrocatalytic signal amplification}

With the growing demand for the trace amount of biomolecule detection, several signalamplification strategies have been developed. These strategies include the polymerase chain reaction, mass spectrophotometry, label-amplified signal enhancement (electroactive 
molecules, different redox molecules and metal ions) and the integration of enzyme-mediated signal-amplification strategies. ${ }^{182,} 183$ Although these methods offer adequate sensitive detection, they are time consuming, destructive, depend on costly detection approaches, and require highly skilled professionals. Integration of the signal-amplification properties of NMs into the sensing platform opens the door to ultrasensitive and selective detection due to their inherent catalytic and conductive properties. The NMs generally act as a catalyst to trigger enhancement of the detectable signal. NP electrocatalysis is highly adaptable and can be readily scaled for the ultralow amount of biomolecule sensing. The biocompatible NMs can produce a synergistic effect between the conductivity and catalytic activity to accelerate the signal transduction events, resulting in the lowering of detection limits even at zeptomolar levels. ${ }^{184}$, 185 Moreover, the accelerated signal-transduction events broaden the gap between the two successive concentrations in a range of 5-6 orders of magnitude. For instance, superparamagnetic NPs based on a highly sensitive, ultralow protein detection approach have been reported by Krishnan et al. In this method, antibody-labeled superparamagnetic NMs were used for signal amplification in a surface plasmon resonance (SPR) immunoassay for the detection of a cancer biomarker, a prostate-specific antigen (PSA) in the serum. A monoclonal antibody, ab2, was first conjugated with a superparamagnetic particles (MP) (Dynabeads, Invitrogen), followed by the formation of MP-Ab2-PSA particles. As can be seen in Fig. 9, the MP-Ab2-PSA bioconjugates were then applied to a PSA-specific antibody (ab2) immobilized Au-SPR chips. The SPR signal was monitored constantly after the addition of MP-Ab2-PSA bioconjugates and the SPR signal quantify a and ultralow amount of PSA with a detection limit of $10 \mathrm{fg} \mathrm{mL}^{-1}$ (ca. $\left.300 \mathrm{aM}\right) .{ }^{186}$ 


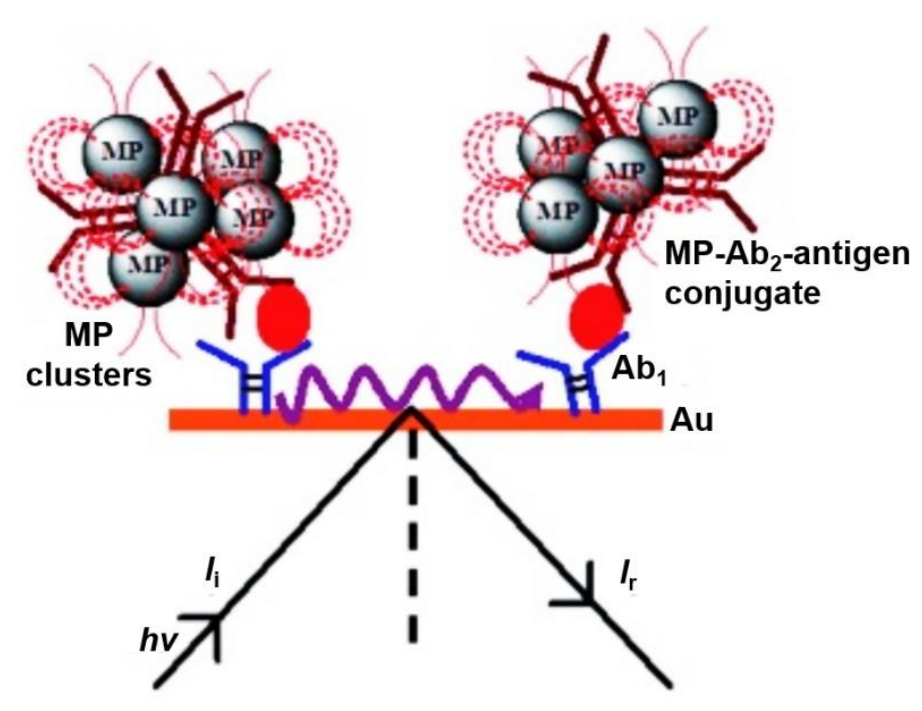

Fig. 9 Schematic representation of an SPR immunosensor based on clustered magnetic NMs for signal amplification. Reproduced with permission. ${ }^{186}$

In constructing electrochemical sensors, one of the crucial requirements is electrical contact between the electrode surface and redox biomolecules. Generally, the active sites of biomolecules are surrounded by a thick protein shell, which blocks the direct electron transfer between biomolecules and the electrode surface. Metal NPs can resolve the barrier and enhance the rate of electron transfer due to their high conductive properties. In those circumstances, MNPs could be potential supporters for an extensive loading and magnetically controlled signal trace with ultrasensitive detection. For example, iron oxide-based NPs were employed as a signal enhancing element for the electrochemical immuno-sensing of carcinoembryonic antigen (CEA). The three-layer $\mathrm{MNP} \mathrm{Au}-\mathrm{PB}-\mathrm{Fe}_{3} \mathrm{O}_{4}\left(\mathrm{Fe}_{3} \mathrm{O}_{4}\right.$ magnetic core, $\mathrm{PB}$ as an interlayer, and gold as a shell) was functionalized with a bioenzyme (HRP and glucose oxidase), and it exhibited excellent redox electrochemical activity and superior enzyme catalysis activity toward glucose in an immunoassay of CEA and $\alpha$-fetoprotein (AFP). The sensor can detect 4 pgmL $^{-1}$ and $7 \mathrm{pgmL}^{-1}$ of CEA and AFP, respectively. An external magnet could be used to isolate NPs, with subsequent magnetic purification to make the sensor reproducible and reusable. ${ }^{187}$ A similar sandwich-type immunoassay has been reported for ultrasensitive detection of the carbohydrate antigen (CA-125), and AFP based on the magnetic NMs as a 
signal amplifier. ${ }^{188}$ Silica NPs and silica-coated magnetic materials can also be used as carriers for signal amplification in the development of an ultrasensitive immunoassay due to the small size, high surface-to-volume ratio, and excellent biocompatibility of silica. ${ }^{189,}, 190$

\subsubsection{Signal-generating probes}

The labeling of biomolecules in the construction of biosensor is a common strategy for obtaining output signals. In the most conventional approaches, different enzymes, redox molecules, electroactive molecules, and metal ions have been used as a signal generation label. ${ }^{191}$ [Note: Is this okay, or do you mean "...used as signal generation labels. ${ }^{189 "}$ ?] The natural enzymes possessed poor stability under environmental stress, and sensor design had a high cost. The application of redox molecules as a label is a popular approach, but it has been limiting their application, as it can only transfer a few electrons (or even just one), which directly affects the sensitivity of the biosensor. The integration of biofunctionalized NMs as a label to obtain a signal, especially an electrochemical signal, has opened new prospects in biosensing. [Note: Is this okay, or do you mean “...NMs as labels to...”?] The NM label generated an enormous signal, which is associated with the ultrasensitive detection of an ultralow number of biomolecules. The biomolecule generally attached to or modified to the biocompatible NMs, and hence retained their activity to interact with its counterpart. There are two strategies by which NMs generate signals: $(i)$ they load an increasingly large number of target biomolecules, and (ii) they act as an ultramicroelectrode array for the electrolysis of a bulk amount of substrates. ${ }^{166}$ NMs generally contain a great many electrochemically active elements (or atoms), thereby increasing the loading of electroactive species onto the transducer surface and enhancing the sensitivity of the readout system. For instance, a flow injection chemiluminescence (FI-CL) assay for the detection of DNA hybridization was developed based on a biobarcode-functionalized MNP label. As can be seen from Fig. 10, MNPs are functionalized with amino-modified probe DNA (pDNA) and biobarcode DNA (bbcDNA) to form bbc-p-DNA-MNPs. 
The target DNA (tDNA) was captured on a capture DNA-assembled (cDNA) gold electrode surface. The bbc-p-DNA-MNPs were then allowed to hybridize with the overhang region of pDNA through pDNA-tDNA hybridization. The bbc-p-DNA-MNPs were dissolved in nitric acid solution, which releases a large number of ferric ions. Thus ultrasensitive detection of a DNA hybridization event was achieved by the luminol- $\mathrm{H}_{2} \mathrm{O}_{2}-\mathrm{Fe}^{3+} \mathrm{CL}$ free-radical reaction system. ${ }^{192}$

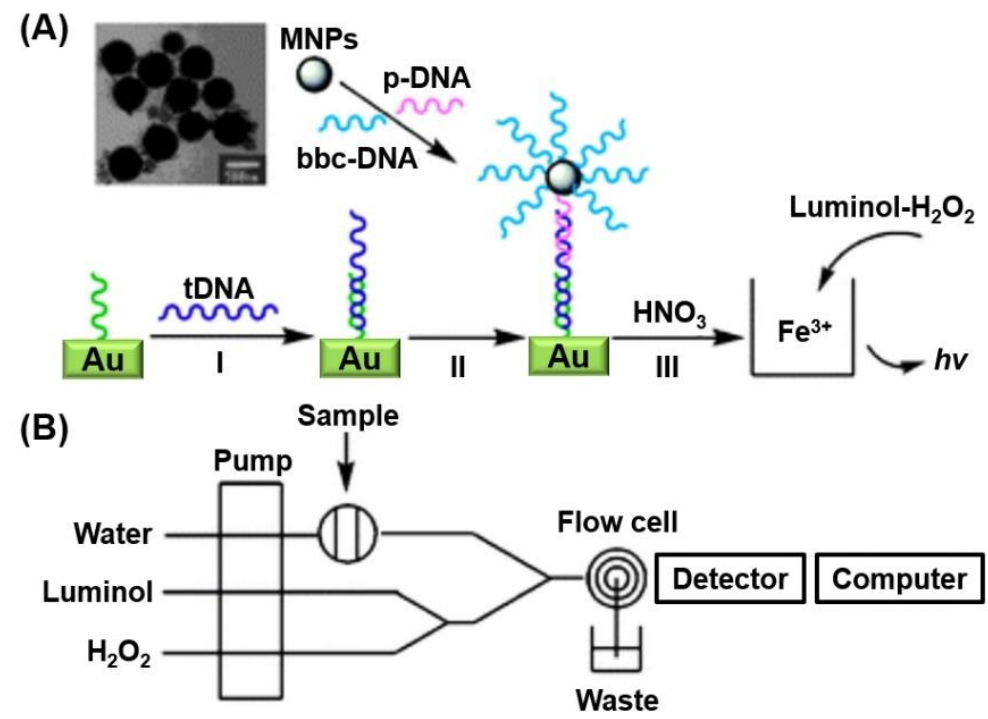

Fig. 10 Schematic representation of a biobarcode-functionalized MNP label-based chemiluminescence detection of DNA hybridization (A); the flow injection chemiluminescence readout system for the quantification of $\mathrm{Fe}^{3+}(\mathrm{B})$. Reproduced with permission. ${ }^{192}$

Iron oxide and some other promising MNPs catalyze common chromogenic substances and efficiently enhance the detection signal in immunosorbent assays. The cascade reactions are highly sensitive to the $\mathrm{pH}$ of the detection buffer, temperature, and time, resulting in a time-consuming, dose-dependent reaction and poor reproducibility. The integration of MNPs as a signal-generation and amplification label in a colorimetric assay could give better and more detection, as the assay is independent of the cascade reaction as well as such reaction conditions. The released ions from MNPs generated an enhanced signal intensity, which is directly linked to the level of target 
biomolecules. Recently, Zhang et al. developed a colorimetric immunoassay for the sensitive detection of a cancer biomarker carcinoembryonic antigen (CEA) based on a ferric oxide MNP as a signal generator and amplifier label. Herein, an antibody (ab1) was loaded into a high-binding 96well microplate, followed by the addition of a target CEA. An antirabbit $\operatorname{IgG}(\mathrm{Ab} 2)-$ functionalized MNP was then added to form a sandwich-like immunocomplex. The MNP, acting as an iron pool, released a large amount of $\mathrm{Fe}^{2+}$ when it was dissolved in a mixture of bathophenanthrolinedisulfonic acid disodium salt (BPT) and ascorbic acid (AA). The $\mathrm{Fe}^{2+}$ generated a stable red solution, which gave a naked-eye and quantitative evaluation through colorimetry results in the sensitive detection of CEA with a limit of detection (LOD) of $3.6 \mathrm{pg} \mathrm{mL}^{-1.193}$. Another exciting application of MNPs is to design novel magneto-switchable electrodes with unique properties. Various MNPs, nanorods, and nanosheets have been used to turn on or off the electrochemical reactions, depending on the physical translocation and orientation of the MNPs in response to the direction of an external magnetic field. ${ }^{194,} 195$ The electrochemical reaction is triggered by the reposition of an external magnet, resulting in a change in the magnetic field strength of the electrode interface. Willner et al. presented an alkyl-chain-functionalized MNP-based magneto-switchable hydrophilicity/hydrophobicity-controlled electrode surface. As can be seen from Fig. 11, the two-phase platform consists of a gold electrode with an aqueous buffer solution and an organic (toluene) phase located on the electrode surface. Hydrophobic superparamagnetic $\mathrm{Fe}_{3} \mathrm{O}_{4} \mathrm{NPs}$ were used to regulate the interfacial properties of the electrode surfaces. When a magnet was placed below the electrode, the hydrophobic MNPs were pulled down from the upper toluene layer into the aqueous layer, resulting in the formation of a membrane-like film on the surface, thereby inhibiting the interfacial electron transfer to create an "off" state. The "on" state was achieved by placing the external magnet above the electrode surface, which pulled the MNPs up from the aqueous to the organic phase, allowing contact of the redox probe (e.g., ferrocene 
or ferrocyanide dicarboxylic acid) with the electrode surface and facilitating the oxidation process. ${ }^{196}$

(A)

(B)

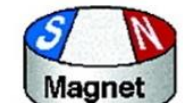

Magnet

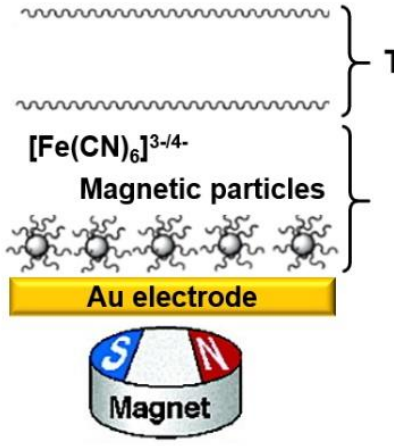

Electrochemistry "OFF"

Electrochemistry "ON"

Fig. 11 Magneto-controlled reversible translocation of the functionalized MNPs between the organic phase above the aqueous electrolyte and the electrode surface. (A) A magnet below the electrode surface pulls the hydrophobic MNPs, forming a membrane-like layer on the electrode surface ("off" state); (B) a magnet positioned above the electrode returns the MNPs to the organic phase, resulting in the generation of an electrochemical reaction ("on" state). Reproduced with permission. ${ }^{196}$

A photoelectrochemical current can also be generated and magnetically controlled via magnet-bound quantum dots. With DNA hybridization, the biocatalytic reaction can be controlled using capture probe-functionalized MNPs directed to and from the electrode surface. ${ }^{197,} 198$ In the most refined magneto-switchable electrode systems, the activity of electrodes was regulated (activation or inactivation) by complex multi-enzyme systems or different biochemicals added to solutions, thereby mimicking the biological event and properties. ${ }^{199,200}$ 


\subsection{Nanocarriers}

Due to their tremendous magnetic nature, biocompatibility, and high surface area, magnetic NMs are becoming excellent candidates for carrying agents in numerous biomedical applications, such as magnetic guided drug delivery, the separation of magnetically tagged DNA, the identification of biological species, magnetic resonance imaging, and cancer therapies. ${ }^{32,201,202} \mathrm{NMs}$ can also be used to support the isolation system for concentrating the target biomolecules or high-level loading of signal molecules. Generally, single-wall carbon nanotubes (SWNTs) have been used to anchor probe DNA in the transducer surface when constructing a hybridization-based sensor. For a DNA sensor, the target DNA was hybridized with the probe DNA. Based on the decreasing DPV response to the guanine base of DNA, the target DNA can be quantified. ${ }^{203}$ Magnetic NMs can easily concentrate and purify the target and hence dramatically enhance detection sensitivity. For instance, Wanunu et al. reported the nanopore-based electronic detection of microRNAs based on a protein-functionalized magnetic bead. In this assay, the target miRNA was first hybridized with a capture probe to form a probemicroRNA duplex. The duplex was allowed to bind with protein p19-functionalized magnetic beads. The magnetic beads authorized the ultrahigh enrichment of the duplex and purification of the duplex from the RNA pool. The suplex was then eluted and electronically detected by using a nanopore system. The magnetic bead produced 100-fold enrichment of the duplex and enabled pictogram-level detection of liver-specific miRNA from rat liver miRNA. ${ }^{204} \mathrm{Au}-$ containing NMs have also been used as carriers for target or signaling molecules. For instance, AuNPs-coated $\mathrm{Fe}_{3} \mathrm{O}_{4}$ NPs can serve as a reusable carrier for the immobilization of biomolecules (enzymes). ${ }^{205}$ Introducing pores into magnetic NMs can tremendously enhance the surface area and significantly improve the functionalization with biomolecules, drug loading, concentrating target molecules. ${ }^{206}$ Therefore, porous magnetic NMs containing AuNPs could provide a great platform as carriers of different biomolecules. Recently, Sharda 
et al. developed a new class of gold-loaded superparamagnetic NMs $\left(\mathrm{Au} @ \mathrm{NPFe}_{2} \mathrm{O}_{3}\right)$ as a dispersible capture agent for the naked-eye and electrochemical detection of cancer-specific autoantibodies. As can be seen in Fig. 12, the synthesized $\mathrm{Au} @ \mathrm{NPFe}_{2} \mathrm{O}_{3}$ nanocubes were functionalized with the $\mathrm{p} 53$ protein, followed by the dispersion of $\mathrm{p} 53$ protein-functionalized NMs into the serum samples containing target p53-specific autoantibodies. The higher surface area of superparamagnetic NMs facilitates the bindings of higher amount of target, and purification and isolation of target as well. The horseradish peroxidase (HRP)-modified IgG (secondary antibody) then bound with the target and was used to catalyze the oxidation of the 3,3,5,5'-tetramethylbenzidine (TMB)/ $\mathrm{H} 2 \mathrm{O} 2$ system. The generated color indicates the presence of a p53 autoantibody, and subsequently, the amount was quantified by colorimetry and amperometry. ${ }^{207}$ Simillarly, different magnetic NMs are also utilized in microfluidics and lab-on-chip systems as a carrier of target molecules, target-binding proteins, or signaling molecules.

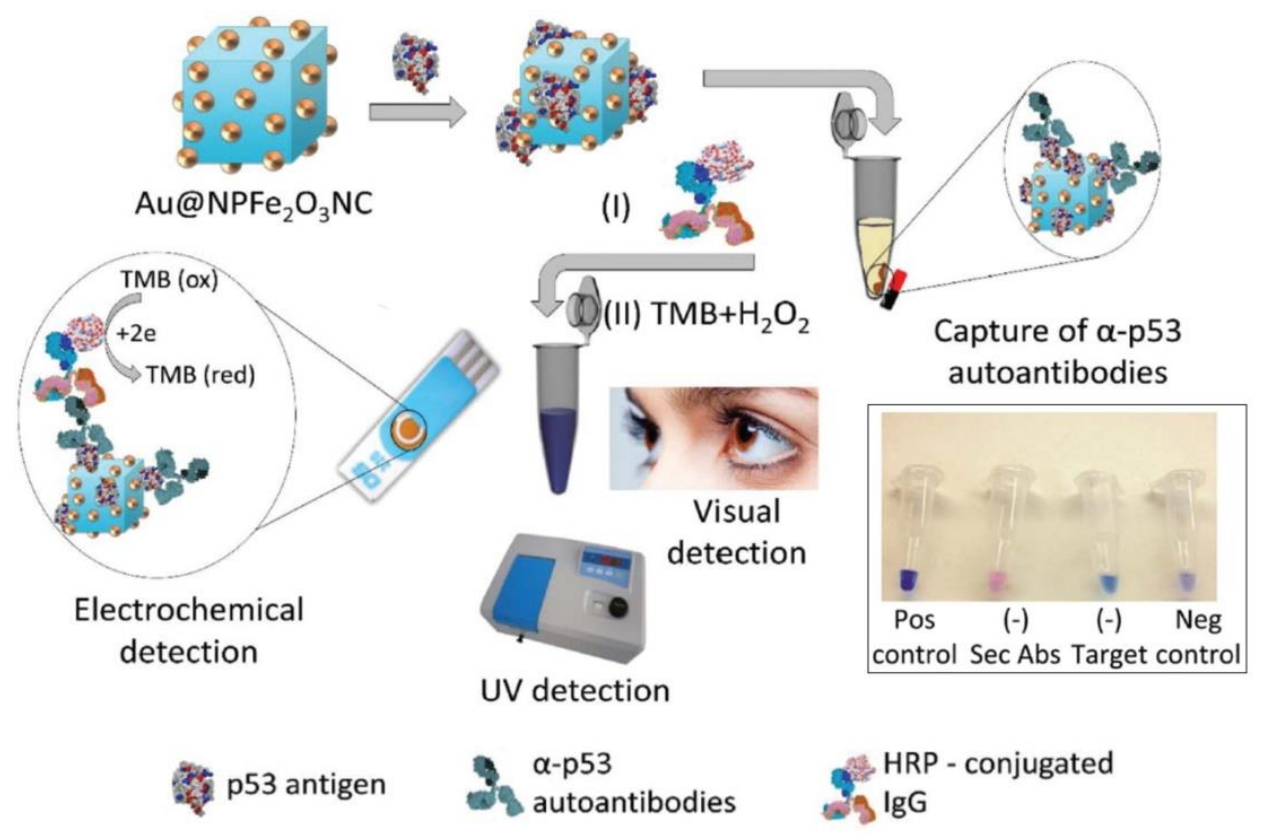

Fig. 12 Schematic representation of the detection of p53 autoantibodies based on a superparamagnetic $\mathrm{Au} @ \mathrm{NPFe}_{2} \mathrm{O}_{3}$ nanocube as a dispersible nanocarrier. Reproduced with permission. $^{207}$ 


\subsection{Natural enzyme mimetics: Nanozymes}

Nanozymes is a term referring to the NMs that exhibit natural enzyme-like activity to catalyze the oxidation reaction of various organic substances (e.g., chromogenic substances). ${ }^{208,209}$ Nanozymes have been considered an excellent alternative to natural enzymes in the fields of biosensor development, nanomedicine, and environment remediation due to their much higher stability, easy storage, and lower cost. ${ }^{210-212}$ With the tremendous advancement in nanoresearch and distinctive properties of NMs, a wide range of NMs (e.g., ferromagnetic NPs, gold NPs, rare earth NPs, metal complexes, and polymers) have been developed to exhibit peroxidase-, oxidase-, catalase-, superoxide dismutase-, and lactase-like activities. ${ }^{213-215}$ Among these NMs, iron oxide-based MNPs are highly advantageous in bioanalysis due to their chemical and biological inertness, easy surface modification, and magnetic field-based separation efficiency. In 2007, Yan et al. discovered that, surprisingly, $\mathrm{Fe}_{3} \mathrm{O}_{4}$ NPs possess an intrinsic peroxidasemimicking activity that catalyzes the oxidation of three chromogenic substances named TMB, DAB (di-azo-aminobenzene), and OPD (o-phenylenediamine). ${ }^{208}$ The experiment showed that the Michaelis-Menten constant $\left(K_{m}\right)$ value of MNPs with TMB was about four times lower than that of those with HRP, indicating that NPs have higher catalyzing activity for the oxidation of TMB. This is because HRP contains only one iron ion, in contrast to a large amount of $\mathrm{Fe}^{2+}$ and $\mathrm{Fe}^{3+}$ on the surface of NPs. However, the $K_{m}$ value of NPs with $\mathrm{H}_{2} \mathrm{O}_{2}$ (as a substrate) was significantly higher than that of those with HRP, demonstrating that a higher amount of $\mathrm{H}_{2} \mathrm{O}_{2}$ was required to achieve the maximum mimicking activity. Like natural HRP, the activity is highly dependent on the $\mathrm{pH}$ and temperature of the reaction buffer. Moreover, the NP size influences the activity: the smaller the particle size, the more activity was observed, as smaller NPs possess a higher surface-to-volume ratio to interact with the substrates. The mimetic activities are generally performed by the generation of a hydroxyl free radical from 
$\mathrm{H}_{2} \mathrm{O}_{2}$ following the Fenton reaction (as shown in equations 1-3), and subsequent oxidation of TMB (equation 4) is carried out by the generated hydroxyl free radical. ${ }^{216-218}$

$$
\begin{aligned}
& \mathrm{Fe}^{3+}+\mathrm{H}_{2} \mathrm{O}_{2} \rightarrow \mathrm{FeOOH}^{2+}+\mathrm{H}^{+} \\
& \mathrm{FeOOH}^{2+} \rightarrow \mathrm{Fe}^{2+}+\mathrm{HO}_{2} . \\
& \mathrm{Fe}^{2+}+\mathrm{H}_{2} \mathrm{O}_{2} \rightarrow \mathrm{Fe}^{3+}+\mathrm{OH}^{-}+\cdot \mathrm{OH} \\
& \cdot \mathrm{OH}+\mathrm{TMB} \rightarrow \mathrm{TMB}_{\text {ox }}(\text { Blue })
\end{aligned}
$$

The reaction mechanism is considered to be the ping-pong mechanism, as no tertiary intermediate is formed between the NPs and the two substrates (the product from one substrate is dissociated before the second one binds). Moreover, the steady-state kinetic experiment showed that the substrate concentration-dependent double-reciprocal (Lineweaver-Burk) plot was parallel, which is characteristic of the ping-pong mechanism.

Inspired by Yan's discovery, many researchers have worked to develop a colorimetric sensing platform of $\mathrm{H}_{2} \mathrm{O}_{2}$, glucose, cysteine, etc., based on the MNP peroxidase mimetic activity using TMB and ABTS (2,2'-and-bis(3-ethylbenzothiazoline-6-sulphonic acid) as substrates. For instance, Wei et al. developed a colorimetric platform for the detection of glucose using $\mathrm{Fe}_{3} \mathrm{O}_{4}$ as a nanozyme and ABTS as a substrate. The oxidized ABTS generated a green product, which enabled naked-eye detection. The colorimetric readout can detect $\mathrm{H}_{2} \mathrm{O}_{2}$ as low as $3 \mathrm{mM}$ and glucose as low as $3 \times 10^{-5} \mathrm{~mol} / \mathrm{L} \cdot{ }^{219}$ Later, $\mathrm{H}_{2} \mathrm{O}_{2}$ detection was used to detect several ions, glucose, etc. In addition to ABTS, other chromogenic substances, such as TMB, 4-AAA-phenol, OPD, and DPD, have also been used, and it has been shown that TMB gives more selective and sensitive detection than ABTS, as $\mathrm{H}_{2} \mathrm{O}_{2}$ can oxidize ABTS even in the absence of peroxidases. $^{220}$ Doped ferrites such as Prussian blue/ $\mathrm{Fe}_{2} \mathrm{O}_{3}, \quad \mathrm{CoFe}_{2} \mathrm{O}_{4}$, graphene/ $\mathrm{Fe}_{2} \mathrm{O}_{3}, \mathrm{ZnFe}_{2} \mathrm{O}_{4}$, and $\mathrm{CoF}_{2} \mathrm{O}_{4}$ had also been explored as peroxidase mimetics for the 
detection of $\mathrm{H}_{2} \mathrm{O}_{2}$, glucose, L-cysteine, etc. ${ }^{221-224}$ For instance, CL detection of $\mathrm{H}_{2} \mathrm{O}_{2}$ and glucose was performed using $\mathrm{CoFe}_{2} \mathrm{O}_{4} \mathrm{MNPs}$. The $\mathrm{CoFe}_{2} \mathrm{O}_{4} \mathrm{MNPs}$ efficiently catalyzed the decomposition of $\mathrm{H}_{2} \mathrm{O}_{2}$ into hydroxyl free radicals $(\cdot \mathrm{OH})$, which subsequently catalyzed the oxidation of luminol. Coupling the NP-catalyzed CL reaction of luminol- $\mathrm{H}_{2} \mathrm{O}_{2}$ with the glucose oxidase-catalyzed glucose oxidation reaction enabled CL detection of glucose from blood samples with a detection limit of $0.024 \mu \mathrm{M} \cdot{ }^{224}$ Apart from iron oxide-based NMs, other nanomaterials, such as AuNPs, $\mathrm{CuONPs}, \mathrm{Eu}_{2} \mathrm{O}_{2} \mathrm{SNPs}, \mathrm{AgX}(\mathrm{X}=\mathrm{Cl}, \mathrm{Br}, \mathrm{I})$, polyoxometalates, PtNPs, carbon nanotubes, and nanodots, have been exhibited peroxidase-like activity. ${ }^{225-227}$ One of the major challenges of MNPs is the specificity of nanozymes, as NPs do not have a binding pocket (active sites). The catalytic reaction of nanozymes takes place at the surface; thus there is a possibility of substrate diffusion to the surface that can react with all substrates, irrespective of substrate shape and size. Many approaches have been utilized to introduce substrate specificity or a molecular-recognition function. These approaches include attaching aptamers, antibodies, peptides, or molecular imprinting. Among them, molecular imprinting has been considered superior to biological ligands, as biological substances are less stable, easily denatured, and expensive and require sophisticated operations. Molecular imprinting refers to the polymerization of a monomer (complement to the template) around template molecules to form a prepolymer binding complex. ${ }^{228}$ Very recently, Zhang et al. grew molecular imprinted polymers on $\mathrm{Fe}_{3} \mathrm{O}_{4}$ to form substrate binding pockets and measured peroxidase-like activity toward the oxidation of TMB and ABTS. Moderate enhancement of the specificity and catalytic activity was achieved by imprinting with a neutral monomer. However, when imprinting with a charged monomer, the catalytic activity increased dramatically, 100-fold, compared to that of the bare $\mathrm{Fe}_{3} \mathrm{O}_{4}{ }^{229}$ Another limitation of MNPs for biosensing is associated with the fact that most of these materials demonstrate their highest peroxidase-like activity at a high temperature $\left(40-45{ }^{\circ} \mathrm{C}\right)$, which limits their application in 
disease-specific biomolecule detection at room temperature. Therefore, a highly porous framework of MNPs with high specificity could offer enhanced peroxidase-mimetic activity even at room temperature.

\section{Application of superparamagnetic nanoparticles in biomolecular detection}

\subsection{Electrochemical biosensors}

Electrochemical techniques have aroused great interest in constructing biosensors for the detection of biomolecules, as the electrochemical biosensors offer sensitive, highly selective, portable, easy-to-operate, and stable operation as well as fast detection. In electrochemical sensors, electrode materials play a critical role in obtaining high-performance sensing platforms via various analytical principles, such as voltammetry (CV, DPV, LSV, etc.) and amperometry (i-t). Incorporating superparamagnetic nanomaterials into common electrode materials not only can produce a synergistic effect among biocompatibility, magnetism, catalysis, and conductivity but also can provide accelerated signal transduction and amplified biorecognition events, resulting in an ultrasensitive biosensing platform. In recent decades, significant research has been conducted on the construction of various magnetic materials, such as the construction of functional electrode surfaces as signaling tags or as electrocatalysts, giving rise to advanced electrochemical biosensors. For example, Zhu et al. highlighted recent advances in nanomaterial-based electrochemical sensors and biosensors. Electrochemical, nonelectrochemical, magnetic, and chemical optical sensors and biosensors based on nanocrystalline iron oxides and their composites have also been highlighted by Urvanoba et

al. ${ }^{41,49}$ In this section, we mainly focus on the advances of nanostructured superparamagnetic materials-based electrochemical nucleic acid assays, immunoassays, and cytosensing platforms. 


\subsubsection{Nucleic acid assay}

The detection of target sequences of nucleic acids (DNA or RNA) has aroused considerable attention due to their wide application in gene therapy, molecular diagnostics, epigenetics, pathogen detection, and early screening of malignant diseases, like cancer. Highly sensitive and specific detection is desirable, as the DNA levels are scant in most of the diagnostic specimens, such as cancer, infectious diseases, or pathogens. In recent decades, several electrochemical DNA/RNA detection platforms have been developed with high selectivity, excellent sensitivity (attomolar detection limit), and on-site measurements. ${ }^{230}$ Most of the standard DNA biosensors consist of a single-stranded (ss) capture probe immobilized onto the sensing surface for the hybridization of target sequences with electrochemical tags for signal generation. ${ }^{6}$ Several amplification strategies have been utilized to achieve ultrasensitive detection. Natural enzyme (e.g., alkaline phosphatase (ALP) and HRP)-assisted amplification (enzymatic catalytic reactions) has been widely used for this purpose. ${ }^{231,232}$ The integration of magnetic materials with such amplification not only can enhance sensitivity and selectivity but also offers a low-cost miniaturization platform. For example, an $\mathrm{HRP}$-modified $\mathrm{Fe}_{3} \mathrm{O}_{4} \mathrm{NP}$ (as a signal amplification source)-based sequence-specific DNA sensor has been proposed by Dong et al. ${ }^{233}$ In this sensor, HRP was adsorbed onto the NP surface through layer-by-layer $(\mathrm{LbL})$ techniques, followed by the loading of $\mathrm{Au}-\mathrm{NPs}$ to obtain $\mathrm{Au}-\mathrm{HRP}-\mathrm{Fe}_{3} \mathrm{O}_{4}$ conjugates. A signal probe and diluting probe sequences were then added to form $\mathrm{DNA}-\mathrm{Au}-\mathrm{HRP}-\mathrm{Fe}_{3} \mathrm{O}_{4}$ (DAHF) bioconjugates. As shown in Fig. 13, the capture probe was immobilized on a freshly prepared gold nanofilm electrode surface to hybridize target DNA (two-base mismatched DNA). In the presence of target DNA, the DAHF bioconjugates attached to the GNF surface via the hybridization of target DNA with a diluting probe sequence. An HRP-catalyzed TMB oxidation reaction was then carried out to amplify the chronoamperometric signal. In conjunction with gold-coated ferric-oxide NPs and streptavidin peroxidase-induced signal 
amplification, Loaiza et al. have developed similar electrochemical DNA sensors for the detection of specific DNA hybridization events. ${ }^{234}$ High sensitivity in such hybridization-based DNA detection can be accomplished by the utilizion of optimum hybridization conditions, the design of the capture and signaling probe, and the elimination of nonspecific bindings in the transducer surface. A peptide nucleic acid (PNA) probe has been known to possess excellent sequence-specific affinity and stability in the recognition of target sequences as they maintain equidistance between nucleobases, rigid amido bonding, flexible amino-ethyl linkers and intramolecular hydrogen bonding, MNPs have also been immobilized with a PNA probe for the construction of DNA sensors based on PNA-DNA hybridization. ${ }^{235}$

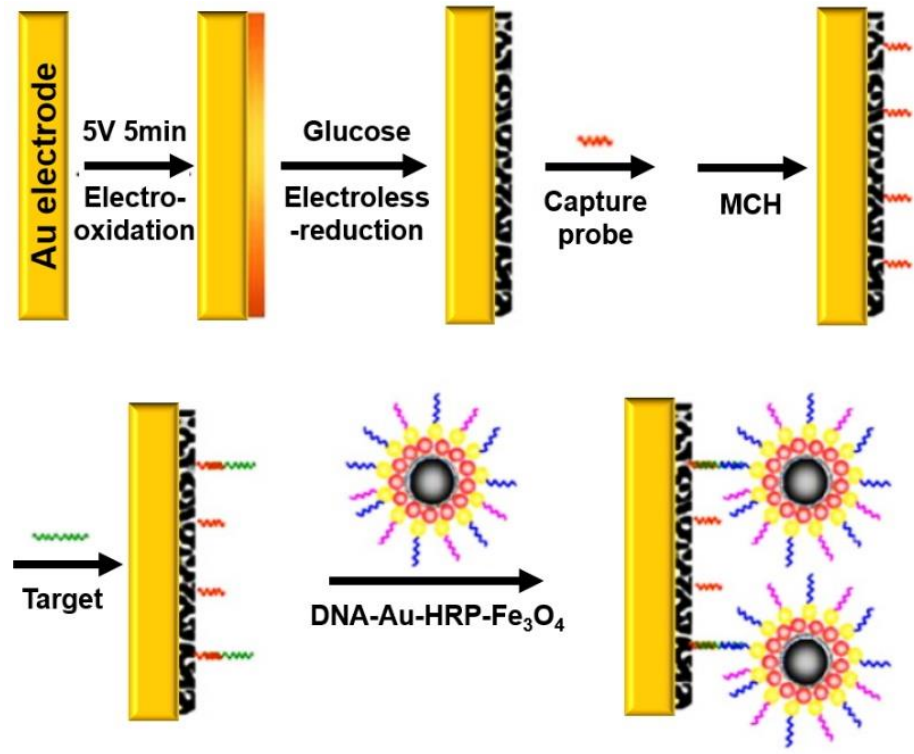

Fig. 13 A magnetic Fe3O4-based sandwich-type detection strategy for two-base mismatched DNA detection. Reproduced with permission. ${ }^{233}$

miRNA is a small noncoding RNA that post-transcriptionally regulates gene expression by modulating downstream proteins, thus acting as a potential diagnostic and prognostic biomarker of various diseases, including cancer. Several conventional approaches, such as northern blotting, in situ hybridization, microarrays, and quantitative real-time PCR (qRTPCR), and several biosensors have been applied successfully. Though each of these methods has superior detection sensitivity, the conventional approaches rely on either PCR-based 
amplification or fluorescent labeling and expensive, complicated procedures. ${ }^{236}$ In recent decades, several electrochemical and optical biosensors have been developed that may give superior analytical performance; yet they still rely on complex and tedious amplification processes, expensive biomaterials, and time-consuming and difficult procedures. Recently, nanomaterials have been merged with conventional biosensors to create an easy and inexpensive miRNA detection platform. For example, carbon nanotube (CNT) and single-wall carbon nanotube (SWCNT) nanowires have been widely used in electrode design. ${ }^{237}$ Recently, we described the synthesis of specially engineered superparamagnetic gold-loaded nanoporous iron oxide nanocubes $\left(\mathrm{Au} @ \mathrm{NPFe}_{2} \mathrm{O}_{3} \mathrm{NC}\right)$ and an amplification-free, nonenzymatic, and sensitive miRNA detection platform ${ }^{45}$ based on the magnetic, electrocatalytic, and miRNAadsorbing properties of these nanocubes. The nanocubes showed excellent electrocatalytic activity toward the reduction of redox molecules $\mathrm{Ru}\left(\mathrm{NH}_{3}\right)_{6} \mathrm{Cl}_{3}$. As can be seen from Fig. 14, the nanocubes have been attached to a screen-printed carbon electrode (SPCE) with the help of an external magnet without any complex electrode modification steps. Target miRNAs were physically adsorbed onto the gold NPs of nanocubes via RNA-gold affinity interactions. The amount of miRNA adsorbed onto the nanocubes was quantified by chronocoulometric (CC) charge interrogation in the presence of a signaling redox molecule $\left[\mathrm{Ru}\left(\mathrm{NH}_{3}\right)_{6}\right]^{3+}$. The assay can successfully detect a $1 \mathrm{pM}$ level of miRNA (miR-21) in tissue samples derived from patients with esophageal squamous cell carcinoma (ESCC). In order to achieve more sensitive detection of miRNA, we recently reported another biosensor design, wherein a redox molecule $\left[\mathrm{Ru}\left(\mathrm{NH}_{3}\right)_{6}\right]^{3+}$ coupled with another redox molecule $\left[\mathrm{Fe}(\mathrm{CN})_{6}\right]^{3-}$ to create an electrocatalytic redox cycle. ${ }^{238}$ The $\mathrm{CC}$ signals for the electrocatalytic reduction of $\left[\mathrm{Ru}\left(\mathrm{NH}_{3}\right)_{6}\right]^{3+}$ were amplified by further reduction of the solution-phase $[\mathrm{Fe}(\mathrm{CN}) 6]^{3-}$. Here, as the $\left[\mathrm{Fe}(\mathrm{CN})_{6}\right]^{3-}$ in solution is a stronger oxidant, it initiates the electrocatalytic cycle via the oxidation of reduced $\left[\mathrm{Ru}\left(\mathrm{NH}_{3}\right)_{6}\right]^{2+}$ for the regeneration of $\left[\mathrm{Ru}\left(\mathrm{NH}_{3}\right)_{6}\right]^{3+}$. The redox cycle-induced signal- 
enhancement steps enhance the detection sensitivity up to $100 \mathrm{aM}$ for the detection of miRNA (miR-107) from cancer cell lines and a panel of tissue samples derived from patients with ESCC. This design could be integrated into a microfluidic device to achieve a low-cost, simple, ultrasensitive miRNA sensor.

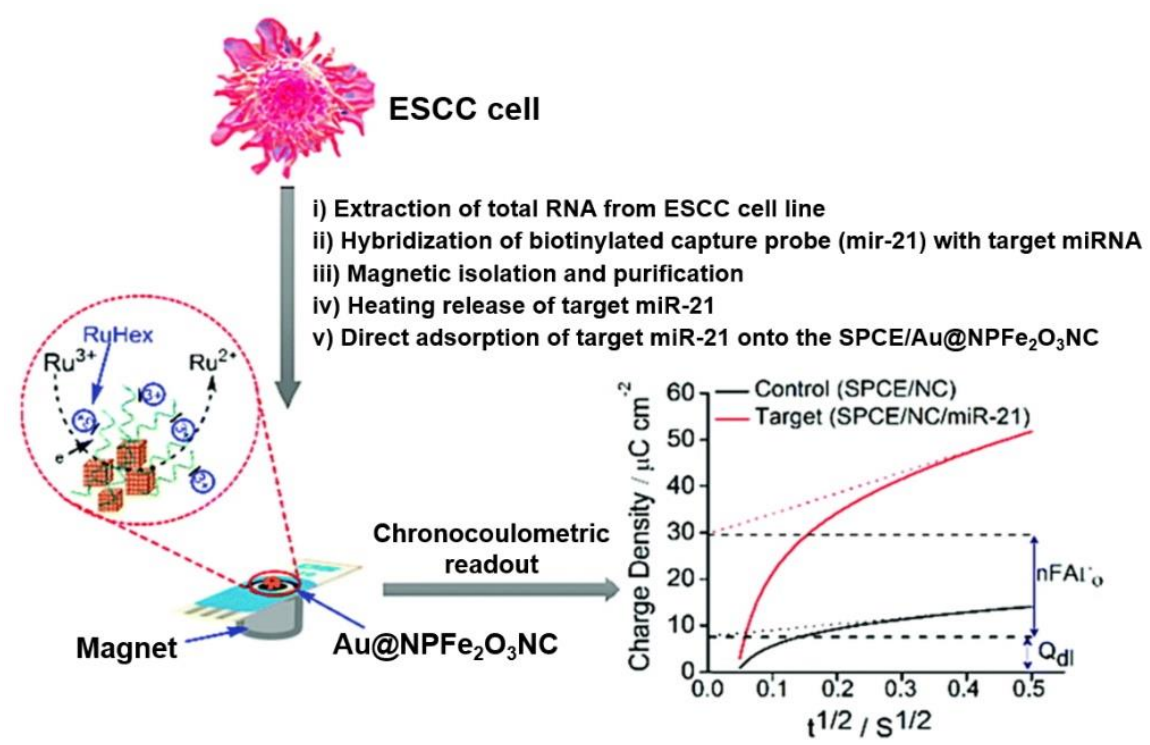

Fig. 14 Superparamagnetic nanoparticle-based miRNA sensor. The target miRNA (miR-21) was initially extracted from target cell lines or tissue samples, followed by magnetic beadbased isolation and purification. The target miR-21 was then directly adsorbed onto the nanocube-attached SPCE. An enhanced electrochemical signal was generated by the CC interrogation of stoichiometrically bound $\left[\mathrm{Ru}\left(\mathrm{NH}_{3}\right)_{6}\right]^{3+/ 2+}$ complexes with nanocube surfacebound miRNA. Reproduced with permission. ${ }^{45}$

\subsubsection{Immuno assay}

Electrochemical immunosensors are a specific antibody-antigen interaction (noncovalent)based detection platform in which the immunochemical reaction event is coupled to a signal transducer. Generally, an enzyme-labeled antibody or antigen is immobilized at the electrode surface to perform a sandwich-mode operation. Voltammetric or amperometric detection is 
used to accomplish the conversion of biorecognition events into an analytically significant electrochemical response. ${ }^{239}$ In MNP-based electrochemical immunosensors, the recognition element is immobilized with the NPs, which are later used for either electrode modification or as signal-generating probes. MNPs have generally been polymerized to obtain a thin polymer shell so they can be easily functionalized with antibodies, redox molecules, or any linking groups. ${ }^{240}$ For example, an ultrasensitive sandwich-type electrochemical immunosensors for the detection of a cancer biomarker; prostate-specific antigen (PSA) have been reported based on ferrocene-modified magnetite NPs. ${ }^{241}$ Ferrocene-functionalized MNPs and graphene sheets were used as the electroactive label and sensing platform, respectively. Graphene sheets were chosen, as they offer an enhanced surface area for capturing a larger amount of primary antibodies (Ab1) and for the sensitive detection of ferrocene. In this assay, dopamine (DA) was first anchored to the magnetite surface, followed by the conjugation of ferrocene monocarboxylic acid (FC) and a secondary antibody (Ab2) onto $\mathrm{Fe}_{3} \mathrm{O}_{4}$ through the amino groups of DA (DA-Fe3O4-FC-Ab2). The high number of DA molecules anchored to the $\mathrm{Fe}_{3} \mathrm{O}_{4}$ surface increased the immobilization of ferrocene and Ab2 onto the magnetite NPs, which in turn increased the sensitivity of the immunosensor. In another report, functional nanocomposites of $\mathrm{Au}$ and $\mathrm{Ag}$ core-shell magnetic graphene loaded with a cadmium ion ( $\mathrm{Au} @ \mathrm{Ag} / \mathrm{GS}-\mathrm{Fe}_{3} \mathrm{O}_{4} / \mathrm{Cd}^{2+}$ )-based immunosensor were used for the detection of $\mathrm{IgG}^{242} \mathrm{The}$ amino-functionalized magnetic graphene nanocomposites $\left(\mathrm{NH}_{2}-\mathrm{GS}-\mathrm{Fe}_{3} \mathrm{O}_{4}\right)$ were used to bond $\mathrm{Au}$ and Ag core-shell NPs (Au@Ag NPs) followed by the adsorption of a cadmium ion $\left(\mathrm{Cd}^{2+}\right)$. The $\mathrm{Au} @ \mathrm{Ag} / \mathrm{GS}-\mathrm{Fe}_{3} \mathrm{O}_{4} / \mathrm{Cd}^{2+}$ increases the electrocatalytic activity toward hydrogen peroxide $\left(\mathrm{H}_{2} \mathrm{O}_{2}\right)$ and improves the effective immobilization of antibodies. The sensor can detect the IgG with a detection limit of $2 \mathrm{fg} / \mathrm{mL}$. 


\subsubsection{Cytosensors}

In electrochemical cytosensors, a biocompatible recognition unit is fabricated onto the electrode surface to specifically recognize the target cells, followed by coupling with a sensitive electrical readout. Varieties of specially engineered nanomaterials have been shown to anchor target-cell recognition units, such as aptamers, antibodies, or receptors, as well as to report enhanced cell-recognition events. For example, $\mathrm{Au} \mathrm{NP}-$ decorated magnetic $\mathrm{Fe}_{3} \mathrm{O}_{4}$ nanoprobes were reported for the construction of an electrochemical cytosensor for the detection of leukemia cells and the quantitative estimation of death-receptor expression on leukemia cell surfaces. ${ }^{243}$ The nanoprobes were assembled through the co-immobilization of both rhTRAIL (recombinant human TRAIL) and HRP on $\mathrm{Au} \mathrm{NP}-\mathrm{Fe}_{3} \mathrm{O}_{4}$ beads. The rhTRAIL had been used for specific and selective recognition of DR4/DR5 on leukemia cell surfaces, and an amplified electrochemical signal was achieved via HRP catalyzation of the oxidation of thionine by $\mathrm{H}_{2} \mathrm{O}_{2}$, resulting in the sensitive detection of leukemia cells with LOD $\sim 40$ cells. In a later year, nonenzymatic nanoelectrocatalysts, $\mathrm{Fe}_{3} \mathrm{O}_{4} @$ nanocage (Ag-Pd) core-satellite hybrid NPs, were engineered by the same research group as signal-amplifying nanoprobes for the ultrasensitive detection of low abundant circulating tumor cells (CTCs). ${ }^{244}$ CTCs have been considered a valuable biomarker for early diagnosis of cancer, as they play critical roles in metastasis. As can be seen from Fig. 15(A), the nanoelectrocatalysts were prepared via the electrostatic interaction between positively charged (as synthesized) $\mathrm{Fe}_{3} \mathrm{O}_{4} / \mathrm{PDDA}$ (di-allyldimethyl ammonium chloride) and negatively charged $\mathrm{Ag}-\mathrm{Pd}$ nanocages. $\mathrm{Fe}_{3} \mathrm{O}_{4} @ \mathrm{Ag}-\mathrm{Pd}$ hybrid particles were shown to be highly catalytically active toward the electrochemical reduction of a redox dye; thionines and the nanocage were used as signal-amplifying nanoprobes for cytosensor design. The inherent electroactive properties of $\mathrm{Fe}_{3} \mathrm{O}_{4}$ and the large surface area, high conductivity, and distinctive porous hollow structure of the $\mathrm{Ag}-\mathrm{Pd}$ nanocages contribute synergistically toward amplification of the catalytic signals. Figure 15(B) 
illustrates the steps involved in the sensor design. A GCE surface was modified with the Au NPs, followed by the conjugation of SYL3C-SH (thiolated cell-targeting aptamers) via $\mathrm{Au}-$ thiol interactions. A SYL3C-functionalized hybrid nanoprobe, SYL3C- $\mathrm{Fe}_{3} \mathrm{O}_{4} @ \mathrm{Ag}-\mathrm{Pd}$, was formed by the conjugation of thiolated SYL3C with the $\mathrm{Ag}-\mathrm{Pd}$ nanocages through metal-thiol interactions. After capturing the target cells (CTCs) onto the SYL3C-Au modified GCE, the SYL3C- $\mathrm{Fe}_{3} \mathrm{O}_{4} @ \mathrm{Ag}-\mathrm{Pd}$ nanoprobes were attached to form a sandwich-resembling superstructure. The DPV responses were then measured in the presence of thionines to quantify the two model cells (MCF-7 and T47D) and the sensors able to detect $\sim 4$ MCF-7 and 5 T47D cells. Thiolated sgc8c aptamer-immobilized $\mathrm{Au} \mathrm{NP}-$ coated magnetic $\mathrm{Fe}_{3} \mathrm{O}_{4}$ NPs were also reported for the detection of leukemia cancer cells. ${ }^{245}$
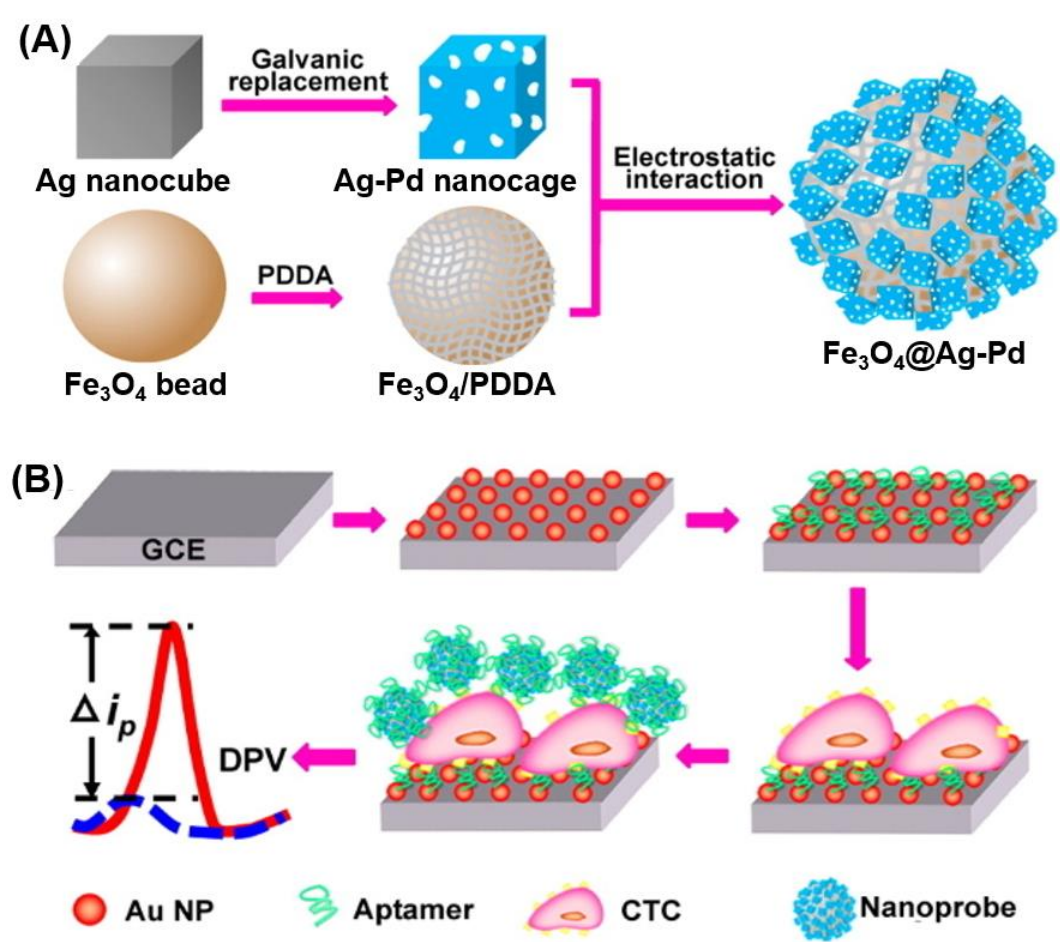

Fig. 15 Schematic illustration of (A) the fabrication of $\mathrm{Fe}_{3} \mathrm{O}_{4} @ \mathrm{Ag}-\mathrm{Pd}$ hybrid NPs and (B) the steps involved in sensor design for the detection of CTCs. Reproduced with permission. $^{244}$ 
Sun and co-workers have engineered a hybrid nanoelectrocatalyst $\left(\mathrm{Fe}_{3} \mathrm{O}_{4} / \mathrm{MnO}_{2} / \mathrm{Au} @ \mathrm{Pd}\right)$ as both an electrochemical signal amplifier and a carrier of nanoprobes for the sensitive detection of human hepatocellular cancer cells (HepG2). ${ }^{246}$ The nanocatalyst was designed by the conjugation of a $\mathrm{Au} @ \mathrm{Pd}$ core-shell nanosphere and $\mathrm{Fe}_{3} \mathrm{O}_{4} / \mathrm{MnO}_{2}$ nanocomposite and modified with a thiolated capture probe, HRP, and hemin to form a $\mathrm{Fe}_{3} \mathrm{O}_{4} / \mathrm{MnO}_{2} / \mathrm{Au} @ \mathrm{Pd}-\mathrm{HRP}-$ aptamer/hemin/G-quadruplex nanoprobe. After the capturing target cells on a thiolated aptamer-attached AuNP/GCE surface, a sandwich-like structure was formed with the as-prepared nanoprobes. After that, an amplified DPV signal was obtained from benzoquinone (BQ) generated from $\mathrm{Fe}_{3} \mathrm{O}_{4} / \mathrm{MnO}_{2} / \mathrm{Au} @ \mathrm{Pd}-\mathrm{HRP}-$ aptamer/hemin/Gquadruplex nanoprobes that catalyzed the oxidation of hydroquinone (HQ) with $\mathrm{H}_{2} \mathrm{O}_{2}$. The generated DPV response was directly related to the number of nanoprobes present on the AuNP/GCE surface, thus reflecting the number of cells present in the system. Very recently, $\mathrm{Fe}_{3} \mathrm{O}_{4} \mathrm{NP}$ nanozymes with reduced graphene oxide/molybdenum disulfide $\left(\mathrm{rGO} / \mathrm{MoS}_{2}\right)$ composites have also been reported for the detection of CTCs. ${ }^{247}$

\subsection{Optical biosensors}

Novel metal nanostructures with a dimension below $100 \mathrm{~nm}$ possess numerous unique optical properties, such as absorption, emission, surface plasmon polariton propagation, and localized and surface plasmon resonance, in the extended visible and near infrared (IR) regions. ${ }^{34,248}$ Their distinct properties, including magnetism, engineered dimension, opto-electronics, and surface functionalization with antibodies, ligands, and recognition elements capacity, make superparamagnetic NPs superior candidates for the rational design of a sensing platform for biomolecules with low concentration. Based on such distinctive properties and plasmonic behaviors, numerous MNPs-based optical detection have been reported. 


\subsubsection{Colorimetry and fluorescence detection}

Colorimetric sensors have been considered for emerging spot-chemical detection techniques, as they offer detection with minimal facilities due to the replacement of complicated steps and expensive instrumentation. They can be easily integrated into the solid strips, papers, smartphone, thus allowing portability and affordability of the detection of target samples. Integration of MNPs with colorimetric sensors offers more sensitive, accurate, miniaturized, cost-effective, instantaneous in situ detection of target analytes. The detection mechanism generally relies on the functionalization of MNPs with the recognition elements (e.g., antibodies or aptamers), followed by the capture and magnetic isolation-purification of targets. ${ }^{249,250}$ The purified MNP-bound target is then used to interact with a chromogenic substance or to undergo NP enrichment to generate analyte-defined colors. For instance, antiStaphylococcus aureus (S. aureus) antibody-functionalized AuNP/MNPs have been used to detect a food pathogen, $S$. aureus, in milk. ${ }^{251}$ The immunomagnetic composite was inoculated into the milk sample to capture the target, followed by magnetic isolation and purification. The resuspension of captured bacteria-antibody/AuNP/MNP complexes was passed through a selective filtration system, while the target unbounded NP composite filtered through the membrane and the target bound NP composite did not penetrate, resulting in corresponding red spot through a gold enhancement solution. The assay can detect $1.5 \times 10^{5} \mathrm{CFU}$ of $S$. aureus in milk, but it required a predesigned filtration system, signal (color intensity) enhancement, and solution treatment. Suaifan et al. reported a lab-on-a-chip (LOC) strip-based biosensor for detecting cancer biomarker PSA protease without using any chromophore labeling or colorenhancement solution. ${ }^{252}$ In this sensor design, a PSA substrate peptide was covalently bound to a magnetic bead and linked to the gold surface of the paper strip. The PSA protease was then applied to cleave the strip-bound PSA substrates, resulting in the release of a black magnetic carrier complex and thereby exposing the target corresponding gold-colored sensor surface to 
naked-eye detection. Recently, several other paper colorimetric biosensors based on the proteolytic activity of the target have also been reported to detect food contaminants in complex foods and milk. ${ }^{253,254}$ However, in recent decades, many MNP-colorimetric sensors have been reported based on the intrinsic peroxidase mimetic activity of MNPs, which is described separately in section 5.3.

\subsubsection{SPR biosensors}

Surface plasmon resonance (SPR) sensors possess a unique capacity for real-time monitoring of the interaction of biological analytes by evaluating the refractive index changes during complex (usually sandwich-type) formation or dissociation at the SPR sensing surfaces. ${ }^{255}$ SPR sensors have generally suffered from low signal intensity and nonspecific bindings for the detection of trace amounts of proteins, nucleic acids, and other small biomolecules. ${ }^{256}$ To obtain signal enhancement, several metal nanoparticles, including $\mathrm{Au},{ }^{257} \mathrm{Pt},{ }^{258} \mathrm{Pd},{ }^{259}$ and $\mathrm{SiO}_{2},{ }^{260}$ have been investigated; however, these NPs (due to their low molecular weight and slow diffusion to the sensor surface) are unable to realize the promise of achieving highly selective and sensitive detection. Target-specific enrichment, isolation of the target from complex biometrics, and simultaneous signal enhancement could be a way to perform targeted and sensitive SPR-based biomolecule or biomarker detection. Magnetic nanostructures hold promise for providing a high surface-to-volume ratio, minimum disturbance to surface functionalization, easy and faster binding, better miscibility, magnet-based isolation and purifications, high molecular weight, and necessarily quick delivery of target analytes to the sensor surface through a magnetic field gradient to choke the slow, diffusiondriven mass transfer. ${ }^{261}$ By utilising $\mathrm{Fe}_{3} \mathrm{O}_{4}$ MNPs as amplification reagent, a sandwich SPR sensor has been reported for detecting thrombin by utilizing $\mathrm{Fe}_{3} \mathrm{O}_{4} \mathrm{MNPs}$ as amplification reagents; the MNP-aptamer conjugates were used to accomplish the antithrombin aptamer-thrombin-MNP sandwich on an SPR sensor, and an LOD of $0.017 \mathrm{nM}$ was achieved ${ }^{262}$ However, though the greater mass and superior refractive index of the MNPs located in the evanescent field give rise to signal 
enhancement, the MNPs tend to aggregate and possess bad biocompatibility if it is not wellfunctionalized with biomolecules or antibody or any metallic coating through cumbersome chemistries. $^{96,263}$ One of the prominent approaches to overcome this is to employ the well-known surface chemistry of Au. The loading (or coating) of gold onto MNPs stabilizes the particles in solution, enabling the straightforward binding of capture probe molecules or target biomolecules and improving the signal enhancement by combining the refractive indexes from both Au and MNPs (GMNPs - gold MNPs). ${ }^{264}$

Besides Au, graphene oxide (GO)-modified MNPs are also promising in SPR-based biosensing. GO provides multiple sites for the deposition of other metal oxides, whereas the reduced GO (rGO) provides an $\mathrm{sp}^{2}$-hybridized lamellar scaffold for carrying different proteins and probe molecules. ${ }^{265}$ By combining both the Au and GO with $\mathrm{Fe}_{3} \mathrm{O}_{4}$ MNPs, an SPR sensor was developed for detecting the human IgG protein. ${ }^{266}$ As shown in Fig. 16, the carboxyl group-functionalized GO was employed as a sensing surface for immobilizing the capture antibody (Ab1). A magnetic nanohybrid was formed by combining the MNPs with hollow Au NPs (HGNPs), followed by modification with a detection antibody (Ab2). An Ab2 nanohybrid was then utilized to magnetically collect target IgG from the sample and to rapidly deliver the target sample to the sensor surface using an external magnet. Taking the advantages of magnetic field-driven mass-transfer, inner and outer surfaces derived notable plasmonic fields, and the significant signal amplification of magnetic nanohybrid the developed SPR sensor achieved a LOD of $1.88 \mathrm{ngmL}^{-1}$ toward the detection of IgG. Distinguished plasmonic enhancements are resulting in if the hollow gold nanospheres (HGNPs) are electromagnetically coupled with the plasmonic effects of the inner and outer surface of HGNPS. Based on this amplification strategy, improved SPR was reported, in which a detection antibody (Ab2)-modified polydopamine- $\mathrm{Ag} @ \mathrm{Fe}_{3} \mathrm{O}_{4} /$ reduced graphene oxide (PDA-Ag@ $\mathrm{Fe}_{3} \mathrm{O}_{4} / \mathrm{rGO}$ ) was utilized to attach the target and form a sandwich structure with the target $\mathrm{IgG}$ and $\mathrm{Ab1}$ immobilized onto an Au surface. ${ }^{267} \mathrm{Fe}_{3} \mathrm{O}_{4}$ facilitates the magnet- 
guided sample and Ab2 collection; the PDA permitted efficient immobilization of the antibody and prevented agglomeration. Ag NPs were excited to generate SPR, and their hot electrons were doped on thin graphene films, which improved the response of the target IgG.

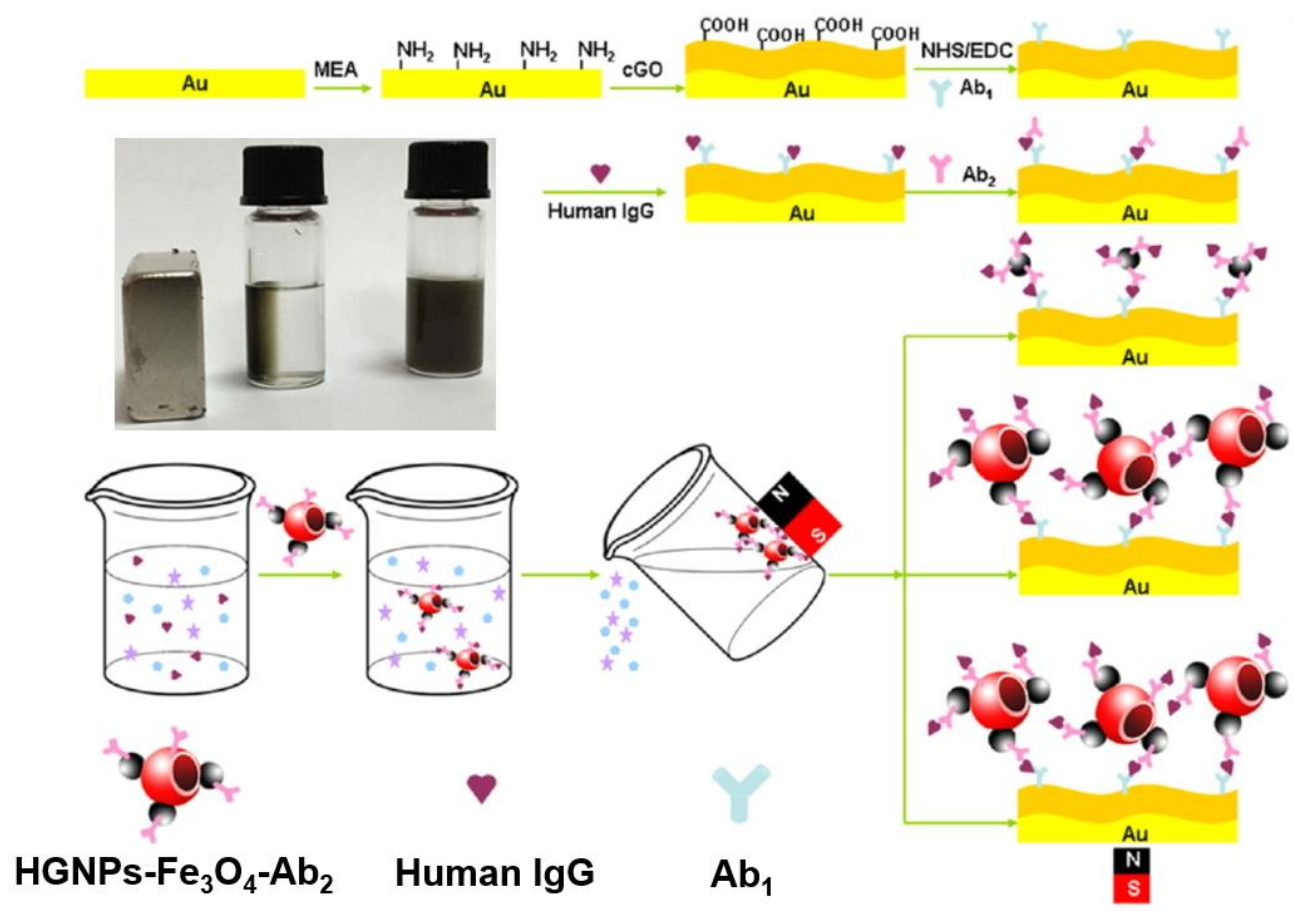

Fig. 16 Schematic representation of a GO-sensing film and $\mathrm{Fe}_{3} \mathrm{O}_{4}-\mathrm{HGNPS}$ - hybrid probe-based magnetic field-assisted SPR biosensor for $\mathrm{IgG}$ detection Reproduced with permission. ${ }^{266}$

\subsubsection{LSPR biosensor}

Unlike SPR, a localized surface plasmon resonance (LSPR) biosensor depends on the lightmatter interactions of noble metal NPs, where the sensing is realized by monitoring the changes in LSPR peak position arising from the refractive index alteration of the environment or changes in nanoparticle coupling strength. ${ }^{255,268}$ LSPR can be designed either in solution-phase or surface-bound mode. Though solution-phase LSPR follows a simpler operation, the colloidal stability and dilution of NPs limit their in-field application. Surface-bound LSPR (in which NPs are immobilized on a solid surface), in contrast, alleviates the problem of NP colloidal stability in solution and is easy to integrate into multiplex and array-based assays. 
Oligo-functionalized Au NPs are primarily used for aggregation-based DNA or RNA sensors, where the hybridization of the target or complementary sequences cause aggregation, resulting in the redshift of the LSPR peak. ${ }^{268,269}$ The integration of MNPs with plasmonic NPs such as $\mathrm{Au}, \mathrm{Ag}$, or Pt facilitates the dual benefit of MNP-based easy and various modes of conjugation, dispersibility, and magnetic separation of preferred biomolecules, as well as plasmonic NPbased SPR signal amplification. ${ }^{270-272}$ For instance, citrate-stabilized $\mathrm{Fe}_{3} \mathrm{O}_{4} @ \mathrm{Au}$ core-shell NPs were employed for the multiplex detection of serum proteins and miRNAs as the plasmon signal amplification label. Both the number of analytes bound onto the sensor (i.e., antigen for an antibody or miRNA for a capture nucleotide) and the level of interaction of the detection probe-loaded core/shell NP labels stimulates the SPR signal change. ${ }^{270}$ Interestingly, the changes are larger for small oligonucleotide hybridization than for the large sandwich protein immuno-mode. A more recent example of a magnet-assisted LSPR immunoassay in which $\mathrm{Fe}_{3} \mathrm{O}_{4} / \mathrm{Au}$ core-shell NPs (FACSNPs) were utilized to fabricate sensing spots of a microarray system. ${ }^{273}$ By coupling the unique superparamagnetic property of the iron oxide nanocore with the strong plasmonic strength of AuNPs on the FACSNPs demonstrated superior sensitivity to the local refractive index change upon cytokine binding. In this microarray system, a magnetassisted self-assembly was performed to obtain pattern uniform antibody functioned microarray on a glass substrate. The FACSNP microarray can conduct 384 of tests on four different cytokines for each sample, with 16 replicates per cytokine test. The integration of FACSNP microarray sensors into a simple opto-fluidic device enables real-time, parallel detection of multiple cytokines with an LOD of $\approx 20 \mathrm{pg} \mathrm{mL}^{-1}$ using $1 \mu \mathrm{L}$ of clinical samples.

\subsubsection{SERS biosensors}

The surface-enhanced Raman spectroscopy (SERS) technique shows vast superiority for use in biological systems aiding from the technology itself using Raman scattering enhancement, since it can provide orders of magnitude of signal intensity on the employment of proper substrates and 
enhancers. Recently, SERS has been integrated with biosensing for the detection of sensitive biomolecules such as proteins, ${ }^{274} \mathrm{DNA},{ }^{275} \mathrm{RNA},{ }^{276}$ and cellular components ${ }^{277}$ due to their unique Raman responses. Generally, Au and Ag NPs are the predominantly utilized ones, as their surface plasmons lie in the visible region of the electromagnetic spectrum that overlaps the laser excitation wavelengths frequently used for Raman. ${ }^{278}$ The integration of MNPs has accelerated the detection by incorporating magnetic capture of the target from clinical samples and occupying reporter molecules (Au, Ag) or dyes. For instance, $\mathrm{Au} @ \mathrm{MNPs}$, in which both plasmonic properties from $\mathrm{Au}$ and magnetic properties from MNPs are integrated, thereby enhancing the SERS detection sensitivity by increasing the active concentration of both the tag and reporter within the stationary focus beam of a laser following magnet-based pull-down. ${ }^{96,279,280}$ Yang et al. explored a SERSbased immunoassay to detect an influenza virus, H3N2, through the formation of a sandwich structure consisting of 4-mercaptobenzoic acid (4-MBA)-labeled Au NPs as SERS tags, $\mathrm{Fe}_{3} \mathrm{O}_{4} / \mathrm{Au}$ NPs magnetic supporting substrates, and target influenza viruses (Fig. 17). ${ }^{281}$ In this immunosensor, $\mathrm{Fe}_{3} \mathrm{O}_{4} / \mathrm{Au}$ magnetic substrates allowed for the enrichment and separation of viruses from a biological matrix, thereby simplifying the sample pretreatment and the coupling agent 4-MBA loaded on Au NPs bind Influenza A IgG. The 4-MBA itself acts as a Raman reporter due to its intrinsically strong Raman scattering. The advantages of utilizing 4-MBA rely on the fact that, unlike thioglycolic acid or $\alpha$-lipoic acid, it does not require the addition of further Raman reporter molecules. ${ }^{282}$ The developed immunoassay could detect down to H3N2 $10^{2} \mathrm{TCID}_{50} / \mathrm{mL}$. Like $\mathrm{Au}, \mathrm{Fe}_{3} \mathrm{O}_{4} @ \mathrm{Ag}$ MNPs were utilized as both a SERS tag and a target capturing agent to design a sensitive miRNA detection platform. ${ }^{279}$ In this sensor design, the DNA probemodified $\mathrm{Fe}_{3} \mathrm{O}_{4} @ \mathrm{Ag}$ MNPs were first allowed to miRNA from cancer cells followed by DSNbased signal amplification for SERS detection. Upon the hydrolysis of the DNA probes of the DNA/RNA duplex, the Raman tags could diffuse away from the Ag surface and induce a Raman intensity attenuation. Though high versatility and tremendous usefulness, the precise 
fabrication of identical nanogaps distribution by means of the metal (single) is highly challenging, which consequently limits the sensor platform from high sensitivity and reproducibility.

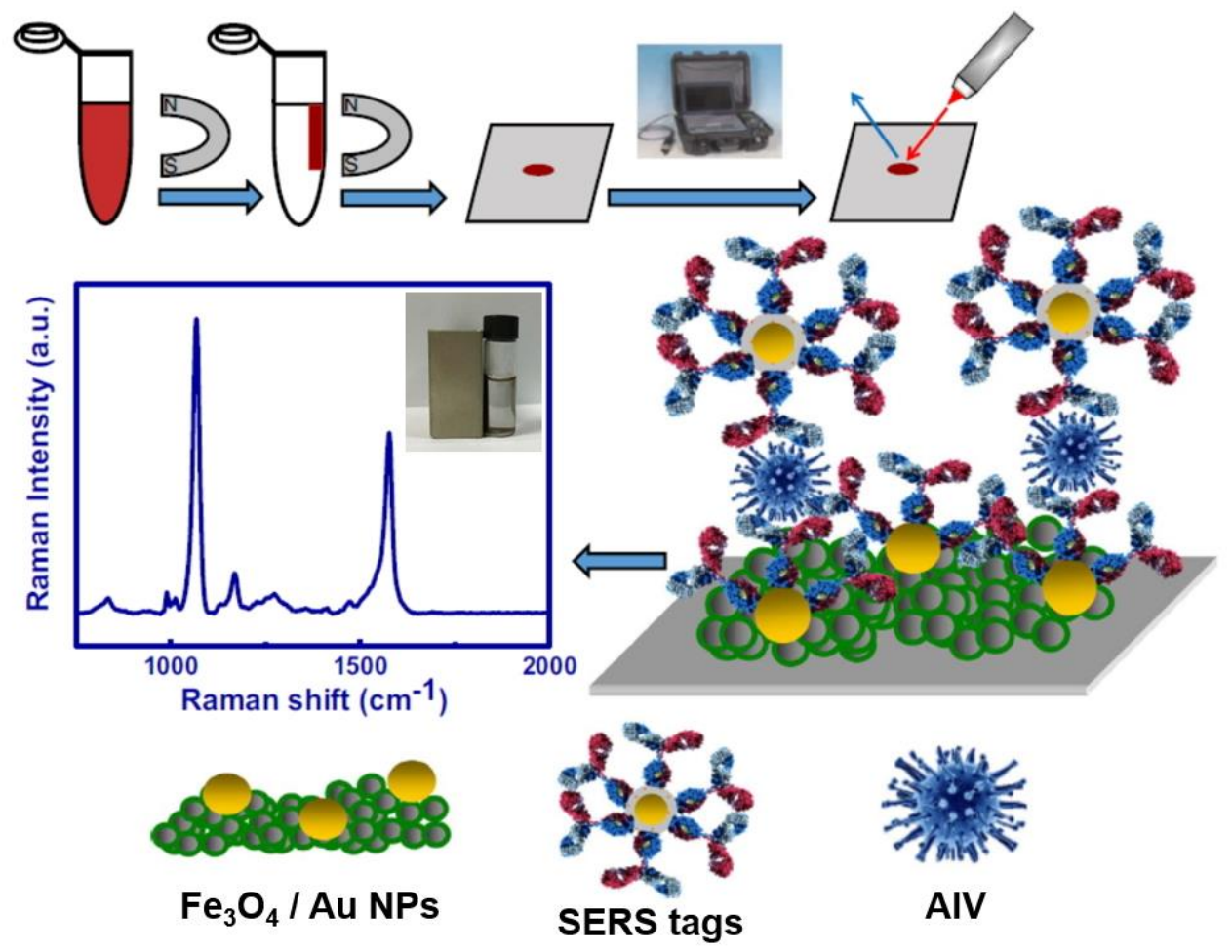

Fig. 17 Schematic illustration of a magnetic SERS immunosensor for sensitive detection of avian influenza virus. Reproduced with permission. ${ }^{281}$

The SERS platform should have both the chemical enhancement abilities and strong electromagnetic effect to provide drastically higher sensitivity than Raman spectroscopy for detecting trace amounts of disease-specific biomarkers (e.g., neurodegenerative disease. This can be achieved by incorporating GO into the SERS platform, due to its ability to improve the Raman signal through chemical enhancement. ${ }^{283}$ The unique structure of $\mathrm{sp}^{2}$-carbon nanosheets is promising for $\pi-\pi$ stacking, and the highly electronegative oxygen species present on the GO surface can enhance the local electric field on the adsorbed molecules. Additionally, GO has a strong ability to quench the molecule's fluorescence, which adds further 
advantages as a SERS substrate via immense decreasing of the background signal. Moreover, the platform with multiple hotspots to enrich the target analytes facilitates amplified SERS signals. The numerous hotspots can be attained by creating subtle nanogaps using a core-shellsatellite structure. Several researchers have reported taking advantage of both the core-shell arrangement and the GO-induced enhancement and magnetic effect of MNPs to produce several SERS platforms. ${ }^{284,} 285$ For instance, magnetic core-plasmonic shell NP-attached hybrid GO-based multifunctional nanoplatforms have been reported for detecting Alzheimer's disease (AD) biomarkers tau-protein and $\beta$-amyloid. ${ }^{285}$ In this platform, magnetic core-shell NPs were assembled on 2D GO surface and utilized to isolate the biomarkers from complex patient samples. However, tremendous applicability of MNPs in SERS, yet need to adopt the integration of different functional particles and required cumbersome conjugation chemistries. A single nanostructure with magnetic properties, high plasmonic and electronic properties, and high analyte adsorption capabilities with an intense layer could provide a single-particle SERS platform and overcome the existing limitation of using multiple materials and complex chemistries.

\subsection{Biosensors based on nanozymes}

Peroxidases (mostly HRP) play significant roles in bioanalytical chemistry, as they are widely used (conjugated with antibodies or signaling molecules) as signaling agents to catalyz the oxidation of various chromogenic substances in sensor design. After Yan's report of the peroxidase mimetics of iron oxide NPs and their application in the development of an immunoassay, a vast number of studies have been conducted on the design of biosensors based on nanozymes. ${ }^{208,214,286}$ Yan and co-author designed two immunoassays for detecting the hepatitis B virus surface antigen (preS1) and cardiac troponin 1 (Tn1) using ferric oxideimmobilized protein A and an antibody, respectively. In the first immunoassay, an ELISA plate was coated with Pres1, followed by the addition of an anti-HBV Pres1 antibody. Ferric oxide- 
immobilized protein A was then added to complete the immunorecognition events and catalyze the TMB substrate solution to generate antigen-corresponding color signals. In the second assay, Tn1-immobilized ferric oxide was mixed with a serum to bind the target Tn1 and magnetically separate it from the complex serum matrix, followed by assay design onto an ELISA plate. Based on such peroxidase mimetics, polyacrylic acid-coated iron oxide MNPs were designed and used to detect carcinoma cells (A549 cells). The assay was able to differentiate A549 cells from noncarcinoma cells (H9c2). ${ }^{287}$ Since then, several immunoassays have been reported using magnetic nanoparticles. However, the nanozyme activity usually decreases when they are modified with proteins, antibodies, or nucleotides. Recently, Yang et al. reported that phosphate-containing adenosine analogues such as adenosine 5'monophosphate (AMP) enhance the oxidation reaction of hydrogen peroxide $\left(\mathrm{H}_{2} \mathrm{O}_{2}\right)$ as well as TMB oxidation. ${ }^{288}$ They have found that the nanozyme activity in $\mathrm{Fe}_{3} \mathrm{O}_{4}$ NPs gradually increases with increasing AMP concentration and polyadenosine length, and it follows a trend: AMP > adenosine 5'-diphosphate > adenosine 5'-triphosphate. Based on these AMP-enhanced peroxidase mimetics, they have designed a selective fluorescent turnoff system for the quantification of human serum albumin (HSA) in the urine. Very recently, we reported on electrocatalytic and colorimetric (naked eye) detection of p53 autoantibodies using peroxidase mimetics of gold-loaded nanoporous ferric oxide nanocubes. ${ }^{289}$ In this sensor design, the biotinylated p53 antigen was immobilized on a neutravidin-modified screen-printed carbon electrode (SPCE), followed by the addition of serum or plasma samples containing the target p53 autoantibody (Fig. 18). $\alpha$-Human IgG-functionalized $\mathrm{Au}-\mathrm{NPFe}_{2} \mathrm{O}_{3} \mathrm{NCs}$ were then added to the electrode surface to form an immunocomplex with the target p53 autoantibody. The electrode surface was then covered and incubated with the freshly prepared $\mathrm{TMB} / \mathrm{H}_{2} \mathrm{O}_{2}$ solution to facilitate the nanocube-catalyzed oxidation of TMB. The color change was observed and quantified by using colorimetry and chronoamperometry. 


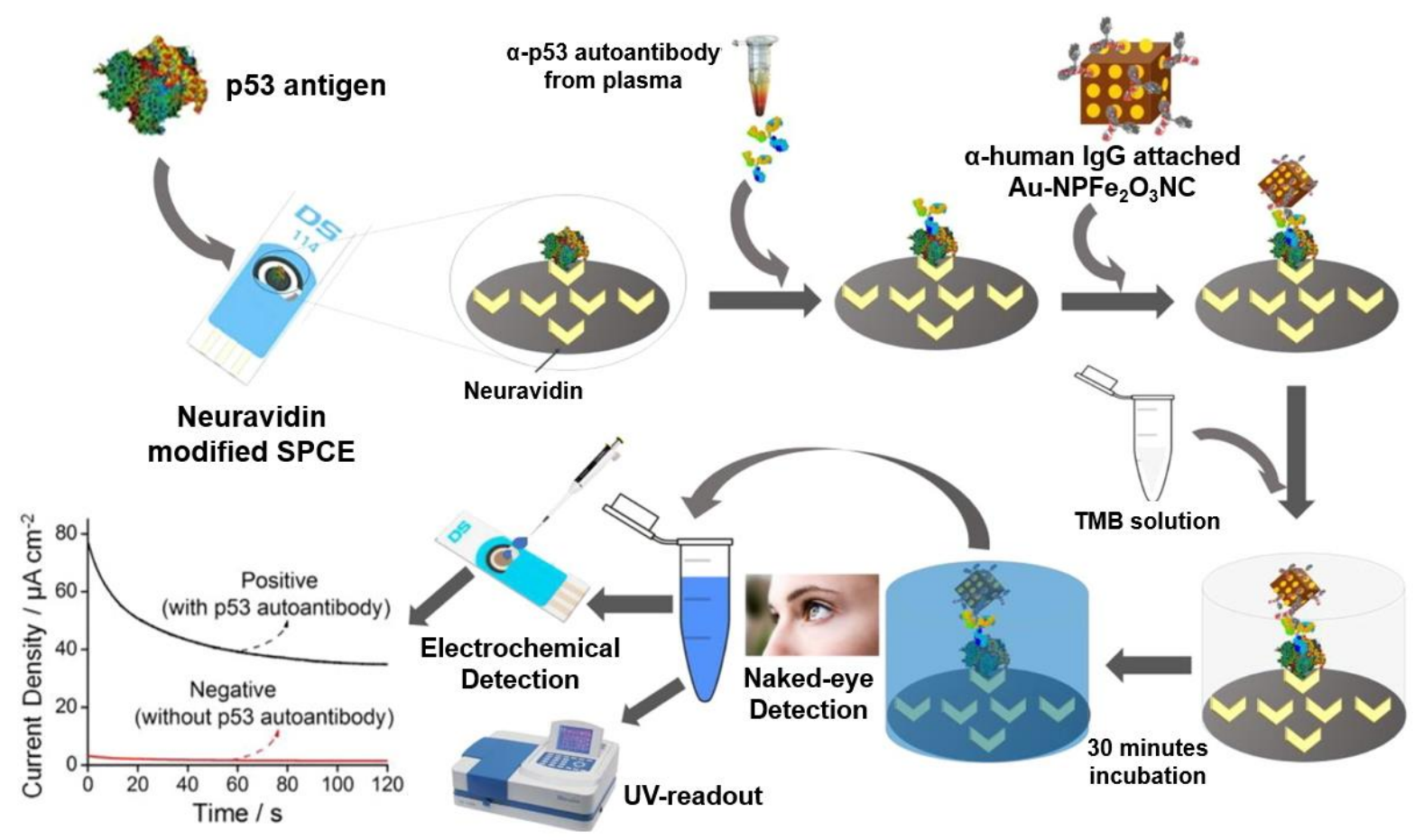

Fig. 18 Schematic representation of the assay for p53 autoantibody detection using the peroxidase mimetics of gold-loaded nanoporous ferric oxide nanocubes. Reproduced with permission. $^{289}$

The peroxidase-mimicking activity of nanozymes has also been used to detect nucleotides. For instance, a colorimetric DNA-sensing platform has been demonstrated using dsDNA shielding activity against the peroxidase mimetics of NPs. ${ }^{290}$ The target was subjected to PCR amplification, followed by mixing with unmodified MNPs. The PCR-amplified target DNA present in the solution results in a decrease in access of the positively charged substrate o-phenylenediamine (OPD) to the MNPs through its electrostatic interactions with the negatively charged phosphate backbone of DNA and direct adsorption of DNA molecules on the surface of MNPs. Therefore, the NPs underwent a significant inhibition of substrate OPD and $\mathrm{H}_{2} \mathrm{O}_{2}$. Table 1 summarizes the recently employed (in the past three years) magnetic nanostructures and their role in the detection of disease-specific biomarkers. In addition to the 
above-discussed strategies, other techniques, such as giant magnetoresistive (GMR), ${ }^{291-293}$ quartz crystal microbalance (QCM), ${ }^{294,} 295$ microcantilevers, ${ }^{296,} 297$ and resonance Rayleigh scattering (RRS), ${ }^{298}$ play critical roles in the development of a sandwich assay for proteinbased biomarker detection. 
Table 1. Engineered MNPs for disease-specific biomolecular (electrochemical and optical) sensing

\begin{tabular}{|c|c|c|c|c|}
\hline Magnetic nanostructures (MNSs) & Function of MNSs & Target biomolecule & LOD & Ref. \\
\hline \multicolumn{5}{|c|}{$\begin{array}{l}\text { Electrochemical detection } \\
\end{array}$} \\
\hline $\mathrm{Au} @ \mathrm{NPFe}_{2} \mathrm{O}_{3} \mathrm{NC}$ & Immobilization of miRNA & miRNA (miR-21) & $100 \mathrm{fM}$ & 45 \\
\hline $\mathrm{Fe}_{3} \mathrm{O}_{4} \mathrm{NPs}$ & $\begin{array}{l}\text { Carrying a large number of redox signaling molecules, } \\
\text { thionine and Fc, for target-specific DPV readout }\end{array}$ & miRNA (miR-141) & $0.28 \mathrm{fM}$ & 299 \\
\hline $\mathrm{CoFe}_{2} \mathrm{O}_{4} \mathrm{MNPs}$ & Nanoelectrocatalyst for toluidine blue catalysis & miRNA (miR-21) & $0.3 \mathrm{fM}$ & 300 \\
\hline $\begin{array}{l}\text { GO-loaded-iron oxide hybrid } \\
\text { materials }\end{array}$ & $\begin{array}{l}\text { Electrocatalytic signal enhancement } \\
\text { Immobilization of miRNA }\end{array}$ & miRNA (miR-21) & $100 \mathrm{aM}$ & 301 \\
\hline $\begin{array}{c}\text { DNA-Au@MNPs as dispersible } \\
\text { electrodes }\end{array}$ & DNA-Au@MNPs as dispersible electrodes & miRNA (miR-21) & $10 \mathrm{aM}$ & 302 \\
\hline PdNPs@Fe-MOFs & $\begin{array}{l}\text { Nanocarriers for signal probe } \\
\text { Immobilization of redox probes and electrocatalysts for } \\
\text { signal enhancement }\end{array}$ & miRNA (miR-122) & $0.003 \mathrm{fM}$ & 303 \\
\hline GO-loaded MNPs & $\begin{array}{l}\text { Immobilization of ssDNA } \\
\text { Electrocatalytic signal amplification }\end{array}$ & $\begin{array}{l}\text { ctDNA (FGFR2 : FAM76A } \\
\text { fusion gene) }\end{array}$ & $1 \mathrm{fM}$ & 304 \\
\hline Porous $\mathrm{Fe}_{3} \mathrm{O}_{4}$ & $\begin{array}{l}\text { Immobilization of probe DNA and redox probe of } \\
{\left[\mathrm{Fe}(\mathrm{CN})_{6}\right]^{3-}}\end{array}$ & miRNA (miR-141) & $1.4 \mathrm{aM}$ & 305 \\
\hline $\mathrm{Fe}_{3} \mathrm{O}_{4} @ \mathrm{GO} @ \mathrm{MIP}$ & $\begin{array}{l}\text { Immobilization of target biomarker and magnetic field- } \\
\text { based assembly }\end{array}$ & Interleukin-8 (IL-8) & $0.04 \mathrm{pM}$ & 306 \\
\hline Au-coated iron oxide NPs & $\begin{array}{l}\text { Magnetic actuator } \\
\text { Immunoprobe }\end{array}$ & PSA & $0.085 \mathrm{ng} / \mathrm{mL}$ & 307 \\
\hline $\mathrm{Fe}_{3} \mathrm{O}_{4} @ 3 \mathrm{D}-\mathrm{rGO} @ \mathrm{PP} 4 \mathrm{VP}$ & $\begin{array}{l}\text { Aptamer immobilization } \\
\text { Electrode fabrication }\end{array}$ & $\begin{array}{l}\text { Thrombin, PDGF-BB } \\
\text { LYS }\end{array}$ & $\begin{array}{l}4.5 \mathrm{pgmL}^{-1} \\
29.4 \mathrm{pgmL}^{-1} \\
14 \mathrm{pgmL}^{-1}\end{array}$ & 308 \\
\hline $\mathrm{Au} @ \mathrm{NPFe}_{2} \mathrm{O}_{3} \mathrm{NC}$ & Nanocarriers for target p53 from serum & p53 autoantibody & $0.02 \mathrm{U} \mathrm{mL}-1$ & 309 \\
\hline $\mathrm{Au}-\mathrm{NPFe}_{2} \mathrm{O}_{3} \mathrm{NC}$ & $\begin{array}{l}\text { Direct isolation of target protein from serum; acts as a } \\
\text { nanozyme }\end{array}$ & $\begin{array}{l}\text { p53 autoantibody } \\
\text { Exosome }\end{array}$ & $\begin{array}{c}0.08 \mathrm{U} / \mathrm{mL} \\
10^{3} \text { exosomes } / \mathrm{mL}\end{array}$ & $\begin{array}{c}40 \\
310\end{array}$ \\
\hline $\mathrm{Fe}_{3} \mathrm{O}_{4} / \mathrm{TMC} / \mathrm{Au}$ & $\begin{array}{l}\text { DNA probe labeled with NPS to offer an electrochemical } \\
\text { readout }\end{array}$ & RASSF1A methylation & $2 \times 10^{-15} \mathrm{M}$ & 311 \\
\hline $\mathrm{Fe}_{3} \mathrm{O}_{4} / \mathrm{TMC} / \mathrm{Au}$ & $\begin{array}{l}\text { Nanocomposite utilized as a tracing tag to label } \\
\text { antibodies }\end{array}$ & EGFR & $\mathrm{fg} / \mathrm{mL}$ & 312 \\
\hline
\end{tabular}




\begin{tabular}{|c|c|c|c|c|}
\hline $\mathrm{Au} / \mathrm{MNP}-\mathrm{CNT}$ & $\begin{array}{l}\text { Magnetic alignment of sensing platform on a } \mathrm{Pt} \\
\text { electrode }\end{array}$ & $\begin{array}{c}\text { Influenza virus DNA } \\
\text { Norovirus DNA }\end{array}$ & $\begin{array}{l}8.4 \mathrm{pM} \\
8.8 \mathrm{pM}\end{array}$ & 313 \\
\hline \multicolumn{5}{|c|}{ Colorimetric and fluorescence detection } \\
\hline $\mathrm{ZnFe}_{2} \mathrm{O}_{4} / \mathrm{rGO}$ & Aptamer conjugation to act as a signal probe & S. typhimurium & $11 \mathrm{CFU} / \mathrm{mL}$ & 314 \\
\hline MNPs & Immobilization of target-specific DNA probe 2 & ETA gene & $1.2 \mathrm{ng} / \mathrm{mL}$ & 315 \\
\hline DL-MBs & $\begin{array}{l}\text { Immobilization of detection antibody and HRP; } \\
\text { colorimetric readout }\end{array}$ & EV71 & $0.1 \mathrm{ng} / \mathrm{mL}$ & 316 \\
\hline AuMNPs & Immobilization with complementary DNA probe & HPV-16 E6 & $100 \mathrm{pM}$ & 317 \\
\hline $\mathrm{SiO}_{2}$-coated iron oxide NPs & $\begin{array}{l}\text { Primary antibody conjugation and magnetic separation } \\
\text { and purification }\end{array}$ & CEA & $3.7 \mathrm{pg} / \mathrm{mL}$ & 318 \\
\hline Immunomagnetic beads & Carrier for purification/separation and magnetic focus & $\begin{array}{l}\text { E. coli pathogens } \\
\text { AFP } \\
\text { CEA }\end{array}$ & $10^{4} \mathrm{CFU} \mathrm{mL}^{-1}$ & 319 \\
\hline Iron oxide NPs & $\begin{array}{l}\text { Functionalizing with detection antibody and iron oxide- } \\
\text { to-Prussian blue (PB) NP transformation for readout } \\
\text { signals }\end{array}$ & PSA & $1.0 \mathrm{ng} \mathrm{mL}^{-1}$ & 320 \\
\hline $\mathrm{Fe}_{3} \mathrm{O}_{4}$ & $\begin{array}{l}\text { Recognition and concentration elements and magnetic } \\
\text { separation }\end{array}$ & $\mathrm{A} \beta$ oligomer & $36 \mathrm{pM}$ & 321 \\
\hline MNPs & Functionalizing with target-specific DNA probe 1 & Vibrio cholera $\mathrm{O} 1 \mathrm{OmpW}$ gene & $2.34 \mathrm{ng} / \mathrm{mL}$ & 322 \\
\hline $\mathrm{Fe}_{3} \mathrm{O}_{4} @ \mathrm{SiO}_{2}-\mathrm{Au}$ nanocomposites & Fluorescence quenching and magnetic separation & PSA & $3.0 \times 10^{-13} \mathrm{~g} / \mathrm{mL}$ & 323 \\
\hline \multicolumn{5}{|c|}{ SPR and LSPR } \\
\hline $\mathrm{Fe}_{3} \mathrm{O}_{4}$ & Signal enhancement & thrombin & $0.017 \mathrm{nM}$ & 262 \\
\hline $\mathrm{Fe}_{3} \mathrm{O}_{4} @ \mathrm{Au}$ & $\begin{array}{l}\text { Loading of capture antibody } \\
\text { Target delivery to the sensor surface } \\
\text { Binding of selective antibody }\end{array}$ & human-interleukin-17A & $0.05 \mathrm{ngmL}^{-1}$ & 264 \\
\hline Iron oxide MNPs & $\begin{array}{l}\text { Signal enhancement due to the large refractive index and } \\
\text { larger mass } \\
\text { Capturing target IgG }\end{array}$ & MCF-7 cancer cell & 500 cells $/ \mathrm{mL}$ & 324 \\
\hline $\mathrm{HGNP}-\mathrm{Fe}_{3} \mathrm{O}_{4}$ & $\begin{array}{l}\text { Magnet-derived faster sample delivery } \\
\text { Signal enhancement by the combined effect of HGNPs } \\
\text { and } \mathrm{Fe}_{3} \mathrm{O}_{4}\end{array}$ & $\mathrm{IgG}$ & $1.88 \mathrm{ngmL}^{-1}$ & 266 \\
\hline MNPs & Capturing target CTnI and LSPR signal enhancement & Cardiac troponin I (cTnI) & $30 \mathrm{pM}$ & 325 \\
\hline
\end{tabular}


$\mathrm{Fe}_{3} \mathrm{O}_{4} / \mathrm{Au}$ Core-shell Magnet pattern sensing array and LSPR signal enhancement

$\mathrm{Fe}_{3} \mathrm{O}_{4} @ \mathrm{Au}$ core/shell

Water-dispersed MNPs

$\mathrm{Ag} @ \mathrm{Fe}_{3} \mathrm{O}_{4} / \mathrm{rGO}$

Aptamer- $-\mathrm{Fe}_{3} \mathrm{O}_{4} \mathrm{NPs}$

Au-spiked silica-coated iron

oxide spheres

$\mathrm{Fe}_{3} \mathrm{O}_{4} @ \mathrm{Ag}$

Au-coated $\mathrm{MnFe}_{2} \mathrm{O}_{4}$

$\mathrm{Fe}_{3} \mathrm{O}_{4} / \mathrm{Au} \mathrm{NPs}$

Iron magnetic core-gold

plasmonic-shell NPs
Signal amplification label

Target capture and immuno-recognition

3-Mode signal enhancement by the combined effect of

HGNPs, $\mathrm{Ag}$, and $\mathrm{Fe}_{3} \mathrm{O}_{4}$

Signal amplification
Separation of target DNA

Reduced signal based on hairpin structure

Magnetic capture, isolation, and purification of miRNA

Conjugation of $S$. aureus antibody to form sandwichstructured immunoassay

Supporting substrates; enrichment and separation of viruses from a complex matrix

Target-specific antibody conjugation, magnetic

separation, and electromagnetic effect on SERS hotspot
Cytokines

Interleukin (IL-6 and IL-8) \& miRNA (miR-21 and miR-155)

cTnI
IgG
$\operatorname{PrP}^{\mathrm{Sc}}$

$\operatorname{PrP}^{\mathrm{Sc}}$ $\approx 20 \mathrm{pgmL}^{-1}$

IL-6, 28 pM; IL-8, 18 pM; miR-21, 502 fM; and miR-155, $483 \mathrm{fM}$

$$
15 \mathrm{ngmL}^{-1}
$$

326

$0.019-40.00 \mu \mathrm{gmL}^{-1} \quad 267$

$1 \times 10^{-4} \mathrm{ng} / \mathrm{mL}$

\section{SERS}

DNA oligonucleotides

miRNA (let-7b)

Staphylococcus aureus ( $S$. aureus)

AIV

$\beta$ Amyloid

Tau protein
328

$0.3 \mathrm{fM}$

329

10 cells $/ \mathrm{mL}$

$10^{2} \mathrm{TCID}_{50} / \mathrm{mL}$

281

$0.312 \mathrm{ng} / \mathrm{mL}$

$0.15 \mathrm{ng} / \mathrm{mL}$

Abbreviation: TMC: N-trimethyl chitosan; EGFR: epidermal growth factor receptor; PSA: prostate-specific antigens; PrPSc: prion disease-associated isoform; AFP: alpha fetal protein; CEA: carcinoembryonic antigen; ETA: Exotoxin A; PP4VP: plasma-polymerized 4-vinyl pyridine; EV 71: human enterovirus 71; HPV: human papillomavirus; IgG: Immunoglobulin G; TCID 50 : tissue culture infection dose at 50\% endpoint; AIV: avian influenza viruses. 


\section{Point-of-care testing: The impact of superparamagnetic particles}

With the advancement of nanotechnology, miniaturization, and microprocessors, it is now possible to analyze samples (urine, blood, saliva, etc.) in real time while discussing with patients. The combination of the microfluidics, paper fluidics, engineered NPs, and magnetic impact represents the automated, integrated POC system that is relatively simple to use and offers rapid and accurate results with moderately complex equipment. In recent decades, there have been numerous reports on various approaches to integrating MNPs into optical, electrochemical, and piezoelectric biosensing platforms as labels or integrating them into the transducer. ${ }^{331}$ For instance, the use of micro-urine nanoparticles ( $\mu$ UNPDs) for the detection of trace amounts of molecular markers KIM-1 and Cystatin C in urine has been reported. ${ }^{332}$ This technique utilizes an automated on-chip assay followed by screening with a handheld device for the readout. Currently, a lateral-flow immunoassay (LFIA) is considered to be a potent, low-cost detection technique for biomolecules. It is highly advantageous over conventional ELISA, as it offers one-step rapid detection by eliminating multiple additions and washing steps. ${ }^{333}$ The commonly used detecting agents in LFIAs are gold NPs, carbon NPs, and monodisperse latex. Though they give good detection, they lack sensitivity, as the signal generated beneath the surface is missed by conventional optical detectors. MNPs, due to their magnetism and brown color, can give sensitive detection that can easily be read with an optical sensor and quantified by magnetic flow reader. ${ }^{334}$ Recently, Pt-decorated magnetic core-shell nanoparticles (MPt/CS NPs) were demonstrated to integrate into lateral-flow POC immunoassay strips for human chorionic gonadotropin (hCG) using the intrinsic magnetic and enzyme-like properties of MPt/CS NPs. ${ }^{335}$ In this POC device design, MPt/CS NPs conjugated with antibodies (Ab-MPt/CS NPs), followed by the magnetic enrichment of target analytes using Ab-MPt/CS NPs. Ab-MPt/CS NPs capturing target analytes were then applied to the sample pad of lateral-flow immunoassay (LFIA) strips. Ab-MPt/CS NPs containing sufficient 
amounts of target analytes were captured on the T line, whereas the remaining Ab-MPt/CS NPs were captured on the $\mathrm{C}$ line. Finally, a substrate solution was applied to the test pad to obtain amplified signals in $\mathrm{T}$ and $\mathrm{C}$ lines by peroxidase-like reactions mediated by MPt/CS NPs, as shown in Fig. 19. A similar LFIA system has been reported for the detection of EVs isolated from human plasma. ${ }^{336}$ In this report, different materials (colloidal gold, carbon black, and MNPs) as LFIA labels were employed and compared. In all such MNP LFIAs, an external magnetic field is required to magnetize the MNPs to detect them in a corresponding applied field. Lago-Cachón et al. reported a superparamagnetic NP-based radio-frequency lateral-flow assay (RF-LFA) method over the external magnetic field-based MLFA, where the continuous flow of MNPs is measured. ${ }^{337}$ The main benefit of this RF-LFA system over the MNP-based LFA is that it does not require an external magnet-based signal readout. Although the MNPbased LFA offers rapid analysis and a simplified detection system, it is not usually well suited to multiplex analysis of several biomarkers from a particular disease or to discriminate among multiple diseases presenting with similar symptoms.

\section{Step 1: Magnetic enrichment}

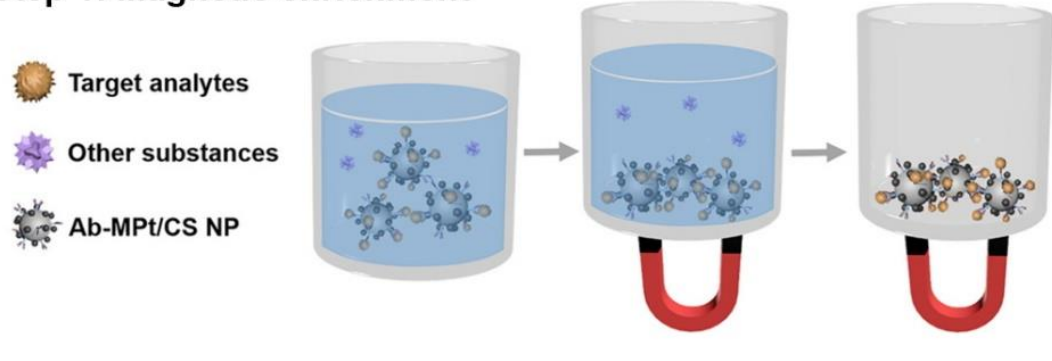

Step 2: Detection using LFIA

Step 3: Nanozyme-mediated signal amplification

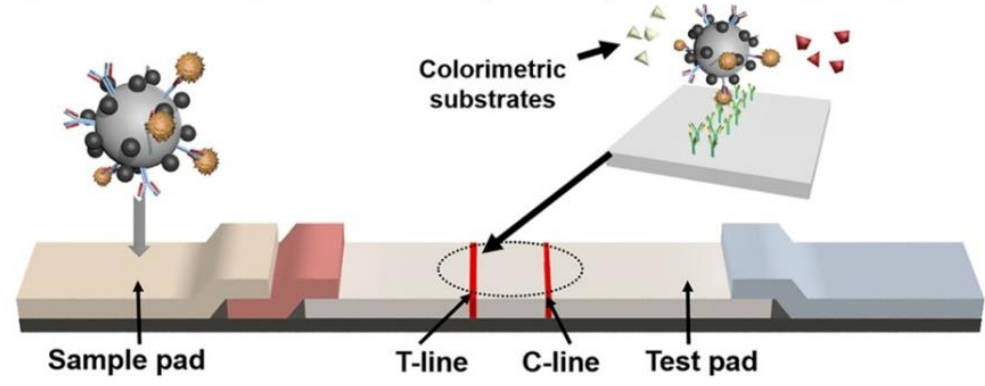


Fig. 19 Schematic demonstration for the detection of human hCG using magnetic nanozymebased LFIA strips. Reproduced with permission. ${ }^{335}$

An easy-to-use, rapid POC system that could detect multiple biomarkers simultaneously and enable the differentiation of disease states would be highly beneficial for in-field diagnostics of outbreaks of infectious diseases. Recently, an immunoassay technology was reported in which the benefit of MNPs is integrated with SERS readout system to enable the detection of three disease-specific antigens from Ebola, Lassa, and malaria from a single blood sample. ${ }^{338}$ In this immunoassay system, disease-specific antibodies were conjugated with both the SERS nanotags and a magnetic microparticle and stored in a tube (either liquid or dried stage) (Fig. 20). Upon the addition of a blood sample, a sandwich was formed containing a magnetic particle-target antigen-SERS tag followed by a magnetic pull to separate the sandwich and bring them to the side of the reaction tube. A laser was exposed outside the tube to illuminate the sidewall corresponding to the SERS tag in the sample. As different Raman reporters were integrated, different SERS spectra (Fig. 20(B)), each with a unique optical "fingerprint," represent each nanotag (proportional to the level of antigen in the blood sample). This POC diagnostic is highly advantageous because it does not require any washing steps, the antibody-modified magnetic particles and SERS tags can be prepackaged, and it is highly suitable for in-field testing. Though several POC systems integrating MNPs (either carrier, magnetic separation, isolation, magnetic focus, or signaling label), LFAs, or an immunoassay system and/or PCR amplification with different readouts (SERS, NMR, or colorimetry) have been reported (Table 2), most of them require antibody functionalization, three-step sandwich formation (using capture and detection antibodies), and a complicated readout system. ${ }^{339-346}$ Table 2 summarizes the recently reported (since 2016) magnetic nanostructure-based POC 
systems for clinics. Therefore, magnetic nanostructures that would not need any further antibody functionalization or a complex readout strategy yet to be performed and highly desirable for future diagnostics in clinics.
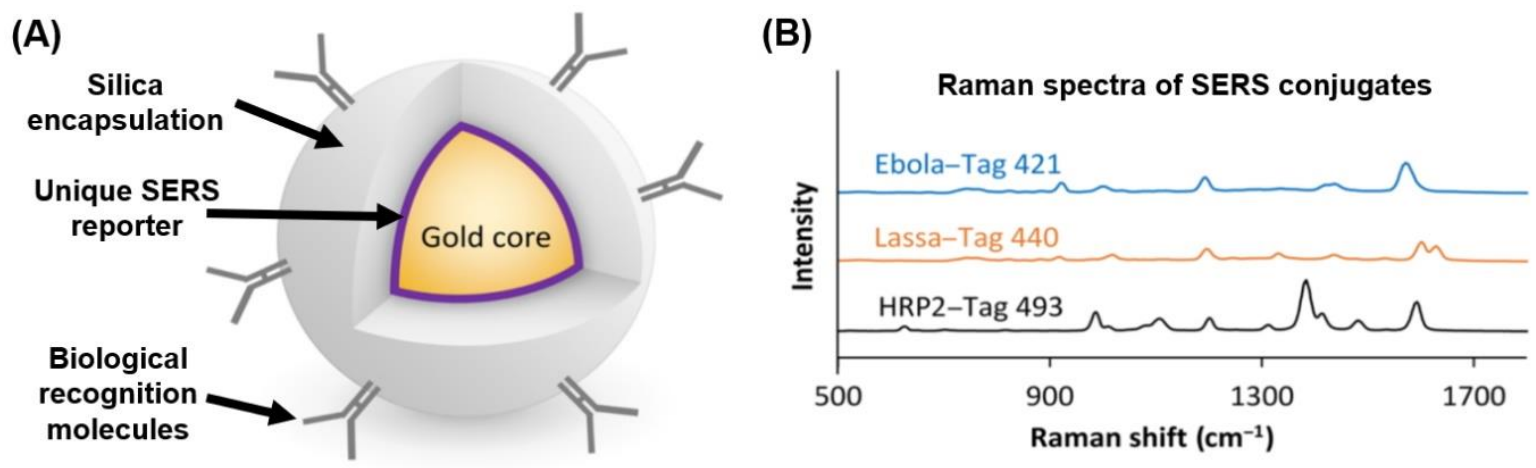

(C)

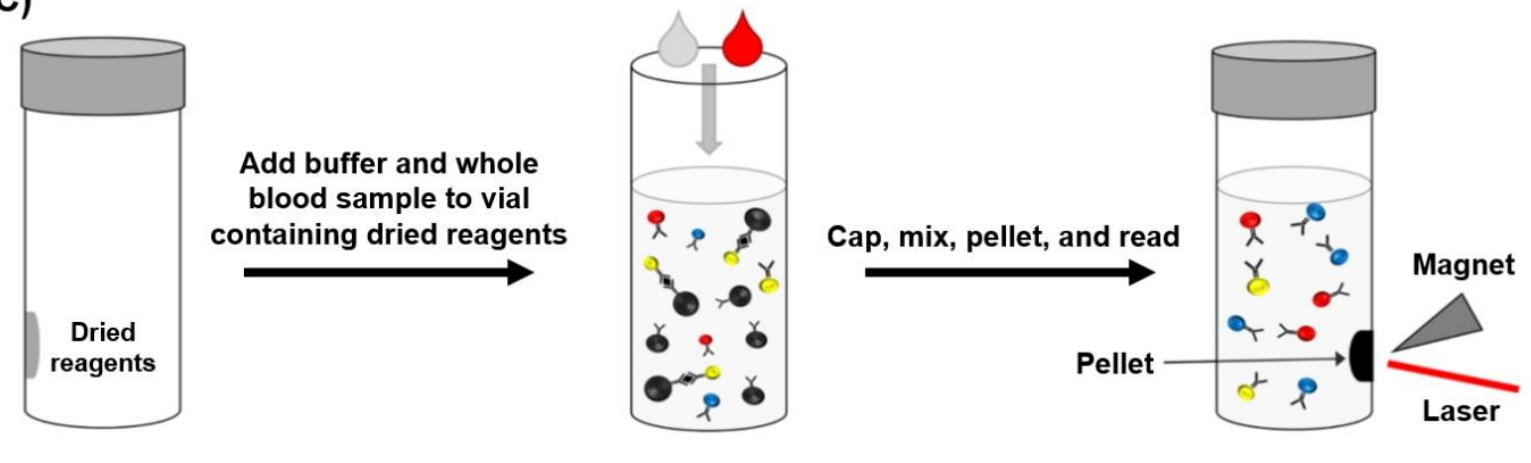

Fig. 20 Schematic representation of the detection of Ebola, Lassa, and malaria using magnetic particles and SERS nanotags. (A) Depiction of SERS nanotag technology. (B) Characteristic spectra from three SERS nanotags specific to the Ebola, Lassa, and malaria histidine-rich protein 2 (HRP2) antigen. (C) Representation of the homogeneous no-wash (HNW) sandwich immunoassay using magnetic particles and SERS nanotags. Reproduced with permission. ${ }^{338}$ 
Table 2. Magnetic nanostructure-based POC diagnostic system for rapid analysis of disease biomarkers

\begin{tabular}{|c|c|c|c|c|c|c|}
\hline $\begin{array}{c}\text { Magnetic } \\
\text { nanostructure }\end{array}$ & Functions & Target biomolecule & $\begin{array}{l}\text { Analyte } \\
\text { volume }\end{array}$ & $\begin{array}{c}\text { Assay } \\
\text { duration }\end{array}$ & Detection limit & Ref \\
\hline $\begin{array}{l}\mathrm{Fe}_{3} \mathrm{O}_{4}-\mathrm{QD} \text { magnetic } \\
\text { nanosphere }\end{array}$ & $\begin{array}{c}\text { Magnetic separations } \\
\text { Magnetic signal (readout) label }\end{array}$ & Antigens from $S$. typhi & $1 \mathrm{~mL}$ & $35 \mathrm{~min}$ & $3.75 \times 10^{3} \mathrm{CFU} / \mathrm{mL}$ & 347 \\
\hline MNPs & $\begin{array}{c}\text { Signaling probe carrier } \\
\text { NMR readout }\end{array}$ & $\begin{array}{c}\text { kim-1 } \\
\text { Cystain C }\end{array}$ & - & - & $\begin{array}{l}0.1 \mathrm{ng} / \mathrm{mL} \\
20 \mathrm{ng} / \mathrm{mL}\end{array}$ & 332 \\
\hline MNPs & $\begin{array}{l}\text { Sandwich structure formation } \\
\text { Magnetic support for SERS tag }\end{array}$ & $\begin{array}{c}\text { Antigens from EBOV, LASV, } \\
\text { and malaria }\end{array}$ & $45 \mu \mathrm{L}$ & $30 \mathrm{~min}$ & $\begin{array}{c}10^{5} \text { to } \\
10^{6} \mathrm{PFU} / \mathrm{ml}\end{array}$ & 338 \\
\hline $\begin{array}{l}\text { Magnetic } \\
\text { beads }\end{array}$ & Magnet-drive fluid mixing & Hendra virus & - & $15 \mathrm{~min}$ & $0.48 \mathrm{ng} / \mathrm{mL}$ & 339 \\
\hline Magnetic beads & $\begin{array}{c}\text { Support of hybridization between capture } \\
\text { probe and DNA } \\
\text { Magnetic capture and purification }\end{array}$ & Foodborne pathogens & - & - & $10 \mathrm{CFU} / \mathrm{mL}$ & 340 \\
\hline $\begin{array}{l}\mathrm{Fe}_{3} \mathrm{O}_{4} \text { core }-\mathrm{Au} \text { shell } \\
\text { nanoprobe }\end{array}$ & $\begin{array}{l}\text { Magnetic capture of analyte } \\
\text { Magnetic focus zone }\end{array}$ & $\begin{array}{l}\text { Valosin-containing proteins } \\
\text { (VCPs) }\end{array}$ & $100 \mu \mathrm{L}$ & $1 \mathrm{hr} 40 \mathrm{~min}$ & $25 \mathrm{fg} / \mathrm{mL}$ & 341 \\
\hline MNPs & Sandwich structure formation & $\begin{array}{l}\text { Acute myocardial infraction } \\
\text { (AMI) }\end{array}$ & $80 \mu \mathrm{L}$ & $20 \mathrm{~min}$ & $0.014 \mathrm{miu} / \mathrm{mL}$ & 342 \\
\hline $\mathrm{Fe}_{3} \mathrm{O}_{4} / \mathrm{Au} / \mathrm{Fe}_{3} \mathrm{O}_{4}$ & Support of PCR amplification & Genomic DNA & & $5 \mathrm{~min}$ & $5 \mathrm{ng}$ & 343 \\
\hline Magnetic beads & $\begin{array}{l}\text { Magnetic field-based protein } \\
\text { preconcentration } \\
\text { Magnetic focus of target }\end{array}$ & Troponin & $100 \mu \mathrm{L}$ & $15 \mathrm{~min}$ & $1 \mathrm{ng} / \mathrm{mL}$ & 344 \\
\hline $\mathrm{Fe}_{3} \mathrm{O}_{4} / \mathrm{SiO}_{2} / \mathrm{QDs}$ & $\begin{array}{l}\text { Magnetic separation of target } \\
\text { Fluorescent label }\end{array}$ & Clenbuterol & $0.3 \mathrm{~mL}$ & - & $0.16 \mathrm{ng} / \mathrm{mL}$ & 345 \\
\hline
\end{tabular}




\begin{tabular}{|c|c|c|c|c|c|c|}
\hline $\begin{array}{c}\mathrm{PAA}-\mathrm{Fe}_{3} \mathrm{O}_{4} \\
\text { Nanocrystal clusters }\end{array}$ & Signaling label & NT-proBNP protein & $70 \mu \mathrm{L}$ & $40 \mathrm{~min}$ & $100 \mathrm{pg} / \mathrm{mL}$ & 346 \\
\hline SMNPs & Signaling label for magnetic signals & Unconjugated estriol $\left(\mu \mathrm{E}_{3}\right)$ & $100 \mu \mathrm{L}$ & $15 \mathrm{~min}$ & $0.86 \mathrm{nmol} / \mathrm{L}$ & 348 \\
\hline $\begin{array}{l}\mathrm{Fe}_{3} \mathrm{O}_{4} / \mathrm{Au} \text { core-shell } \\
\text { nanoprobes }\end{array}$ & $\begin{array}{l}\text { Modification of pathogen-specific antibodies } \\
\text { to control the movement of the captured } \\
\text { bacteria at the detection zone }\end{array}$ & $\begin{array}{l}\text { E. coli } \mathrm{O} 157: \mathrm{H} 7 \\
\text { S. typhimurium }\end{array}$ & $100 \mu \mathrm{l}$ & $30 \mathrm{~min}$ & $\begin{array}{l}\sim 23 \mathrm{CFU} \\
\text { per ml } \\
\sim 17 \mathrm{CFU} \\
\text { per ml }\end{array}$ & 349 \\
\hline Au MNPs (GMNPs) & $\begin{array}{l}\text { Antibody functionalization and magnetic } \\
\text { readout }\end{array}$ & $\begin{array}{l}\text { Single nucleotide } \\
\text { polymorphisms (SNPs) }\end{array}$ & $\begin{array}{l}3 \mu \mathrm{L} \\
\text { genomic } \\
\text { DNA }\end{array}$ & $5 \mathrm{~min}$ & $\begin{array}{l}0.04 \mathrm{pg} / \mu \mathrm{L} \text { with } \\
\text { plasmid }\end{array}$ & 350 \\
\hline
\end{tabular}




\section{Future perspectives and conclusion}

The requirements of ultrasensitive detection of biomolecules with low concentration and miniaturized biosensing have made the engineering of MNPs in the synthesis, biofunctionalization, and direct application onto a sensor platform the hottest direction in current research. As discussed in this review, many nanotechnological biosensing applications have been reported in both academic research and commercial products over the last two decades. Magnetism properties have been used to capture and isolate the target analytes from a complex biomatrix, therefore reducing the presence of nonspecific biomolecules in the sensors. The application of MNPs in biosensing has broadened when it has been capable of functionalizing with different biomolecules through covalent and noncovalent interactions. The biofunctional MNPs can be used as capturing agents, tracers, carriers, signal generators, signal enhancers, catalysts, and optical emitters. The intrinsic peroxidase-mimicking properties of MNPs have also been widely used in sensor design, and this has opened a broader window of catalysis and replace natural enzymes. These excellent and unique physicochemical properties make MNPs a superior choice for electronic, optical, and optoelectronic biosensor design for the detection of cells, nucleic acid, proteins, extracellular vesicles, and pathogens. Additionally, the nanodimension and favorable size of biomolecules may facilitate progress toward advanced uses in point-of-care diagnostics and clinics. In this review, we have summarized recently reported (2015 to 2019) remarkable achievements in the application of magnetic nanostructures for the development of electrochemical and optical biosensors and POC diagnostics. Moreover, with a brief focus on MNPs and their synthesis, biofunctionalization, and intrinsic properties required for advanced biosensing, this review has described the challenges involved in current MNP-based detection approaches and has offered an outlook on where imminent developments may be focused. 
The advances in (superpara-) magnetic, nanostructure-based, disease-specific biomarker quantification reported in recent scientific literature are a sign of flourishing research, though a great deal of work still needs to be performed to make it suitable for a pointof-care platform; (i) The stability of SMNPs in the aqueous system (e.g., different buffer) still needs to be considered, as many biosensors are based on an aggregation of MNPs; (ii) biomolecules are radially highly sensitive to environmental stress, and they require certain physiological conditions; thus a higher degree of MNP biocompatibility is required. To biofunctionalize them, a variety of ligands, polymers, enzymes, and inorganic materials have been employed. Though these functionalizations enable them to be used for biosensing, the half-life of biomolecule-MNP complexes is still low. Another restraint of such functionalization is that the functional molecules cover the core magnetic molecules, hence interfering with the magnetic susceptibility of MNPs. (iii) Two or more nanostructures are generally combined to achieve functional magnetic nanostructures that have large surface areas, are high loading, are magnetic, and have signal transduction and enhancement capacity as well as disease-specific biomolecule binding sites. Single-step magnetic nanostructure synthesis with in situ probe functionalization and easy signal transduction and readout (electrochemical or optical) could also be considered for future magnetic nanostructure-based diagnostics for clinics.

\section{Conflicts of interest}

The authors declare no conflicts of interest. 


\section{References}

1. H. Heyn and M. Esteller, Nat. Rev. Genet, 2012, 13, 679-692.

2. D. Sayed and M. Abdellatif, Physiol. Rev., 2011, 91, 827-887.

3. P. A. Jones and S. B. Baylin, Nat. Rev. Genet, 2002, 3, 415-428.

4. P. S. Mitchell, R. K. Parkin, E. M. Kroh, B. R. Fritz, S. K. Wyman, E. L. PogosovaAgadjanyan, A. Peterson, J. Noteboom, K. C. O'Briant and A. Allen, Proc. Natl. Acad. Sci. U.S.A., 2008, 105, 10513-10518.

5. E. Van der Pol, A. Böing, E. Gool and R. Nieuwland, J. Thromb. Haemost., 2016, 14, 48-56.

6. M. Labib, E. H. Sargent and S. O. Kelley, Chem. Rev, 2016, 116, 9001-9090.

7. J. S. Mattick, FEBS Lett., 2011, 585, 1600-1616.

8. R. R. Sinden, DNA structure and function, Elsevier, 2012.

9. J. Zhang, S. Li, L. Li, M. Li, C. Guo, J. Yao and S. Mi, Genomics Proteomics Bioinformatics, 2015, 13, 17-24.

10. T. K. Wojdacz, T. H. Møller, B. B. Thestrup, L. S. Kristensen and L. L. Hansen, Expert Rev. Mol. Diagn., 2010, 10, 575-580.

11. K. Srinivasan, L. Shiue, J. D. Hayes, R. Centers, S. Fitzwater, R. Loewen, L. R. Edmondson, J. Bryant, M. Smith and C. Rommelfanger, Methods, 2005, 37, 345-359.

12. S. Fleige and M. W. Pfaffl, Mol. Aspects Med., 2006, 27, 126-139.

13. F. Ozsolak and P. M. Milos, Nat. Rev. Genet, 2011, 12, 87-98.

14. M. P. Ebert, M. Korc, P. Malfertheiner and C. Röcken, J. Proteome Res. , 2006, 5, 1925.

15. W.-C. Law, K.-T. Yong, A. Baev and P. N. Prasad, ACS Nano, 2011, 5, 4858-4864.

16. M. Culha, D. Stokes, L. R. Allain and T. Vo-Dinh, Anal. Chem., 2003, 75, 6196-6201. 
17. J. Yang, G. Xu, H. Kong, Y. Zheng, T. Pang and Q. Yang, J. Chromatogr. B, 2002, 780, 27-33.

18. W. Kolch, C. Neusüß, M. Pelzing and H. Mischak, Mass Spectrom. Rev., 2005, 24, 959977.

19. J. Wang, Biosens. Bioelectron., 2006, 21, 1887-1892.

20. T. Hossain, G. Mahmudunnabi, M. K. Masud, M. N. Islam, L. Ooi, K. Konstantinov, M. S. Al Hossain, B. Martinac, G. Alici and N.-T. Nguyen, Biosens. Bioelectron., 2017, 94, 63-73.

21. M. N. Islam, M. K. Masud, M. H. Haque, M. S. A. Hossain, Y. Yamauchi, N. T. Nguyen and M. J. Shiddiky, Small Methods, 2017, 1, 1700131.

22. J. J. Maurer, Annu. Rev. Food. Sci. Technol., 2011, 2, 259-279.

23. G. R. Cooper, Standard Methods of Clinical Chemistry: By the American Association of Clinical Chemists, Elsevier, 2013.

24. G. Chen, I. Roy, C. Yang and P. N. Prasad, Chem. Rev., 2016, 116, 2826-2885.

25. A. B. Steel, T. M. Herne and M. J. Tarlov, Anal. Chem., 1998, 70, 4670-4677.

26. J. Shi and D. M. Porterfield, in Biosensors-Emerging Materials and Applications, InTech, 2011.

27. J. Li, S. N. Tan and H. Ge, Anal. Chim. Acta., 1996, 335, 137-145.

28. J. S. Beveridge, J. R. Stephens and M. E. Williams, Annu. Rev. Anal. Chem., 2011, 4, 251-273.

29. L. H. Reddy, J. L. Arias, J. Nicolas and P. Couvreur, Chem. Rev., 2012, 112, 58185878.

30. M. K. Masud, J. Kim, M. M. Billah, K. Wood, M. J. Shiddiky, N.-T. Nguyen, R. K. Parsapur, Y. V. Kaneti, A. A. Alshehri and Y. G. Alghamidi, J. Mater. Chem. B, 2019, 7, 5412-5422. 
31. M. Colombo, S. Carregal-Romero, M. F. Casula, L. Gutiérrez, M. P. Morales, I. B. Böhm, J. T. Heverhagen, D. Prosperi and W. J. Parak, Chem. Soc. Rev., 2012, 41, 43064334.

32. T. Neuberger, B. Schöpf, H. Hofmann, M. Hofmann and B. Von Rechenberg, J. Magn. Magn. Mater., 2005, 293, 483-496.

33. R. Banerjee, Y. Katsenovich, L. Lagos, M. Mclintosh, X. Zhang and C.-Z. Li, Curr. Med. Chem., 2010, 17, 3120-3141.

34. S. Zhang, R. Geryak, J. Geldmeier, S. Kim and V. V. Tsukruk, Chem. Rev., 2017, 117, 12942-13038.

35. A. Chen and S. Chatterjee, Chem. Soc. Rev., 2013, 42, 5425-5438.

36. D. Quesada-González and A. Merkoçi, Chem. Soc. Rev., 2018, 47, 4697-4709.

37. S. Mishra, S. Sharma, M. Javed, F. Pottoo, M. B. Abul, M. Amir and M. Sarfaroz, Pharm. Nanotechnol., 2019.

38. X. Zhu, J. Li, H. He, M. Huang, X. Zhang and S. Wang, Biosens. Bioelectron., 2015, 74, 113-133.

39. N. Xia and L. Zhang, Materials, 2014, 7, 5366-5384.

40. M. K. Masud, S. Yadav, M. N. Islam, N. T. Nguyen, C. Salomon, R. Kline, H. R. Alamri, Z. A. Alothman, Y. Yamauchi, M. S. A. Hossain and M. J. A. Shiddiky, Anal. Chem., 2017, 89, 11005-11013.

41. V. Urbanova, M. Magro, A. Gedanken, D. Baratella, F. Vianello and R. Zboril, Chem. Mater., 2014, 26, 6653-6673.

42. A. Azhar, Y. Li, Z. Cai, M. B. Zakaria, M. K. Masud, M. S. A. Hossain, J. Kim, W. Zhang, J. Na and Y. Yamauchi, Bull. Chem. Soc. Jpn., 2019, 92, 875-904.

43. R. Hao, R. Xing, Z. Xu, Y. Hou, S. Gao and S. Sun, Adv. Mater., 2010, 22, 2729-2742.

44. J. D. Ryckman, M. Liscidini, J. Sipe and S. Weiss, Nano Lett., 2010, 11, 1857-1862. 
45. M. K. Masud, M. N. Islam, M. H. Haque, S. Tanaka, V. Gopalan, G. Alici, N.-T. Nguyen, A. K. Lam, M. S. A. Hossain and Y. Yamauchi, Chem. Commun., 2017, 53, 8231-8234.

46. Q. Wei, F. Xiong, S. Tan, L. Huang, E. H. Lan, B. Dunn and L. Mai, Adv. Mater., 2017, 29, 1602300.

47. J. Liu, S. Z. Qiao, Q. H. Hu and G. Q. Lu, Small, 2011, 7, 425-443.

48. A. H. Lu, E. e. L. Salabas and F. Schüth, Angew. Chem. Int. Ed., 2007, 46, 1222-1244.

49. C. Zhu, G. Yang, H. Li, D. Du and Y. Lin, Anal. Chem., 2014, 87, 230-249.

50. Z. Xi, H. Ye and X. Xia, Chem. Mater., 2018, 30, 8391-8414.

51. S. Devi and V. Tharmaraj, in Advanced Nanostructured Materials for Environmental Remediation, Springer, 2019, 91-110.

52. H. M. Yadav and S. V. Otari, in Hybrid Nanostructures for Cancer Theranostics, Elsevier, 2019, 159-172.

53. G. Reina, J. M. González-Domínguez, A. Criado, E. Vázquez, A. Bianco and M. Prato, Chem. Soc. Rev., 2017, 46, 4400-4416.

54. S. Kumar, R. Rani, N. Dilbaghi, K. Tankeshwar and K.-H. Kim, Chem. Soc. Rev., 2017, 46, 158-196.

55. Y. Xu, X. Wang, W. L. Zhang, F. Lv and S. Guo, Chem. Soc. Rev., 2018, 47, 586-625.

56. M. K. Masud, M. Umer, M. S. A. Hossain, Y. Yamauchi, N.-T. Nguyen and M. J. Shiddiky, Trends Biochem. Sci, 2019, 44, 433-452.

57. J. Wang, Q. Ma, Y. Wang, Z. Li, Z. Li and Q. Yuan, Chem. Soc. Rev., 2018, 47, 87668803.

58. R. Massart, IEEE Trans. Magn., 1981, 17, 1247-1248.

59. W. Wu, Q. He and C. Jiang, Nanoscale Res. Lett., 2008, 3, 397-415.

60. T. Sugimoto and E. Matijević, J. Colloid Interface Sci., 1980, 74, 227-243. 
61. S. Wu, A. Sun, F. Zhai, J. Wang, W. Xu, Q. Zhang and A. A. Volinsky, Mater. Lett., 2011, 65, 1882-1884.

62. C. Pereira, A. M. Pereira, C. Fernandes, M. Rocha, R. Mendes, M. P. Fernández-García, A. Guedes, P. B. Tavares, J.-M. Grenèche and J. o. P. Araújo, Chem. Mater., 2012, 24, 1496-1504.

63. O. Karaagac, B. B. Yildiz and H. Köçkar, J. Magn. Magn. Mater., 2019, 473, $262-$ 267.

64. I. Y. Goon, C. Zhang, M. Lim, J. J. Gooding and R. Amal, Langmuir, 2010, 26, 1224712252.

65. S. K. Suh, K. Yuet, D. K. Hwang, K. W. Bong, P. S. Doyle and T. A. Hatton, J. Am. Chem. Soc., 2012, 134, 7337-7343.

66. W. Wu, Z. Wu, T. Yu, C. Jiang and W.-S. Kim, Sci. Technol. Adv. Mater, 2015, 16, 023501

67. J. Park, K. An, Y. Hwang, J.-G. Park, H.-J. Noh, J.-Y. Kim, J.-H. Park, N.-M. Hwang and T. Hyeon, Nat. Mater., 2004, 3, 891-895.

68. A. Ali, M. Z. Hira Zafar, I. ul Haq, A. R. Phull, J. S. Ali and A. Hussain, Nanotechnol. Sci. Appl., 2016, 9, 49-67.

69. W. Xie, Z. Guo, F. Gao, Q. Gao, D. Wang, B.-s. Liaw, Q. Cai, X. Sun, X. Wang and L. Zhao, Theranostics, 2018, 8, 3284

70. S. Majidi, F. Zeinali Sehrig, S. M. Farkhani, M. Soleymani Goloujeh and A. Akbarzadeh, Artif. Cells. Nanomed. Biotechnol., 2016, 44, 722-734.

71. B. D. Stojanovic, A. S. Dzunuzovic and N. I. Ilic, in Magnetic, Ferroelectric, and Multiferroic Metal Oxides, Elsevier, 2018, pp. 333-359.

72. F. Del Monte, M. Morales, D. Levy, A. Fernandez, M. Ocana, A. Roig, E. Molins, K. O'Grady and C. Serna, Langmuir, 1997, 13, 3627-3634. 
73. I. Khan, K. Saeed and I. Khan, Arab. J. Chem., 2017.

74. A. K. Gupta and M. Gupta, Biomaterials, 2005, 26, 3995-4021.

75. A. Huczko, Appl. Phys. A, 2000, 70, 365-376.

76. T. Wade and J.-E. Wegrowe, Eur. Phys. J-Appl. Phys., 2005, 29, 3-22.

77. A. Thomas, F. Goettmann and M. Antonietti, Chem. Mater., 2008, 20, 738-755.

78. H. Wu, G. Wu, Y. Ren, X. Li and L. Wang, Chem.: Eur. J., 2016, 22, 8864-8871.

79. M. Sasidharan, D. Liu, N. Gunawardhana, M. Yoshio and K. Nakashima, J. Mater. Chem., 2011, 21, 13881-13888.

80. Y. Tang, Y. Chen, P. Zhou, Y. Zhou, L. Lu, J. Bao and T. Lu, J. Solid State Electrochem., 2010, 14, 2077-2082.

81. Q. Liu, H. Liu, M. Han, J. Zhu, Y. Liang, Z. Xu and Y. Song, Adv. Mater., 2005, 17, 1995-1999.

82. G.-H. Wang, Q. Sun, R. Zhang, W.-C. Li, X.-Q. Zhang and A.-H. Lu, Chem. Mater., $2011,23,4537-4542$.

83. R. Purbia and S. Paria, Nanoscale, 2015, 7, 19789-19873.

84. Q. Sun, C. Z. Guo, G. H. Wang, W. C. Li, H. J. Bongard and A. H. Lu, Chem.: Eur. J., 2013, 19, 6217-6220.

85. B. Wang, G. Wang and H. Wang, Electrochim. Acta, 2015, 156, 1-10.

86. Y. Xiang, S. Lu and S. P. Jiang, Chem. Soc. Rev., 2012, 41, 7291-7321.

87. H. Kamata, X. Li, U.-i. Chung and T. Sakai, Adv Healthc. Mater., 2015, 4, 2360-2374.

88. G. Prieto, H. Tüysüz, N. Duyckaerts, J. Knossalla, G.-H. Wang and F. Schüth, Chem. Rev., 2016, 116, 14056-14119.

89. Y. Liu, J. Goebl and Y. Yin, Chem. Soc. Rev., 2013, 42, 2610-2653.

90. J. Liu and C. Wöll, Chem. Soc. Rev., 2017, 46, 5730-5770. 
91. M. Hu, A. A. Belik, M. Imura, K. Mibu, Y. Tsujimoto and Y. Yamauchi, Chem. Mater., 2012, 24, 2698-2707.

92. M. Hu, J.-S. Jiang and Y. Zeng, Chem. Commun., 2010, 46, 1133-1135.

93. Y. D. Chiang, M. Hu, Y. Kamachi, S. Ishihara, K. Takai, Y. Tsujimoto, K. Ariga, K. C. W. Wu and Y. Yamauchi, Eur. J. Inorg. Chem., 2013, 2013, 3141-3145.

94. H. Zeng and S. Sun, Adv. Funct. Mater., 2008, 18, 391-400.

95. N. V. S. Vallabani and S. Singh, 3 Biotech, 2018, 8, 279-279.

96. S. M. Silva, R. Tavallaie, L. Sandiford, R. D. Tilley and J. J. Gooding, Chem. Commun., 2016, 52, 7528-7540.

97. P. Hu, S. Zhang, T. Wu, D. Ni, W. Fan, Y. Zhu, R. Qian and J. Shi, Adv. Mater., 2018, 30, 1801690.

98. K. C.-F. Leung, S. Xuan, X. Zhu, D. Wang, C.-P. Chak, S.-F. Lee, W. K.-W. Ho and B. C.-T. Chung, Chem. Soc. Rev., 2012, 41, 1911-1928.

99. N. Erathodiyil and J. Y. Ying, Acc. Chem. Res., 2011, 44, 925-935.

100. S. F. Chin, K. S. Iyer and C. L. Raston, Cryst. Growth Des., 2009, 9, 2685-2689.

101. H. Teymourian, A. Salimi and S. Khezrian, Biosens. Bioelectron., 2013, 49, 1-8.

102. S. Wu, Q. He, C. Zhou, X. Qi, X. Huang, Z. Yin, Y. Yang and H. Zhang, Nanoscale, $2012,4,2478-2483$.

103. S. Tanaka, R. R. Salunkhe, Y. V. Kaneti, V. Malgras, S. M. Alshehri, T. Ahamad, M. B. Zakaria, S. X. Dou, Y. Yamauchi and M. S. A. Hossain, RSC Advances, 2017, 7, 33994-33999.

104. Y. Cao, Fuller. Nanotub. Car. N., 2015, 23, 623-626.

105. L. Xu, H.-W. Liang, Y. Yang and S.-H. Yu, Chem. Rev., 2018, 118, 3209-3250.

106. V. F. Cardoso, A. Francesko, C. Ribeiro, M. Bañobre-López, P. Martins and S. Lanceros-Mendez, Adv.Healthc. Mater., 2018, 7, 1700845. 
107. X. Huang, A. Schmucker, J. Dyke, S. M. Hall, J. Retrum, B. Stein, N. Remmes, D. V. Baxter, B. Dragnea and L. M. Bronstein, J. Mater. Chem., 2009, 19, 4231-4239.

108. M. Shen, H. Cai, X. Wang, X. Cao, K. Li, S. H. Wang, R. Guo, L. Zheng, G. Zhang and X. Shi, Nanotechnology, 2012, 23, 105601.

109. D. Li, D. Jiang, M. Chen, J. Xie, Y. Wu, S. Dang and J. Zhang, Mater. Lett., 2010, 64, $2462-2464$.

110. L. Lartigue, K. Oumzil, Y. Guari, J. Larionova, C. Guérin, J.-L. Montero, V. BarraganMontero, C. Sangregorio, A. Caneschi and C. Innocenti, Org. Lett., 2009, 11, 29922995.

111. R. Chalasani and S. Vasudevan, J. Mater. Chem., 2012, 22, 14925-14931.

112. J. Gao, X. Ran, C. Shi, H. Cheng, T. Cheng and Y. Su, Nanoscale, 2013, 5, 7026-7033.

113. M. Lattuada and T. A. Hatton, Langmuir, 2007, 23, 2158-2168.

114. R. Ghosh Chaudhuri and S. Paria, Chem. Rev., 2011, 112, 2373-2433.

115. J. K. Oh and J. M. Park, Prog. Polym. Sci., 2011, 36, 168-189.

116. H. El-Sherif, M. El-Masry and H. S. Emira, J. Macromol. Sci. A., 2010, 47, 1096-1103.

117. N. Pimpha, S. Chaleawlert-umpon and P. Sunintaboon, Polymer, 2012, 53, 2015-2022.

118. P. A. Jarzyna, T. Skajaa, A. Gianella, D. P. Cormode, D. D. Samber, S. D. Dickson, W. Chen, A. W. Griffioen, Z. A. Fayad and W. J. Mulder, Biomaterials, 2009, 30, 69476954.

119. I. I. Lungu, M. Radulescu, G. D. Mogosanu and A. M. Grumezescu, Rom. J. Morphol. Embryol., 2016, 57, 23-32.

120. M. Ghorbani, H. Hamishehkar, N. Arsalani and A. A. Entezami, J. Nanopart. Res., $2015,17,305$.

121. S. Dai, P. Ravi and K. C. Tam, Soft Matter, 2008, 4, 435-449. 
122. S. G. Grancharov, H. Zeng, S. Sun, S. X. Wang, S. O'Brien, C. Murray, J. Kirtley and G. Held, J. Phys. Chem. B, 2005, 109, 13030-13035.

123. C.-C. You, M. De and V. M. Rotello, Curr. Opin. Chem. Biol., 2005, 9, 639-646.

124. E. Katz and I. Willner, Angew. Chem. Int. Ed. Engl., 2004, 43, 6042-6108.

125. X.-R. Song, N. Goswami, H.-H. Yang and J. Xie, Analyst, 2016, 141, 3126-3140.

126. C. Lee, K. Huang, P. Wei and Y. Yao, J. Magn. Magn. Mater, 2006, 304, e412-e414.

127. J. R. McCarthy and R. Weissleder, Adv. Drug Deliv. Rev., 2008, 60, 1241-1251.

128. O. Veiseh, C. Sun, C. Fang, N. Bhattarai, J. Gunn, F. Kievit, K. Du, B. Pullar, D. Lee and R. G. Ellenbogen, Cancer Res., 2009, 69, 6200-6207.

129. S. Laurent, D. Forge, M. Port, A. Roch, C. Robic, L. Vander Elst and R. N. Muller, Chem. Rev., 2008, 108, 2064-2110.

130. K. Kluchova, R. Zboril, J. Tucek, M. Pecova, L. Zajoncova, I. Safarik, M. Mashlan, I. Markova, D. Jancik and M. Sebela, Biomaterials, 2009, 30, 2855-2863.

131. G. Wang, L. Jin, Y. Dong, L. Niu, Y. Liu, F. Ren and X. Su, New J. Chem., 2014, 38, 700-708.

132. G. S. Gowd, M. K. Patra, M. Mathew, A. Shukla, S. Songara, S. R. Vadera and N. Kumar, Opt. Mater. , 2013, 35, 1685-1692.

133. K. M. Koo, A. A. Sina, L. G. Carrascosa, M. J. Shiddiky and M. Trau, Anal. Methods, $2015,7,7042-7054$.

134. M. H. Haque, V. Gopalan, M. N. Islam, M. K. Masud, R. Bhattacharjee, M. S. Al Hossain, N.-T. Nguyen, A. K. Lam and M. J. Shiddiky, Anal. Chim. Acta., 2017, 976, 84-93.

135. O. Hosu, A. Florea, C. Cristea and R. Sandulescu, in Advanced Biosensors for Health Care Applications, Elsevier, 2019, 171-207. 
136. D. K. Yi, S. T. Selvan, S. S. Lee, G. C. Papaefthymiou, D. Kundaliya and J. Y. Ying, J. Am. Chem. Soc., 2005, 127, 4990-4991.

137. W. Stöber, A. Fink and E. Bohn, J. Colloid. Interface Sci., 1968, 26, 62-69.

138. S.-h. Xuan, S.-F. Lee, J. T.-F. Lau, X. Zhu, Y.-X. J. Wang, F. Wang, J. M. Lai, K. W. Sham, P.-C. Lo and J. C. Yu, ACS Appl. Mater. Interfaces, 2012, 4, 2033-2040.

139. J.-N. Park, P. Zhang, Y.-S. Hu and E. W. McFarland, Nanotechnology, 2010, 21, 225708.

140. Y. Li, Y. Hu, H. Jiang and C. Li, Nanoscale, 2013, 5, 5360-5367.

141. H. P. Cong, J. J. He, Y. Lu and S. H. Yu, Small, 2010, 6, 169-173.

142. E. C. Dreaden, A. M. Alkilany, X. Huang, C. J. Murphy and M. A. El-Sayed, Chem. Soc. Rev., 2012, 41, 2740-2779.

143. J. Zhang, A. Thurber, C. Hanna and A. Punnoose, Langmuir, 2009, 26, 5273-5278.

144. L. Wang, J. Luo, M. M. Maye, Q. Fan, Q. Rendeng, M. H. Engelhard, C. Wang, Y. Lin and C.-J. Zhong, J. Mater. Chem., 2005, 15, 1821-1832.

145. W. Wu, S. Zhang, X. Xiao, J. Zhou, F. Ren, L. Sun and C. Jiang, ACS Appl. Mater. Interfaces, 2012, 4, 3602-3609.

146. L. Sun, W. Wu, S. Zhang, Y. Liu, X. Xiao, F. Ren, G. Cai and C. Jiang, J. Nanosci. Nanotechnol., 2013, 13, 5428-5433.

147. S.-K. Li, F.-Z. Huang, Y. Wang, Y.-H. Shen, L.-G. Qiu, A.-J. Xie and S.-J. Xu, J. Mater. Chem., 2011, 21, 7459-7466.

148. L. Liu, L. Xiao, H.-Y. Zhu and X.-W. Shi, J. Nanopart. Res., 2013, 15, 1394.

149. Y. Li, Y. Liu, J. Tang, H. Lin, N. Yao, X. Shen, C. Deng, P. Yang and X. Zhang, J. Chromatogr. A., 2007, 1172, 57-71.

150. D. Wang, J. He, N. Rosenzweig and Z. Rosenzweig, Nano Letters, 2004, 4, 409-413. 
151. F. Chen, R. Shi, Y. Xue, L. Chen and Q.-H. Wan, J. Magn. Magn. Mater, 2010, 322, 2439-2445.

152. I. Yildiz, Nanotechnol. Rev., 2016, 5, 331-340.

153. M. Franzreb, M. Siemann-Herzberg, T. J. Hobley and O. R. Thomas, Appl. Microbiol. Biotechnol., 2006, 70, 505-516.

154. H. Fatima and K.-S. Kim, Korean J. Chem. Eng., 2017, 34, 589-599.

155. J. H. Min, M.-K. Woo, H. Y. Yoon, J. W. Jang, J. H. Wu, C.-S. Lim and Y. K. Kim, Anal. Biochem., 2014, 447, 114-118.

156. J. Kř́žžová, A. Španová, B. Rittich and D. Horák, J. Chromatogr. A., 2005, 1064, $247-$ 253.

157. I. Safarik and M. Safarikova, Biomagn. Res. Technol., 2004, $2,7$.

158. A. Wittrup, S.-H. Zhang, K. J. Svensson, P. Kucharzewska, M. C. Johansson, M. Mörgelin and M. Belting, Proc. Natl. Acad. Sci. U.S.A., 2010, 107, 13342-13347.

159. S. M. Mandal, A. K. Ghosh and M. Mandal, Prep. Biochem. Biotechnol., 2008, 39, 2031.

160. J. K. Herr, J. E. Smith, C. D. Medley, D. Shangguan and W. Tan, Anal. Chem., 2006, 78, 2918-2924.

161. E.-Q. Song, G.-P. Wang, H.-Y. Xie, Z.-L. Zhang, J. Hu, J. Peng, D.-C. Wu, Y.-B. Shi and D.-W. Pang, Clin. Chem., 2007, 53, 2177-2185.

162. M. Van Engeland, L. J. Nieland, F. C. Ramaekers, B. Schutte and C. P. Reutelingsperger, Cytometry, 1998, 31, 1-9.

163. N. Pamme, J. C. Eijkel and A. Manz, J. Magn. Magn. Mater, 2006, 307, 237-244.

164. G. D. Chen, C. J. Alberts, W. Rodriguez and M. Toner, Anal. Chem., 2009, 82, 723728. 
165. M. Kilianová, R. Prucek, J. Filip, J. Kolařík, L. Kvítek, A. Panáček, J. Tuček and R. Zbořil, Chemosphere, 2013, 93, 2690-2697.

166. A. Hayat, G. Catanante and J. L. Marty, Sensors, 2014, 14, 23439-23461.

167. S. A. Ansari and Q. Husain, Biotechnol. Adv., 2012, 30, 512-523.

168. A. K. Johnson, A. M. Zawadzka, L. A. Deobald, R. L. Crawford and A. J. Paszczynski, J. Nanopart. Res., 2008, 10, 1009-1025.

169. D. T. Mitchell, S. B. Lee, L. Trofin, N. Li, T. K. Nevanen, H. Söderlund and C. R. Martin, J. Am. Chem. Soc., 2002, 124, 11864-11865.

170. E. P. Cipolatti, M. J. A. Silva, M. Klein, V. Feddern, M. M. C. Feltes, J. V. Oliveira, J. L. Ninow and D. de Oliveira, J. Mol. Catal. B Enzym., 2014, 99, 56-67.

171. J. Choi, J. I. Lee, Y. B. Lee, J. H. Hong, I. S. Kim, Y. K. Park and N. H. Hur, Chem. Phys. Lett., 2006, 428, 125-129.

172. Z.-C. Xing, Y. Chang and I.-K. Kang, Sci. Technol. Adv. Mater, 2010, 11, 014101.

173. L. Stanciu, Y.-H. Won, M. Ganesana and S. Andreescu, Sensors, 2009, 9, 2976-2999.

174. G. K. Kouassi and J. Irudayaraj, Anal. Chem., 2006, 78, 3234-3241.

175. J. Kudr, Y. Haddad, L. Richtera, Z. Heger, M. Cernak, V. Adam and O. Zitka, Nanomaterials, 2017, 7, 243.

176. L. Gloag, M. Mehdipour, D. Chen, R. D. Tilley and J. J. Gooding, Adv. Mater., 2019, 1904385.

177. L. X. Tiefenauer, G. Kuehne and R. Y. Andres, Bioconjug. Chem. , 1993, 4, 347-352.

178. L. Josephson, C.-H. Tung, A. Moore and R. Weissleder, Bioconjug. Chem. , 1999, 10, 186-191.

179. C. Sestier, M. F. Da-Silva, D. Sabolovic, J. Roger and J. N. Pons, Electrophoresis, 1998, 19, 1220-1226.

180. T.-H. Wang and W.-C. Lee, Biotechnol. Bioprocess. Eng., 2003, 8, 263-267. 
181. M. Di Marco, S. Shamsuddin, K. A. Razak, A. A. Aziz, C. Devaux, E. Borghi, L. Levy and C. Sadun, Int. J. Nanomedicine., 2010, 5, 37-49.

182. T. Qing, D. He, X. He, K. Wang, F. Xu, L. Wen, J. Shangguan, Z. Mao and Y. Lei, Anal. Bioanal. Chem., 2016, 408, 2793-2811.

183. J. Lei and H. Ju, Chem. Soc. Rev., 2012, 41, 2122-2134.

184. B. Cannon, A. R. Campos, Z. Lewitz, K. A. Willets and R. Russell, Anal. Biochem., $2012, \mathbf{4 3 1}, 40-47$.

185. R. Tel-Vered and A. J. Bard, J. Phys. Chem. B, 2006, 110, 25279-25287.

186. S. Krishnan, V. Mani, D. Wasalathanthri, C. V. Kumar and J. F. Rusling, Angew. Chem. Int. Ed. Engl., 2011, 50, 1175-1178.

187. Y. Zhuo, P.-X. Yuan, R. Yuan, Y.-Q. Chai and C.-L. Hong, Biomaterials, 2009, 30, 2284-2290.

188. S. Bi, Y. Yan, X. Yang and S. Zhang, Chem.: Eur. J., 2009, 15, 4704-4709.

189. D. Tang, B. Su, J. Tang, J. Ren and G. Chen, Anal. Chem., 2010, 82, 1527-1534.

190. J. Pan and Q. Yang, Anal. Bioanal. Chem., 2007, 388, 279-286.

191. A. Ahmed, J. V. Rushworth, N. A. Hirst and P. A. Millner, Clin. Microbiol. Rev., 2014, 27, 631-646.

192. S. Bi, H. Zhou and S. Zhang, Chem. Commun., 2009, 37, 5567-5569.

193. Z. Zhang, J. Xie, J. Yu, Z. Lu and Y. Liu, J. Mater. Chem. B, 2017, 5, 1454-1460.

194. B. Pacakova, S. Kubickova, G. Salas, A. Mantlikova, M. Marciello, M. Morales, D. Niznansky and J. Vejpravova, Nanoscale, 2017, 9, 5129-5140.

195. E. Katz, Electroanalysis, 2016, 28, 904-919.

196. E. Katz, L. Sheeney-Haj-Ichia, B. Basnar, I. Felner and I. Willner, Langmuir, 2004, 20, 9714-9719.

197. E. Katz and I. Willner, Angew. Chem. Int. Ed., 2005, 117, 4869-4872. 
198. X. Zhu, K. Han and G. Li, Anal. Chem., 2006, 78, 2447-2449.

199. M. Privman, T. K. Tam, M. Pita and E. Katz, J. Am. Chem. Soc., 2008, 131, 1314-1321.

200. X. Wang, J. Zhou, T. K. Tam, E. Katz and M. Pita, Bioelectrochemistry, 2009, 77, 6973.

201. A. Zablotskaya, I. Segal, Y. Popelis, A. Mishnev, M. Maiorov, D. Zablotsky, E. Blums, V. Nikolajeva and D. Eze, Appl. Organomet. Chem., 2015, 29, 376-383.

202. N. D. Thorat, R. A. Bohara, V. Malgras, S. A. Tofail, T. Ahamad, S. M. Alshehri, K. C.-W. Wu and Y. Yamauchi, ACS Appl. Mater. Interfaces, 2016, 8, 14656-14664.

203. X. Zhang, K. Jiao, S. Liu and Y. Hu, Anal. Chem., 2009, 81, 6006-6012.

204. M. Wanunu, T. Dadosh, V. Ray, J. Jin, L. McReynolds and M. Drndić, Nat. Nanotechnol., 2010, 5, 807-814.

205. Y. Cao, L. Wen, F. Svec, T. Tan and Y. Lv, Chem. Eng. J., 2016, 286, 272-281.

206. M. B. Zakaria, A. A. Belik, C. H. Liu, H. Y. Hsieh, Y. T. Liao, V. Malgras, Y. Yamauchi and K. Wu, Chem. Asian J., 2015, 10, 1457-1462.

207. S. Yadav, M. K. Masud, M. N. Islam, V. Gopalan, A. K.-y. Lam, S. Tanaka, N.-T. Nguyen, M. S. A. Hossain, C. Li, M. Y. Yamauchi and M. J. A. Shiddiky, Nanoscale, $2017,9,8805-8814$

208. L. Gao, J. Zhuang, L. Nie, J. Zhang, Y. Zhang, N. Gu, T. Wang, J. Feng, D. Yang and S. Perrett, Nat. Nanotechnol., 2007, 2, 577-583.

209. X. Wang, Y. Hu and H. Wei, Inorg. Chem. Front., 2016, 3, 41-60.

210. W. Luo, C. Zhu, S. Su, D. Li, Y. He, Q. Huang and C. Fan, ACS Nano, 2010, 4, 74517458.

211. N. Gao, K. Dong, A. Zhao, H. Sun, Y. Wang, J. Ren and X. Qu, Nano Res., 2016, 9, 1079-1090. 
212. X. Shen, L. Zhu, G. Liu, H. Tang, S. Liu and W. Li, New J. Chem., 2009, 33, 22782285.

213. R. Breslow, J. Biol. Chem., 2009, 284, 1337-1342.

214. H. Wei and E. Wang, Chem. Soc. Rev., 2013, 42, 6060-6093.

215. H. Y. Shin, T. J. Park and M. I. Kim, J. Nanomater., 2015, 2015, 756278.

216. Z. Chen, J.-J. Yin, Y.-T. Zhou, Y. Zhang, L. Song, M. Song, S. Hu and N. Gu, ACS Nano, 2012, 6, 4001-4012.

217. A. Dalui, B. Pradhan, U. Thupakula, A. H. Khan, G. S. Kumar, T. Ghosh, B. Satpati and S. Acharya, Nanoscale, 2015, 7, 9062-9074.

218. S. Tanaka, M. K. Masud, Y. V. Kaneti, M. J. Shiddiky, A. Fatehmulla, A. M. Aldhafiri, W. A. Farooq, Y. Bando, M. S. A. Hossain and Y. Yamauchi, ChemNanoMat, 2019, 5, 506-513.

219. H. Wei and E. Wang, Anal. Chem., 2008, 80, 2250-2254.

220. X. Zuo, C. Peng, Q. Huang, S. Song, L. Wang, D. Li and C. Fan, Nano Res., 2009, 2, $617-623$.

221. Y. Liu and F. Yu, Nanotechnology, 2011, 22, 145704.

222. A. K. Dutta, S. K. Maji, D. N. Srivastava, A. Mondal, P. Biswas, P. Paul and B. Adhikary, J. Mol. Catal. A-Chem., 2012, 360, 71-77.

223. Z. Xing, J. Tian, A. M. Asiri, A. H. Qusti, A. O. Al-Youbi and X. Sun, Biosens. Bioelectron., 2014, 52, 452-457.

224. W. Shi, X. Zhang, S. He and Y. Huang, Chem. Commun., 2011, 47, 10785-10787.

225. A. B. Ghosh, N. Saha, A. Sarkar, A. K. Dutta, P. Biswas, K. Nag and B. Adhikary, New J. Chem., 2016, 40, 1595-1604.

226. G.-L. Wang, X.-F. Xu, L. Qiu, Y.-M. Dong, Z.-J. Li and C. Zhang, ACS Appl. Mater. Interfaces, 2014, 6, 6434-6442. 
227. M. Kim, M. S. Kim, S. H. Kweon, S. Jeong, M. H. Kang, M. I. Kim, J. Lee and J. Doh, Adv Healthc. Mater., 2015, 4, 1311-1316.

228. R. Schirhagl, Anal. Chem, 2014, 86, 250-261.

229. Z. Zhang, X. Zhang, B. Liu and J. Liu, J. Am. Chem. Soc., 2017, 139, 5412-5419.

230. K. M. Abu-Salah, M. M. Zourob, F. Mouffouk, S. A. Alrokayan, M. A. Alaamery and A. A. Ansari, Sensors, 2015, 15, 14539-14568.

231. B. Martín-Fernández, A. J. Miranda-Ordieres, M. J. Lobo-Castañón, G. FrutosCabanillas, N. de-los-Santos-Álvarez and B. López-Ruiz, Biosens. Bioelectron., 2014, 60, 244-251.

232. Y. Peng, J. Jiang and R. Yu, Anal. Methods, 2014, 6, 2889-2893.

233. X.-Y. Dong, X.-N. Mi, B. Wang, J.-J. Xu and H.-Y. Chen, Talanta, 2011, 84, 531-537.

234. Ó. A. Loaiza, E. Jubete, E. Ochoteco, G. Cabañero, H. Grande and J. Rodríguez, Biosens. Bioelectron., 2011, 26, 2194-2200.

235. J. Wang, E. Palecek, P. E. Nielsen, G. Rivas, X. Cai, H. Shiraishi, N. Dontha, D. Luo and P. A. Farias, J. Am. Chem. Soc., 1996, 118, 7667-7670.

236. E. A. Hunt, D. Broyles, T. Head and S. K. Deo, Annu. Rev. Anal. Chem., 2015, 8, $217-$ 237.

237. A. Aldalbahi, M. Rahaman, M. Almoiqli, A. Hamedelniel and A. Alrehaili, Nanomaterials, 2018, 8, 527.

238. M. N. Islam, M. K. Masud, N.-T. Nguyen, V. Gopalan, H. R. Alamri, Z. A. Alothman, M. S. Al Hossain, Y. Yamauchi, A. K.-Y. Lam and M. J. Shiddiky, Biosens. Bioelectron., 2017, 101, 275-281.

239. C. Kokkinos, A. Economou and M. I. Prodromidis, Trends Anal. Chem., 2016, 79, 88105. 
240. M. Moreno-Guzmán, A. González-Cortés, P. Yáñez-Sedeño and J. M. Pingarrón, Anal. Chim. Acta., 2011, 692, 125-130.

241. H. Li, Q. Wei, J. He, T. Li, Y. Zhao, Y. Cai, B. Du, Z. Qian and M. Yang, Biosens. Bioelectron., 2011, 26, 3590-3595.

242. F. Li, Y. Li, Y. Dong, L. Jiang, P. Wang, Q. Liu, H. Liu and Q. Wei, Sci Rep., 2016, 6, 21281.

243. T. Zheng, J.-J. Fu, L. Hu, F. Qiu, M. Hu, J.-J. Zhu, Z.-C. Hua and H. Wang, Anal. Chem., 2013, 85, 5609-5616.

244. T. Zheng, Q. Zhang, S. Feng, J.-J. Zhu, Q. Wang and H. Wang, J. Am. Chem. Soc., 2014, 136, 2288-2291.

245. S. M. Khoshfetrat and M. A. Mehrgardi, Bioelectrochemistry, 2017, 114, 24-32.

246. D. Sun, J. Lu, Y. Zhong, Y. Yu, Y. Wang, B. Zhang and Z. Chen, Biosens. Bioelectron., 2016, 75, 301-307.

247. L. Tian, J. Qi, K. Qian, O. Oderinde, Y. Cai, C. Yao, W. Song and Y. Wang, Sens. Actuator B-Chem., 2018, 260, 676-684.

248. S. A. Maier, M. L. Brongersma, P. G. Kik, S. Meltzer, A. A. Requicha and H. A. Atwater, Adv. Mater., 2001, 13, 1501-1505.

249. L. Moro, M. Turemis, B. Marini, R. Ippodrino and M. T. Giardi, Biotechnol. Adv., 2017, 35, 51-63.

250. A. P. VS, P. Joseph, K. D. SCG, S. Lakshmanan, T. Kinoshita and S. Muthusamy, Mater. Sci. Eng. C., 2017, 78, 1231-1245.

251. Y. J. Sung, H.-J. Suk, H. Y. Sung, T. Li, H. Poo and M.-G. Kim, Biosens. Bioelectron., $2013, \mathbf{4 3}, 432-439$.

252. G. A. Suaifan, C. Esseghaier, A. Ng and M. Zourob, Analyst, 2013, 138, 3735-3739. 
253. R. Chinnappan, S. Al Attas, W. E. Kaman, F. J. Bikker and M. Zourob, Anal. Biochem., $2017, \mathbf{5 2 3}, 58-64$.

254. G. A. Suaifan, S. Alhogail and M. Zourob, Biosens. Bioelectron., 2017, 92, 702-708.

255. J.-F. Masson, ACS sensors, 2017, 2, 16-30.

256. E. Mauriz, M. García-Fernández and L. M. Lechuga, TrAC, Trends Anal. Chem., 2016, 79, 191-198.

257. B. Wu, R. Jiang, Q. Wang, J. Huang, X. Yang, K. Wang, W. Li, N. Chen and Q. Li, Chem. Commun., 2016, 52, 3568-3571.

258. D. Beccati, K. M. Halkes, G. D. Batema, G. Guillena, A. Carvalho de Souza, G. van Koten and J. P. Kamerling, ChemBioChem, 2005, 6, 1196-1203.

259. K. Lin, Y. Lu, J. Chen, R. Zheng, P. Wang and H. Ming, Opt. Express, 2008, 16, 1859918604.

260. R. Tabassum and B. D. Gupta, Appl. Opt., 2015, 54, 1032-1040

261. L. He, E. A. Smith, M. J. Natan and C. D. Keating, J. Phys. Chem. B, 2004, 108, 1097310980.

262. J. Wang, Z. Zhu, A. Munir and H. S. Zhou, Talanta, 2011, 84, 783-788.

263. H. Nguyen, J. Park, S. Kang and M. Kim, Sensors, 2015, 15, 10481-10510.

264. X. Guo, Sens. Actuator B-Chem., 2014, 205, 276-280.

265. L. Cai, R. Zhan, K.-Y. Pu, X. Qi, H. Zhang, W. Huang and B. Liu, Anal. Chem., 2011, 83, 7849-7855.

266. Q. Wu, Y. Sun, D. Zhang, S. Li, X. Wang and D. Song, Biosens. Bioelectron., 2016, 86, 95-101.

267. S. Li, Q. Wu, P. Ma, Y. Zhang, D. Song, X. Wang and Y. Sun, Talanta, 2018, 180, $156-161$.

268. S. Unser, I. Bruzas, J. He and L. Sagle, Sensors, 2015, 15, 15684-15716. 
269. J. J. Storhoff, R. Elghanian, C. A. Mirkin and R. L. Letsinger, Langmuir, 2002, 18, 6666-6670.

270. G. Premaratne, A. C. Dharmaratne, Z. H. Al Mubarak, F. Mohammadparast, M. Andiappan and S. Krishnan, Sens. Actuators B Chem., 2019, 299, 126956.

271. P. P. A. Suthanthiraraj and A. K. Sen, Biosens. Bioelectron., 2019, 132, 38-46.

272. P. K. Jain, Y. Xiao, R. Walsworth and A. E. Cohen, Nano Lett., 2009, 9, 1644-1650.

273. Y. Cai, J. Zhu, J. He, W. Yang, C. Ma, F. Xiong, F. Li, W. Chen and P. Chen, Adv. Healthc. Mater., 2019, 8, 1801478.

274. I. Pavel, E. McCarney, A. Elkhaled, A. Morrill, K. Plaxco and M. Moskovits, J. Phys. Chem. C, 2008, 112, 4880-4883.

275. H. T. Ngo, H.-N. Wang, A. M. Fales and T. Vo-Dinh, Anal. Bioanal. Chem., 2016, 408, $1773-1781$.

276. H.-N. Wang, B. M. Crawford, A. M. Fales, M. L. Bowie, V. L. Seewaldt and T. VoDinh, J. Phys. Chem. C, 2016, 120, 21047-21055.

277. L. Li, M. Liao, Y. Chen, B. Shan and M. Li, J. Mater. Chem. B, 2019, 7, 815-822.

278. S. Laing, K. Gracie and K. Faulds, Chem. Soc. Rev., 2016, 45, 1901-1918.

279. Y. Pang, C. Wang, J. Wang, Z. Sun, R. Xiao and S. Wang, Biosens. Bioelectron., 2016, 79, 574-580.

280. H. Zhang, Y. Yi, C. Zhou, G. Ying, X. Zhou, C. Fu, Y. Zhu and Y. Shen, RSC Advances, 2017, 7, 52782-52793.

281. Y. Sun, L. Xu, F. Zhang, Z. Song, Y. Hu, Y. Ji, J. Shen, B. Li, H. Lu and H. Yang, Biosens. Bioelectron., 2017, 89, 906-912.

282. Y. Qiu, D. Deng, Q. Deng, P. Wu, H. Zhang and C. Cai, J. Mater. Chem. B, 2015, 3, 4487-4495.

283. A. C. Ferrari and D. M. Basko, Nat. Nanotechnol., 2013, 8, 235-246. 
284. M. Chen, W. Luo, Z. Zhang, F. Zhu, S. Liao, H. Yang and X. Chen, Talanta, 2017, 171, 152-158.

285. T. Demeritte, B. P. Viraka Nellore, R. Kanchanapally, S. S. Sinha, A. Pramanik, S. R. Chavva and P. C. Ray, ACS Appl. Mater. Interfaces, 2015, 7, 13693-13700.

286. W. Zheng and X. Jiang, Analyst, 2016, 141, 1196-1208.

287. C. Kaittanis, S. Santra and J. M. Perez, J. Am. Chem. Soc., 2009, 131, 12780-12791.

288. Y.-C. Yang, Y.-T. Wang and W.-L. Tseng, ACS Appl. Mater. Interfaces, 2017, 9, 10069-10077.

289. M. K. Masud, S. Yadav, M. N. Islam, N.-T. Nguyen, C. Salomon, R. Kline, H. R. Alamri, Z. A. Alothman, Y. Yamauchi and M. S. A. Hossain, Anal. Chem., 2017, 89, 11005-11013.

290. K. S. Park, M. I. Kim, D. Y. Cho and H. G. Park, Small, 2011, 7, 1521-1525.

291. Y. Li, B. Srinivasan, Y. Jing, X. Yao, M. A. Hugger, J.-P. Wang and C. Xing, J. Am. Chem. Soc., 2010, 132, 4388-4392.

292. J. Choi, A. W. Gani, D. J. Bechstein, J.-R. Lee, P. J. Utz and S. X. Wang, Biosens. Bioelectron., 2016, 85, 1-7.

293. V. D. Krishna, K. Wu, A. M. Perez and J.-P. Wang, Front. Microbiol., 2016, 7, 400.

294. Y. Zhou and Q. Xie, Sen. Actuators B Chem., 2016, 223, 9-14.

295. W. Sun, W. Song, X. Guo and Z. Wang, Anal.Chim. Acta, 2017, 978, 42-47.

296. S. Zhan, X. Lou, P. Zhou and F. Xia, in Biosensors Based on Sandwich Assays, Springer, 2018, 69-91.

297. J. Körner, C. F. Reiche, R. Ghunaim, R. Fuge, S. Hampel, B. Büchner and T. Mühl, Sci. Reports, 2017, 7, 8881.

298. Q. Yue, L. Tao, Y. Hou, C. Zhang, Y. Wang, M. Hong and C.-Z. Li, Nanomedicine, 2018, 13, 2301-2310. 
299. Y.-H. Yuan, Y.-D. Wu, B.-Z. Chi, S.-H. Wen, R.-P. Liang and J.-D. Qiu, Biosens. Bioelectron., 2017, 97, 325-331.

300. N. Yu, Z. Wang, C. Wang, J. Han and H. Bu, Anal. Chim. Acta, 2017, 962, 24-31.

301. M. N. Islam, L. Gorgannezhad, M. K. Masud, S. Tanaka, M. S. A. Hossain, Y. Yamauchi, N.-T. Nguyen and M. J. A. Shiddiky, ChemElectroChem, 2018, 5, 24882495.

302. R. Tavallaie, J. McCarroll, M. Le Grand, N. Ariotti, W. Schuhmann, E. Bakker, R. D. Tilley, D. B. Hibbert, M. Kavallaris and J. J. Gooding, Nat. Nanotechnol., 2018, 13, 1066-1071.

303. Y. Li, C. Yu, B. Yang, Z. Liu, P. Xia and Q. Wang, Biosens. Bioelectron., 2018, 102, $307-315$.

304. L. Gorgannezhad, M. Umer, M. Kamal Masud, M. S. A. Hossain, S. Tanaka, Y. Yamauchi, C. Salomon, R. Kline, N.-T. Nguyen and M. J. A. Shiddiky, Electroanalysis, 2018, 30, 2293-2301.

305 T. Zhang, H. Chai, F. Meng, Z. Guo, Y. Jiang and P. Miao ACS Appl. Mater. Interfaces, 2018, 10, 36796-36804.

306. P. Tang, H. Zhang, J. Huo and X. Lin, Anal. Methods, 2015, 7, 7784-7791.

307. H. Hwang, E. Choi, S. Han, Y. Lee, T. Choi, M. Kim, H. Shin, J. Kim and J. Choi, Anal. Chim. Acta, 2019, 1061, 92-100.

308. S. Fang, X. Dong, S. Liu, D. Penng, L. He, M. Wang, G. Fu, X. Feng and Z. Zhang, Electrochim. Acta, 2016, 212, 1-9.

309. S. Yadav, M. K. Masud, M. N. Islam, V. Gopalan, A. K. Lam, S. Tanaka, N. T. Nguyen, M. S. A. Hossain, C. Li, M. Y. Yamauchi and M. J. A. Shiddiky, Nanoscale, 2017, 9, $8805-8814$ 
310. K. Boriachek, M. K. Masud, C. Palma, H.-P. Phan, Y. Yamauchi, M. S. A. Hossain, N.-T. Nguyen, C. Salomon and M. J. A. Shiddiky, Anal. Chem., 2019, 91, 3827-3834.

311. M. Daneshpour, P. Izadi and K. Omidfar, Biosens. Bioelectron., 2016, 77, 1095-1103.

312. K. Omidfar, M. Darzianiazizi, A. Ahmadi, M. Daneshpour and H. Shirazi, Sensors and Actuators B: Chemical, 2015, 220, 1311-1319.

313. J. Lee, M. Morita, K. Takemura and E. Y. Park, Biosens. Bioelectron., 2018, 102, 425431.

314. S. Wu, N. Duan, Y. Qiu, J. Li and Z. Wang, Int. J. Food Microbiol., 2017, 261, 42-48.

315. B. Amini, M. Kamali, M. Salouti and P. Yaghmaei, Biosens. Bioelectron., 2017, 92, 679-686.

316. Y.-H. Hou, J.-J. Wang, Y.-Z. Jiang, C. Lv, L. Xia, S.-L. Hong, M. Lin, Y. Lin, Z.-L. Zhang and D.-W. Pang, Biosens. Bioelectron., 2018, 99, 186-192.

317. A. M. J. Jimenez, M. A. M. Rodrigo, V. Milosavljevic, S. Krizkova, P. Kopel, Z. Heger and V. Adam, Sens. Actuator B-Chem., 2017, 240, 503-510.

318. J. Qian, D. Xu, S.-L. Ho, K. Wang, M. S. Wong and H.-W. Li, Sens. Actuator B-Chem., 2018, 258, 133-140.

319. Y. Chen, Y. Xianyu, J. Sun, Y. Niu, Y. Wang and X. Jiang, Nanoscale, 2016, 8, 11001107.

320. G. Fu, S. T. Sanjay and X. Li, Analyst, 2016, 141, 3883-3889.

321. L.-F. Jiang, B.-C. Chen, B. Chen, X.-J. Li, H.-L. Liao, H.-M. Huang, Z.-J. Guo, W.-Y. Zhang and L. Wu, Talanta, 2017, 170, 350-357.

322. A. Narmani, M. Kamali, B. Amini, H. Kooshki, A. Amini and L. Hasani, Process Biochem., 2018, 65, 46-54.

323. L. Yang, N. Li, K. Wang, X. Hai, J. Liu and F. Dang, Talanta, 2018, 179, 531-537. 
324. H. Chen, Y. Hou, Z. Ye, H. Wang, K. Koh, Z. Shen and Y. Shu, Sens. Actuator BChem., 2014, 201, 433-438.

325. L. Tang, J. Casas and M. Venkataramasubramani, Anal.Chem., 2013, 85, 1431-1439.

326. Z. Mei, A. Dhanale, A. Gangaharan, D. K. Sardar and L. Tang, Talanta, 2016, 151, 2329.

327. Z. Lou, H. Han, M. Zhou, J. Wan, Q. Sun, X. Zhou and N. Gu, Anal. Chem., 2017, 89, 13472-13479.

328. E. E. Bedford, S. Boujday, C.-M. Pradier and F. X. Gu, Talanta, 2018, 182, 259-266.

329. Y. Pang, C. Wang, J. Wang, Z. Sun, R. Xiao and S. Wang, Biosens. Bioelectron., 2016, 79, 574-580.

330. J. Wang, X. Wu, C. Wang, Z. Rong, H. Ding, H. Li, S. Li, N. Shao, P. Dong and R. Xiao, ACS Appl. Mater. Iinterfaces, 2016, 8, 19958-19967.

331. Y. Xianyu, Q. Wang and Y. Chen, TrAC, Trends Anal. Chem., 2018, 106, 213-224.

332. H. J. Chung, K. L. Pellegrini, J. Chung, K. Wanigasuriya, I. Jayawardene, K. Lee, H. Lee, V. S. Vaidya and R. Weissleder, PloS one, 2015, 10, e0133417.

333. E. Eltzov, S. Guttel, A. Low Yuen Kei, P. D. Sinawang, R. E. Ionescu and R. S. Marks, Electroanalysis, 2015, 27, 2116-2130.

334. Y. Wang, H. Xu, M. Wei, H. Gu, Q. Xu and W. Zhu, Mater. Sci. Eng. C, 2009, 29, 714718.

335. M. S. Kim, S. H. Kweon, S. Cho, S. S. A. An, M. I. Kim, J. Doh and J. Lee, ACS Appl. Mater. Iinterfaces, 2017, 9, 35133-35140.

336. M. Oliveira-Rodríguez, E. Serrano-Pertierra, A. C. García, S. López-Martín, M. YañezMo, E. Cernuda-Morollón and M. d. C. Blanco-López, Biosens. Bioelectron., 2017, 87, $38-45$. 
337. D. Lago-Cachón, M. Rivas, J. C. Martínez-García, M. Oliveira-Rodríguez, M. d. C. Blanco-López and J. García, J. Magn. Magn. Mater., 2017, 423, 436-440.

338. D. Sebba, A. G. Lastovich, M. Kuroda, E. Fallows, J. Johnson, A. Ahouidi, A. N. Honko, H. Fu, R. Nielson and E. Carruthers, Sci. Transl. Med., 2018, 10, eaat0944.

339. K. Petkovic, G. Metcalfe, H. Chen, Y. Gao, M. Best, D. Lester and Y. Zhu, Lab Chip, 2017, 17, 169-177.

340. X. Wei, W. Zhou, S. T. Sanjay, J. Zhang, Q. Jin, F. Xu, D. C. Dominguez and X. Li, Anal. Chem., 2018, 90, 9888-9896.

341. W. Ren, S. I. Mohammed, S. Wereley and J. Irudayaraj, Anal. Chem., 2019, 91, 28762884.

342. W. Yan, K. Wang, H. Xu, X. Huo, Q. Jin and D. Cui, Nano-Micro Letters, 2019, 11, 7.

343. Y. Xuhong, Z. Sinong, L. Jianping, C. Yu, Z. Juanli, Z. Chao, L. Desheng, H. Kai, C. Yali and H. Wenli, Artif. Cells. Nanomed. Biotechnol., 2019, 47, 636-643.

344. A. Sharma, A. I. Y. Tok, C. Lee, R. Ganapathy, P. Alagappan and B. Liedberg, Sens. Actuator B-Chem., 2019, 285, 431-437.

345. Z. Huang, Z. Xiong, Y. Chen, S. Hu and W. Lai, J. Agric. Food. Chem., 2019, 67, 30283036.

346. D. Yang, J. Ma, C. Xue, L. Wang and X. Wang, J. Pharm. Biomed. Anal., 2018, 159, $119-126$.

347. J. Hu, Y.-Z. Jiang, M. Tang, L.-L. Wu, H.-y. Xie, Z.-L. Zhang and D.-W. Pang, Anal. Chem., 2018, 91, 1178-1184.

348. C. Wang, D. Guan, C. Chen, S. He, X. Liu, C. Wang and H. Wu, Anal. Bioanal. Chem., 2018, 410, 123-130.

349. W. Ren, I.-H. Cho, Z. Zhou and J. Irudayaraj, Chem. Commun., 2016, 52, 4930-4933. 
350. X. Liu, C. Zhang, K. Liu, H. Wang, C. Lu, H. Li, K. Hua, J. Zhu, W. Hui and Y. Cui, Anal. Chem., 2018, 90, 3430-3436 